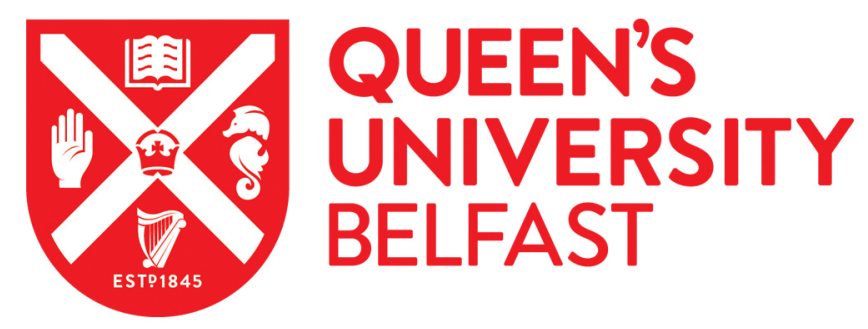

\title{
Lack of genetic structure and evidence for long-distance dispersal in ash (Fraxinus excelsior) populations under threat from an emergent fungal pathogen: implications for restorative planting
}

Beatty, G. E., Brown, J. A., Cassidy, E. M., Finlay, C. M. V., McKendrick, L., Montgomery, W. I., Reid, N., Tosh, D. G., \& Provan, J. (2015). Lack of genetic structure and evidence for long-distance dispersal in ash (Fraxinus excelsior) populations under threat from an emergent fungal pathogen: implications for restorative planting. Tree Genetics and Genomes, 11, 1-13. [53]. https://doi.org/10.1007/s11295-015-0879-5

Published in:

Tree Genetics and Genomes

Document Version:

Peer reviewed version

Queen's University Belfast - Research Portal:

Link to publication record in Queen's University Belfast Research Portal

\section{Publisher rights}

Copyright $\odot 2015$, Springer-Verlag Berlin Heidelberg

The final publication is available at Springer via http://link.springer.com/article/10.1007\%2Fs11295-015-0879-5

\section{General rights}

Copyright for the publications made accessible via the Queen's University Belfast Research Portal is retained by the author(s) and / or other copyright owners and it is a condition of accessing these publications that users recognise and abide by the legal requirements associated with these rights.

Take down policy

The Research Portal is Queen's institutional repository that provides access to Queen's research output. Every effort has been made to ensure that content in the Research Portal does not infringe any person's rights, or applicable UK laws. If you discover content in the

Research Portal that you believe breaches copyright or violates any law, please contact openaccess@qub.ac.uk. 


\section{Lack of genetic structure and evidence for long-distance dispersal in ash (Fraxinus excelsior) populations under threat from an} emergent fungal pathogen: implications for restorative planting

Gemma E. Beatty ${ }^{1,2}$ - James A. Brown ${ }^{2}$ Eamon M. Cassidy ${ }^{2}$ Caroline M. V. Finlay $^{2}$. Lorraine McKendrick $^{2}$ - W. Ian Montgomery ${ }^{1,2} \cdot$ Neil Reid $^{1,2} \cdot$ David G. Tosh $^{1,2}$ • Jim Provan ${ }^{1,2,3^{*}}$

${ }^{1}$ Quercus, School of Biological Sciences, Queen's University Belfast, 97 Lisburn Road, Belfast BT9 7BL

${ }^{2}$ School of Biological Sciences, Queen's University Belfast, 97 Lisburn Road, Belfast BT9 7BL

${ }^{3}$ Institute for Global Food Security, Queen's University Belfast

* For correspondence: Dr. Jim Provan

School of Biological Sciences, Queen's University Belfast Tel: +442890972280

Fax: +44 2890975877

E-mail: J.Provan@qub.ac.uk 
1 Abstract Genetic analysis on populations of European ash (Fraxinus excelsior) throughout

2 Ireland was carried out to determine the levels and patterns of genetic diversity in naturally

3 seeded trees in ash woodlands and hedgerows, with the aim of informing conservation and

4 replanting strategies in the face of potential loss of trees as a result of ash dieback. Samples

5 from 33 sites across Northern Ireland and three sites in the Republic of Ireland were

6 genotyped for eight nuclear and ten chloroplast microsatellites. Levels of diversity were high

$7 \quad\left(\right.$ mean $A_{\mathrm{R}}=10.53$; mean $H_{\mathrm{O}}=0.709$; mean $\left.H_{\mathrm{E}}=0.765\right)$, and were similar to those in Great

8 Britain and continental Europe, whilst levels of population genetic differentiation based on

9 nuclear microsatellites were extremely low $\left(\Phi_{\mathrm{ST}}=0.0131\right)$. Levels of inbreeding (mean $F_{\mathrm{IS}}=$

10 0.067) were significantly lower than those reported for populations from Great Britain. Fine-

11 scale analysis of seed dispersal indicated potential for dispersal over hundreds of metres. Our

12 results suggest that ash woodlands across Ireland could be treated as a single management

13 unit, and thus native material from anywhere in Ireland could be used as a source for

14 replanting. In addition, high potential for dispersal has implications for recolonization

15 processes post-ash dieback (Chalara fraxinea) infection, and could aid in our assessment of

16 the capacity of ash to shift its range in response to global climate change.

17

ADDITIONAL KEYWORDS: Gene flow, genetic diversity, inbreeding, microsatellites, spatial genetic structure, replanting 
In recent years, many ecologically and economically important tree species have come under threat from a range of emergent pathogens. The outbreaks of the fungus Ophiostoma novo$u l m i$, the agent of Dutch elm disease in the 1900s, led to extensive losses of several Ulmus species, including an estimated two-thirds of the elm population of the UK during the 1970s (Webber 1981). In the last decade in the UK and Ireland, notable fungal and oomycete pathogens have included sudden oak death, chestnut blight and red needle blight. Most recently, outbreaks of ash dieback, a potentially serious threat which affects several species of ash (Fraxinus spp.), have been reported in continental Europe, and have subsequently spread to Great Britain and Ireland. Common or European ash (F. excelsior) is a key species of mixed broadleaved woodlands across Europe, with a natural range that extends from southern Scandinavia to northern Spain and the Balkans, and from Ireland in the west to continental Russia in the east. European ash within woodlands forms mixed stands, usually with beech (Fagus sylvatica), pedunculate oak (Quercus robur), sessile oak (Q. petraea), alder (Alnus glutinosa) and sycamore (Acer pesudoplatanus), and is an important component of woodland ecosystems, as well as being a valuable timber species (FRAXIGEN 2005). The symptoms of ash dieback were first reported in Poland in the early 1990s (Pautasso et al. 2013), but it was not until 2006 that the causative agent of ash dieback was identified as Chalara fraxinea (Kowalski 2006), which has since been found to be synonymous with the ascomycete fungus Hymenoscyphus pseudoalbidus (Queloz et al. 2011). The disease was first recorded in Britain in February 2012, and the first case of ash dieback in Ireland was reported in October 2012. substantial loss of trees, either via pathogenic mortality or anthropogenic clearance to prevent Page | 3 
possible spread. In Great Britain, the Forestry Commission has developed recommendations to maintain provenance of replanted individuals, by using seed sourced from the same area (Herbert et al. 1999). Consequently, a map of "seed zones" that divide Great Britain into 24 areas delineated by geographic features and general climatic similarity has been drawn up to assist restorative conservation programmes. However, a recent study on ash in England, Scotland and Wales (Sutherland et al. 2010) found limited genetic differentiation between 42 populations from 21 of the 24 seed zones, indicating large-scale genetic homogeneity. This suggests that all populations of ash in Britain could be treated as a single management unit (DeSalle and Amato 2004), a more efficient and cost-effective approach to replanting, contrary to recommendations based on previously identified "seed zones".

Seed dispersal plays a central role in the demography of natural plant populations across a broad range of geographic scales, from initial colonization to shaping community structure and regeneration (Howe and Smallwood 1982; Nathan and Muller-Landau 2000; Levine and Murrell 2003). Despite the importance of dispersal in plant population ecology, the logistics of tracing dispersal events accurately from source are not straightforward. Methods involving "tagging" of seeds are generally less than optimal due to factors such as extremely low recovery rates and the effects of the tags themselves on the dispersal process (reviewed in Wang and Smith 2002; Forget and Wenny 2005; Ashley 2010). Most attempts to estimate seed dispersal distributions have instead relied on seed trapping, coupled with models that generally make a priori assumptions about seed source (Nathan and Muller-Landau 2000). In recent years, climate change, habitat loss and fragmentation, and increased mortality associated with emergent plant pathogens, such as $H$. pseudoalbidus, have increased interest in more direct, precise measurements of seed dispersal to determine the capacity of plant populations to recover from these threats. 
69 With the recent report of the first case of ash dieback in Ireland, and the lack of population

70 genetic information for the species across the island, the main aim of the present study was to

71 determine the levels and patterns of genetic diversity in naturally seeded trees in ash

72 woodlands and hedgerows. We focused on Northern Ireland which, like the rest of Ireland,

73 has no map of "seed zones" on which to base management units, and the development of

74 rational conservation and replanting strategies. We analysed populations from the northern,

75 eastern, southern and western extremes of Ireland to ensure our findings are applicable to the

76 island as a whole. We also used a molecular genetic approach to quantify fine-scale seed

77 dispersal distances in two natural ash woodlands, employing a combination of high-resolution

78 nuclear and chloroplast microsatellite markers. Our results suggest that ash woodlands across

79 Ireland could be treated as a single management unit, and thus material from anywhere in

80 Ireland could be used as a source for replanting. We also identified potential for seed

81 dispersal over hundreds of metres, which will be important in addressing both post-ash

82 dieback recolonization, and assessing the capacity of ash to migrate in response to global

83 climate change. 
Materials and methods

85

Study species reproductive ecology

87 European ash (Fraxinus excelsior) has protandrous, anemophilous flowers. The species exhibits a wide range of complex polygamy, ranging from pure male and female trees, through combinations of male / female and hermaphroditic flowers in the same individual, to sexual changes across successive years (Wardle 1961; Bacles and Ennos 2008). Although $F$. excelsior is preferentially outcrossing, hermaphrodites are self-compatible, and whereas females and hermaphrodites exhibit high seed set, hermaphrodites exhibit reduced male fertility. Fruits are winged and wind-dispersed, and generally contain a single seed.

Seedlings are shade-tolerant, but need good light levels to promote full growth, generally only establishing in clearings within woodlands (Marigo et al. 2000).

\section{Sampling and DNA extraction}

For the broad-scale study, samples were collected from 33 sites across Northern Ireland and three sites in the Republic of Ireland that had been previously designated as ancient or seminatural woodland based on data collected for the Woodland Trust Inventory of ancient and long-established woodland in Northern Ireland (www.backonthemap.org.uk) and the National Survey of Native Woodlands 2003-08 in the Republic of Ireland (www.npws.ie; Fig. 1 and Table 1). The congeneric F. angustifolia has been planted in the Republic of Ireland, but is not found in the vicinity of any of the native woodlands analyzed in the present study. A single leaf was collected from each of 30 trees per site and stored in silica gel, and GPS coordinates recorded for every tree sampled. DNA was extracted using the CTAB method of Doyle and Doyle (1987). 
For the fine-scale study, two sites were chosen. The first, Barnett Demesne, was also used for the broad-scale study. It is a $c a .40$ ha public park in South Belfast, Northern Ireland $\left(54.55^{\circ} \mathrm{N}, 5.96^{\circ} \mathrm{W}-\right.$ Fig. 2$)$, and is an area of mixed parkland and woodland, the woodland being semi-continuous stands of mixed deciduous trees, primarily beech and oak. The ash is found in the northern part of the main wooded area, with a few scattered trees in the adjoining parkland. The second site, Cregagh Glen, is a narrow $(50-60 \mathrm{~m})$, steep-sided ravine $c a .700$ $\mathrm{m}$ long on the eastern outskirts of Belfast $\left(54.56^{\circ} \mathrm{N}, 5.89^{\circ} \mathrm{W}-\right.$ Fig. 2). It is the surviving remnant of a former $c a .400$ ha forest and comprises mixed woodland of Scots pine, sycamore, beech and ash. The ash is distributed sporadically throughout the length of the Glen. For both sites, samples were obtained from all reproductive (adult) trees, as well as from selected saplings (96 from Barnett Demesne and 48 from Cregagh Glen; Figure 2). A single leaf was collected from each individual and stored in silica gel, and GPS coordinates recorded (Table S1, Supporting Information). DNA was extracted using the CTAB method of Doyle and Doyle (1987).

\section{Genotyping}

All trees and saplings were genotyped for eight nuclear and ten chloroplast microsatellite loci. For nuclear microsatellite genotyping, we used six previously reported loci which have been widely used in population genetic studies on ash: Femsatl-4, Femsatl-8, Femsatl-11, Femsatl-16 and Femsatl-19 (Lefort et al. 1999) and M230 (Brachet et al. 1999), as well as two loci developed for the present study (FR639485 and FR646655). As previous studies highlighted the possibility of null alleles using the Lefort et al. (1999) and Brachet et al. (1999) primers (Morand et al. 2002; Ferrazzini et al. 2007; Sutherland et al. 2010), we designed new primers for all loci (Table 2) using the Primer3 program (v 0.4.0; http://primer3.ut.ee). The $F_{\text {IS }}$ values calculated in the present broad-scale study were lower Page $\mid 7$ 
than those from several previous studies, which is consistent with the occurrence of null alleles when using the original primers. To investigate this further, we also genotyped a subset of our samples for comparison using the original Femsatl-4, Femsatl-8 and Femsatl-16 primers, since these exhibited the highest $F_{\text {IS }}$ values in the earlier studies. To develop further markers, we also tested five pairs of primers developed from EST sequences in GenBank, but only two of these (FR639485 and FR646655) consistently gave clear, reproducible products.

Fraxinus excelsior chloroplast sequences in the GenBank database were searched for mononucleotide repeats of ten or more (Provan et al. 2001). Primers were designed using the Primer3 program to amplify the ten loci in four multiplexes (Table S2, Supporting Information). One of these (AF528042.2) corresponds to the highly polymorphic CPFRAX6 locus described in Harbourne et al. (2005), but was monomorphic across all samples tested. Consequently, we screened a subset of our samples using the original CPFRAX6 primers, but these did not reveal any additional variation to that displayed using the AF528042.2 primers. PCR was carried out in a total volume of $10 \mu$ containing 100 ng genomic DNA, 5 pmol of 6-FAM- or HEX-labelled M13 primer, 0.5 pmol of M13-tailed forward primer, 5 pmol reverse primer, $1 \mathrm{x}$ PCR reaction buffer, $200 \mu \mathrm{M}$ each $\mathrm{dNTP}, 2.5 \mathrm{mM} \mathrm{MgCl} 2$ and $0.25 \mathrm{U}$ GoTaq Flexi DNA polymerase (Promega, Sunnyvale, CA, USA). PCR was carried out on a MWG Primus thermal cycler (Ebersberg, Germany) using the following conditions: initial denaturation at $94{ }^{\circ} \mathrm{C}$ for 3 min followed by 40 cycles (30 for chloroplast loci) of denaturation at $94{ }^{\circ} \mathrm{C}$ for $30 \mathrm{~s}$, annealing at $55^{\circ} \mathrm{C}$ for $30 \mathrm{~s}$, extension at $72{ }^{\circ} \mathrm{C}$ for $30 \mathrm{~s}$, and a final extension at $72{ }^{\circ} \mathrm{C}$ for $5 \mathrm{~min}$. Genotyping was carried out on an AB3730xl capillary genotyping system. (Applied Biosystems, Foster City, CA, USA). Allele sizes were scored using the GENEMAPPER software package (v4.1; Applied Biosystems) using LIZ-500 size standards, and were checked by comparison with previously sized control samples. Chromatograms were all inspected visually to check for large allele dropout (see Discussion). 
GENEPoP (V3.4; Raymond and Rousset, 1995) was used to test for linkage disequilibrium between nuclear microsatellite loci. To estimate genetic diversity within the populations, levels of observed $\left(H_{O}\right)$ and expected $\left(H_{E}\right)$ heterozygosity, levels of allelic richness $\left(A_{R}\right)$ and fixation indices $\left(F_{I S}\right)$ were calculated using the FSTAT software package (V2.9.3.2; Goudet, 2001). Significance of $F_{I S}$ was determined by 10,000 randomisation steps. We also estimated null allele frequencies using the CERVUS software package (V3.0.3; Kalinowski et al. 2007), as previous studies using the same microsatellites (Femsatl-4, Femsatl-8, Femsatl11, Femsatl-16, Femsatl-19 and M230) have suggested the possibility of null alleles.

Chloroplast microsatellite allele sizes were combined into haplotypes, and levels of genetic diversity $(H)$ based on haplotype frequencies were calculated using the ARLEQUIN software package (V3.5.1.2; Excoffier and Lischer, 2010).

The overall level of genetic differentiation between populations was estimated using $\Phi_{\mathrm{ST}}$, which gives an analogue of $F_{\mathrm{ST}}$ (Weir and Cockerham, 1984) calculated within the analysis of molecular variance (AMOVA) framework (Excoffier et al. 1992) using ARLEQUIN. In addition, as the high numbers of alleles and high levels of diversity associated with microsatellite loci can lead to an underestimation of genetic differentiation between populations, we also calculated Hedrick's $G{ }_{S T}($ Hedrick 2005) for the nuclear microsatellite data set. To further identify possible patterns of genetic structure, the software package BAPS (V5; Corander et al. [2003]) was used to identify clusters of genetically similar populations using a Bayesian approach. Ten replicates were run for all possible values of the maximum number of clusters $(K)$ up to $K=36$, the number of populations sampled, with a burn-in period of 10,000 iterations followed by 100,000 iterations. Multiple independent runs always gave the same outcome. 

hypothesis of a stepping-stone model of gene flow between populations of $F$. excelsior. The ISOLDE test implemented in the GENEPOP software package was used to assess the relationship between genetic distance, measured as Hedrick's $G_{S T}$ (Hedrick 2005), and geographical distance between population pairs. 1,000 permutations were used for the Mantel test.

To test for spatial genetic structuring (SGS) within populations, which could give rise to

Wahlund effects, we carried out spatial autocorrelation analyses using SPAGEDI (V1.4;

Hardy and Vekemans, 2002). Mean coancestry coefficients ( $\theta_{x y}$; Loiselle et al. 1995)

between pairs of individuals were calculated for both the 0-50 $\mathrm{m}$ and 50-100 $\mathrm{m}$ distance classes for each population, with the remaining size intervals $(50 \mathrm{~m}$ to $500 \mathrm{~m})$ reflecting the overall size of each population, and plotted as a correlogram, with 95\% confidence intervals calculated from 1,000 permutations of individuals within each distance class, and for estimates of $\theta_{x y}$ using 1,000 permutations. Finally, for comparison of levels of SGS with other species, we calculated the $S p$ statistic of Vekemans and Hardy (2004) as $-b_{k} /\left(1-\theta_{1}\right)$, where $b_{k}$ is the slope of the regression of $\theta_{x y}$ against the logarithm of the distance, and $\theta_{1}$ is the mean value of the pairwise coancestry coefficients calculated between all pairs of individuals within the first distance class $(0-50 \mathrm{~m})$.

200

\section{Data analysis - fine-scale}

202 Only seven nuclear microsatellite loci were used in the fine-scale study, since locus Femsat19 exhibited alleles that differed by only a single base pair, and we wanted to ensure exact matches between putative parents and offspring. We employed two approaches to determine parentage of saplings. The first was a simple exclusion approach, based on the premise that we had sampled all potential adult parents in each stand. Any adult that did not have at least Page | 10 
207 one allele matching those exhibited by a sapling at all seven loci was excluded as a potential 208 parent of that sapling. The second was a likelihood-based approach implemented in the 209 CERVUS software package (V3.0; Kalinowski et al. 2007). This was used in addition to strict 210 exclusion, since the program can allow for potential genotyping errors, and the fact that not 211 all putative parents may have been sampled. Simulations were run for 10,000 iterations, with 212 a genotyping error rate of 0.01 , since we had manually scored all markers to check for 213 automated miscalls and allelic dropout, and assuming 95\% sampling of putative parents.

214 Parent-pairs or individual parents were assigned based on the critical values for the $95 \%$ strict 215 log-likelihood (LOD) scores. 


\section{Broad-scale study}

219 No evidence of linkage disequilibrium was detected between any of the eight nuclear microsatellites analysed. Between nine (FR646655) and 51 (M230) alleles were detected per locus, with a total of 261 (mean $=32.625$ per locus; Table 2$)$. Levels of observed $\left(H_{\mathrm{O}}\right)$ and expected $\left(H_{\mathrm{E}}\right)$ heterozygosity ranged from $0.442($ FR646655) to $0.909(\mathrm{M} 230 ;$ mean $=$ 0.709), and from 0.477 (FR646655) to $0.937(\mathrm{M} 230$; mean $=0.765)$, respectively. Levels of $F_{\text {IS }}$ ranged from -0.004 (Femsatl-16) to 0.236 (Femsatl-8), with a mean value of 0.067 . The estimated frequency of null alleles ranged from zero (Femsatl-16) to 0.142 (Femsatl-8), with a mean value of 0.041 . The proportion of large alleles not called by the GENEMAPPER software under the default settings in the four loci where there was significant large allele dropout (Femsatl-4, Femsatl-8, Femsatl-11 and M230) ranged from 2.98\% (Femsatl-4) to $11.59 \%(\mathrm{M} 230)$.

Within populations, levels of allelic richness $\left(A_{\mathrm{R}}\right)$ averaged over loci ranged from 9.52 (Glenarm Forest) to 11.52 (Killeter Forest), with a mean value of 10.53 (Table 1). A total of 41 private alleles was detected, with the number per population ranging from zero to four. The majority (38) of these were restricted to a single individual, with the remaining three being found in two individuals. Levels of observed $\left(H_{\mathrm{O}}\right)$ and expected $\left(H_{\mathrm{E}}\right)$ heterozygosity ranged from 0.637 (Castle Hill) to 0.823 (Glenarm Forest; mean =0.709), and from 0.712 (Trassey Road) to 0.809 (Rostrevor and Randalstown; mean $=0.765$ ) respectively. The heterozygote deficit observed in the majority of the populations gave rise to $F_{\text {IS }}$ values which were significantly higher than zero in 27 of the 36 populations studied, ranging from 0.053 (Killeter Forest) to 0.168 (Letterfrack; mean $=0.067$ ). Diversity statistics for individual loci by population are given in Table S3, Supporting Information, and indicate that significant $F_{I S}$ Page | 12 
values were generally due to high values at locus Femsatl-8, which were significantly higher than zero in 32 of the 36 population studied, suggesting the presence of null alleles at this locus.

Five of the ten chloroplast microsatellite loci studied were polymorphic in the samples analysed, exhibiting between two and four alleles (Table S1, Supporting Information). Combining allele sizes across loci gave eight haplotypes (See Figure S1, Supporting Information for a network of evolutionary relationships between haplotypes). One of these (H1) was found in the vast majority (995 out of 1052) of the trees studied. Levels of haplotype diversity $(H)$ ranged from zero (several populations) to 0.572 (Barnett Demesne; Table 1).

Levels of population differentiation were $\Phi_{\mathrm{ST}}=0.0131$ and Hedrick's $G{ }_{S T}=0.0547$ for the nuclear microsatellites, and $\Phi_{\mathrm{ST}}=0.2629$ for the chloroplast microsatellites (results of the AMOVA are given in Table 3). The BAPS analysis assigned all 36 populations to a single genetic cluster, although a weak but significant isolation-by-distance $(P=0.005)$ was observed across all populations, but not across NI populations only $(\mathrm{P}=0.09$; Figure 3$)$. Finally, the spatial autocorrelation analyses revealed very little significant within-population spatial genetic structuring, with structuring only observed up to $50 \mathrm{~m}$ in the Dromora, Information), and $S p$ values ranging from 0.000 (several populations) to 0.020 (Knockninney Hill; Table 1).

Fine-scale study

We successfully genotyped 140 adult trees and 93 saplings from Barnett Demesne, and 44 adults and 39 saplings from Cregagh Glen. For the Barnett Demesne stand, there was extremely good agreement between parentage based on strict exclusion, and assignments Page | 13 
based on likelihood implemented in CERVUS: in only five cases, CERVUS identified a second parent where strict exclusion only identified a single parent, and there were four cases where a sapling/parent combination was identified by exclusion, but where the adult had a LOD score below the threshold calculated by CERVUS. Based on the CERVUS results, a single parent was identified for 42 saplings, both parents were identified for 41 saplings, and no parent within the stand was identified for five saplings. Three putative parents above the LOD threshold were identified for a single sapling, which was not included further in the analysis, as were the four saplings where a parent was identified by exclusion, but this adult had a LOD score below the threshold. Three chloroplast microsatellite haplotypes were identified, and in the 41 cases where both parents were identified, differences in chloroplast haplotypes between the parents allowed the identification of the seed parent in 13 cases. Consequently, seed dispersal distances could be calculated for 55 of the saplings: 13 where the seed parent was identified in the parent-pair, and for the 42 saplings where a single parent was identified, since the assumption that a single parent is the seed parent is far more parsimonious than the alternative explanation of the adult being the pollen parent, which pollinated another tree outside the stand, with the seed subsequently dispersing back into the stand. Furthermore, in all cases of single parent assignment, there was a match between the adult and sapling chloroplast haplotype, consistent with the adult being the seed parent. This includes the rarest haplotype, found in a single sapling and a single adult, which were classed as parent-offspring pairs by both CERVUS and strict exclusion. Dispersal distances ranged from 3 to $223 \mathrm{~m}($ mean $=42 \mathrm{~m}$; median $=31 \mathrm{~m}$; Figure 4$)$. Pollination distances were calculated for the 13 parent-pairs, and ranged from 2 to $266 \mathrm{~m}$ (mean $=93 \mathrm{~m}$; median $=83$ $168 \mathrm{~m}($ mean $=65 \mathrm{~m}$; median $=47 \mathrm{~m}$; Table 4$)$. 
290 In the Cregagh Glen stand, very few putative parents were identified by CERVUS which 291 had LOD scores above the critical value. This was due to a combination of lower overall 292 genetic variation, and the occurrence of high-frequency alleles at several of the microsatellite 293 loci. Four dispersal events from separate single parents were identified, with distances of 23, 29482,123 and $148 \mathrm{~m}$. In eleven cases, however, no parent was identified, suggesting 295 immigration of seed into the stand. All adults and saplings shared a single chloroplast 296 microsatellite haplotype. 


\section{Lack of genetic structure and implications for restorative planting}

300

For over 50 years now, the concept of provenance has been integral to forestry practices, particularly with respect to restocking and / or replanting of woodlands (reviewed in Jones and Burley 1973). This reflects observed phenotypic and underlying genetic variation across species' distributions, and recommends that where possible, woodlands should be restocked with local seeds or seedlings. Our finding that ash woodlands across Ireland are genetically uniform suggests that the concept of provenance might more usefully reflect the geographic distribution of genetic variation, and that all could be treated as a single management unit, given the lack of genetic differentiation between populations and the low incidence of private alleles. The observed level of population differentiation based on nuclear microsatellites $\left(\Phi_{\mathrm{ST}}=0.0131\right)$ was the second lowest reported for European ash, with previous studies estimating between 1.2\% (Hebel et al. 2006) and 8.7\% (Heuertz et al. 2001) of nuclear diversity partitioned between populations, and is consistent with wind pollination and seed dispersal (Wardle 1961). Unfortunately, these previous studies did not calculate comparable

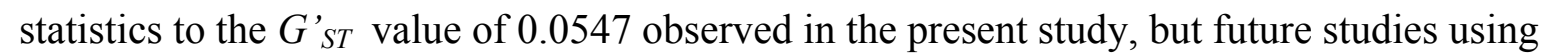
microsatellites should calculate the equivalent statistic to take into account underestimation of levels of differentiation when using highly variable markers (Hedrick 2005).

Replacement of native trees for whatever reason should be based on knowledge of the geographic distribution of genetic variation (Godefroid et al. 2011). Our results clearly indicate that the source of material for replanting ash, at least in Ireland, is largely irrelevant, given such low levels of differentiation. The inclusion of samples from the extreme east (Co. Wicklow), south (Co. Cork) and west (Co. Galway) of Ireland in the same genetic cluster as the 33 populations from Northern Ireland indicates that our findings are probably applicable Page | 16 
to ash woodlands across the island of Ireland as a whole. Furthermore, the Irish samples of ash exhibited similar levels of nuclear genetic diversity to those in Great Britain and continental Europe, including populations from putative refugial areas that should harbour the highest levels of variation (Heuertz et al. 2001; Morand et al. 2002; Heuertz et al. 2004a; Heuertz et al. 2004b; Ferrazzini et al. 2007; Sutherland et al. 2010; Gérard et al. 2013). However, such replanting should be carried out using native material from long-established, unplanted / unstocked woodlands, since recent studies have shown that material used for replanting in Ireland often contains individuals that possess alleles introgressed from the congeneric $F$. angustifolia (Thomasset et al. 2013).

Levels of chloroplast genetic diversity were very low, with a single haplotype found in almost $95 \%$ of all the individuals studied. This haplotype most likely corresponds to Haplotype H04 from Heuertz et al. (2004a), which is also the dominant haplotype in Britain as a result of postglacial recolonization from Iberia. Populations in the east of Northern Ireland tended to exhibit the highest levels of chloroplast diversity, with most of the populations in the west fixed for the most common haplotype. This could be due to founder effects associated with westward recolonization from Britain or to predominantly eastward seed dispersal by prevailing westerly winds, since the chloroplast genome is maternally inherited in ash, or to a combination of both.

Several previous population genetic studies on ash have reported significant, and often high, levels of $F_{\text {IS }}$, which have been attributed to various factors including inbreeding, null alleles, large allele dropout and Wahlund effect (Morand et al. 2002; Ferrazzini et al. 2007; Sutherland et al. 2010). The mean $F_{\text {IS }}$ calculated for ash populations across Northern Ireland (0.067) is significantly lower than that reported by Sutherland et al. (2010), who used six of the eight loci analysed in the present study to examine populations throughout Great Britain (mean $F_{\mathrm{IS}}=0.182$; Mann-Whitney test, $z=6.07, P<0.0001$ ). We designed new primers to Page | 17 
amplify previously characterized microsatellite loci with the aim of circumventing any potential problems with null alleles, and our estimated null allele frequencies were generally much lower than those reported in Sutherland et al. (2010). However, on genotyping a subset of our samples using the same primers as Sutherland et al. (2010), we did not observe an increase in $F_{\text {IS }}$ or estimated null allele frequencies, suggesting that the previously observed homozygote deficiencies were not due to null alleles as a result of non-amplification.

Furthermore, although Femsatl-8 exhibited the highest $F_{\text {IS }}$ among the loci analysed in both cases, which might suggest null alleles associated with this particular marker, the same locus exhibited the lowest $F_{\text {IS }}$ in a previous study in Germany (Hebel et al. 2006). The fact that this locus was significantly higher than zero in 32 of the 36 populations studied, even where the majority of the other alleles in these populations did not yield significant $F_{I S}$ values, however, does suggest the presence of null alleles.

Another potential cause of heterozygote deficiency is large allele dropout, where short alleles are preferentially amplified during the PCR. Automated scoring software packages, such as GENOTYPER and GENEMAPPER, will often not identify these long alleles. We took the precaution of manually checking each chromatogram, and using the default settings for allele scoring in the GENEMAPPER package, we identified uncalled large alleles at frequencies ranging from $2.98 \%$ to $11.59 \%$ at four of the eight loci studied (see Figure S3, Supplementary information for an example). The phenomenon is particularly prevalent at loci with a high number of alleles over a large size range, and with such high frequencies of uncalled alleles, analyses based on the raw outputs from these genotyping packages would result in apparent homozygote excesses and subsequently inflated $F_{\text {IS }}$ values.

Sutherland et al. (2010) suggested that the $F_{\text {IS }}$ values observed in their study might be due to a Wahlund effect, namely the occurrence of spatial genetic structuring within populations, a scenario also proposed to a lesser degree by Ferrazzini et al. (2007). Because we recorded Page | 18 
372 GPS coordinates for each of the trees sampled in the present study, we were able to carry out spatial autocorrelation analyses to test for such structuring. With the exception of significantly higher levels of relatedness up to $50 \mathrm{~m}$ in only four populations out of the 36 studied, we found no evidence of Wahlund effects.

Given that we can exclude null alleles (with the possible exception of locus Femsatl-8, which consistently exhibits high $F_{\text {IS }}$ levels across most studies), large allele dropout and Wahlund effects, the $F_{\text {IS }}$ values observed would appear to give a true measure of the levels of inbreeding in populations of ash in the present study. Our spatial autocorrelation analyses found little evidence for the breeding "subunits" previously suggested to exist within ash woodlands (Heuertz et al. 2001; Morand et al. 2002). The mean value of $S p$ calculated for the 36 populations studied (0.006) was lower than the mean value reported for trees $(0.010)$ by Vekemans and Hardy (2004) and the mean value from six microsatellite-based studies in tropical trees (0.017; Hardy et al. 2006), although higher than that calculated for a Romanian population of $F$. excelsior ( 0.002 ; Heuertz et al. 2003). This may be due at least in part to the differing densities of ash trees in the various woodlands analysed in the present study. For example, the Knockninney Hill population, which presented the highest $S p$ value, had only a single pair of individuals within $100 \mathrm{~m}$ of each other.

\section{Evidence for frequent long-distance dispersal events}

Although the use of molecular genetic techniques, particularly high-resolution microsatellite markers, has provided valuable insights into seed dispersal in natural plant populations (Powell et al. 1996; Ashley 2010), there still remain problems associated with identifying the seed parents of established plants and / or seedlings in monoecious species. Estimates of pollen-mediated gene flow can be relatively easily obtained by genotyping seeds and "subtracting" the genotype of the maternal plant, thus leaving the paternal genotype which Page | 19 
can be matched to putative parent plants. Such an approach has been employed previously in ash, indicating pollination events at distances over several hundred metres, and up to nearly 3 km (Bacles et al. 2005; Bacles and Ennos 2008; Thomasset et al. 2014). Estimating seed dispersal, however, is a more difficult process, particularly in monoecious species (Sork and Smouse 2006). Previous studies have attempted to genotype the endocarp tissue to identify the maternal parent of dispersed seeds (Godoy and Jordano 2001; Garcia et al. 2007), but this only provides estimates of initial dispersal, and does not necessarily provide an indication of true population demography and recruitment (effective dispersal), for which identification of the mothers of seedlings or established plants is necessary. For seedlings in a population of an outcrossing species, it may be possible to identify both parents, one parent, which will be either the pollen or seed parent, or neither parent, indicating immigration of seed into the population. In angiosperms, chloroplast-specific markers can be used in conjunction with biparentally inherited nuclear markers to assign the maternal and the paternal parent where both parents are identified, since the chloroplast genome is usually maternally inherited. One drawback of such an approach is the low mutation rate in chloroplast genomes, meaning that often there is inadequate resolution to assign the maternal parent (Wolfe et al. 1987). By using highly polymorphic chloroplast microsatellite markers, which allow the high-resolution of maternal genotypes, it may often be possible to determine which is the mother plant in cases where both parents are identified using nuclear microsatellites (Provan et al. 2001).

By using a combination of nuclear and chloroplast microsatellite markers, we were able to assign seed and pollen parents unambiguously for 13 out of 41 saplings for which both parents were identified within the Barnett Demesne stand, as well as assigning putative seed parents to a further 42 saplings. Previous studies using genetic markers to identify the source of established seedlings relied on genotyping any maternal tissue associated with the seedling, but these approaches can be problematic due to the low quality of DNA typically Page | 20 

the majority of angiosperms and paternal in the majority of gymnosperms) that can be run on leaf material from established plants, and thus allow the assignment of seed and pollen parents where both parents are identified (Provan et al. 2001; Ebert and Peakall 2009a), circumventing the need to rely on genotypes from maternal tissues. Primers to amplify chloroplast microsatellites are available for a wide range of species, and the high levels of conservation of the chloroplast genome means that primers developed for a particular species often give polymorphic markers in related taxa (Provan et al. 2001). In addition, sets of universal primers are available to facilitate de novo development of these markers, particularly for non-model organisms or taxa with little sequence information available in DNA sequence databases such as GenBank (e.g. Ebert and Peakall 2009b). known within-stand dispersal events (over $10 \%$ ) exceeding this range. We also identified immigration into the stand in 16 cases (five out of 93 [5\%] from Barnett Demesne and eleven out of 39 [28\%] from Cregagh Glen). Barnett Demesne is located in a largely urban area, and the nearest stand of ash trees was $400 \mathrm{~m}$ to the east, at Shaw's bridge (Fig. 1), suggesting that this was the minimum dispersal distance of immigrant seed into the stand. Despite the lower genetic diversity in the Cregagh Glen population, which led to a lower level of parentage assignment, the higher rate of immigration appeared to result from extra-stand fertilization.

442 Cregagh Glen is in a more agriculture-dominated landscape on the eastern edge of Belfast, and it is possible that immigrant seed dispersed from neighbouring isolated individuals, lowdensity hedgerow trees, or from the next-nearest substantial stand of ash, which was a similarly-sized stand in a ravine $c a .500 \mathrm{~m}$ to the east (Fig. 1). 
Only two previous genetic studies on seed dispersal in ash have been carried out. Heuertz et al. (2003) used simulation studies coupled with estimates of kinship from five biparentally inherited nuclear microsatellites, including four of the seven loci used in the present study, to infer levels of seed and pollen dispersal in a continuous forest in southeast Romania. The estimated levels of seed dispersal, which were $\leq 14 \mathrm{~m}$, were lower than both the mean and median values calculated for the Barnett Demesne stand in the present study, and far lower than the majority of individual events identified. Bacles et al. (2006) used a direct, individual-based approach to assess seed dispersal in a highly fragmented landscape in southern Scotland. They detected multiple long-distance events, often between fragments of up to $1.4 \mathrm{~km}$, but this is most likely due to the chronically fragmented nature of their study site, with far fewer barriers to dispersal, and the increased chance of the winged seeds being uplifted in the initial stages of dispersal. This scenario is very different to the closed, semicontinuous woodlands analysed in the present study, and our findings may better reflect patterns of dispersal in more typical mixed-deciduous woodlands. Interestingly, since Bacles et al. (2006) had no means to identify the seed parent where parent pairs were identified, they assumed that the closer of the two to the seedling was the seed parent, but our analysis indicated that the seed parent was the more distant parent of the two in four out of twelve cases (and in one case they were equidistant). This further highlights the utility and results of dispersal in population demography i.e. initial dispersal followed by germination and survival / recruitment into the population. This means that post-dispersal processes, such as competition and density-dependent mortality, can be addressed. This was not possible in early genetic studies on dispersal, which relied on genotyping seeds, and thus could only Page | 22 
471 assess initial seed dispersal (e.g. Godoy and Jordano 2001; Ziegenhagen et al. 2003; Grivet et 472 al. 2005). Although we did not specifically test for such effects, our plot of effective seed 473 dispersal distances within Barnett Demesne is consistent with a Janzen-Connell recruitment 474 process (Janzen 1970; Connell 1971; Augspurger 1983). Dispersal in the stand peaked at 30 $475-40 \mathrm{~m}$, before tailing off quickly, suggesting density-dependent mortality close to the mother 476 plant. A similar pattern was observed in a genetic study on Aleppo pine (Pinus halepensis) 477 specifically designed to test for Janzen-Connell effects (Steinitz et al. 2011). 


\section{Conclusions}

479 Our results suggest that although there is considerable genetic variation in ash trees across the 480 whole of Ireland, there is no evidence of population genetic structure. Hence, the imposition 481 of "seed zones" as part of a recovery plan for ash trees in the aftermath of near total mortality 482 due to ash dieback may not be justified, and is an avoidable cost. Our findings of frequent, 483 long-distance dispersal events have further implications for the survival and persistence of 484 ash woodlands in the face of a range of threats. Infection by the causal agent of ash dieback, 485 Chalara fraxinea, may lead to loss of woodlands, either by pathogenic mortality or by 486 anthropogenic clearance as a means of control (Pautasso et al. 2013). The high capacity for 487 dispersal indicated by our results suggests good potential for natural regeneration, as well as 488 for the spread of resistance to the disease, both via seeds and via pollen-mediated gene flow 489 from individuals exhibiting inherent resistance. In addition, high levels of migration will be 490 necessary to respond to global climate change, although this is very much dependent on the 491 rate and extent of these changes. 
493

494 We are grateful to four anonymous referees, whose suggestions and comments greatly

495 improved an earlier draft of the manuscript. This study was funded by the Natural Heritage

496 Research Partnership (NHRP) between the Northern Ireland Environment Agency (NIEA)

497 and Quercus, Queen's University Belfast (QUB). Thanks to Dr Philip Perrin, Botanical,

498 Environmental \& Conservation (BEC) Consultants Ltd. for providing data on the location

499 and composition of ash woodlands in the Republic of Ireland and Kieran Coyle for assistance

500 with leaf collection. John Farren acted as NIEA Client Officer. 


\section{Data archiving statement}

502

503 All data will be deposited in DRYAD on acceptance. 


\section{References}

505

506

507

508

509

510

511

512

513

514

515

516

517

518

519

520

521

522

523

524

525

526

527

Ashley MV (2010) Plant parentage, pollination and dispersal: how DNA microsatellites have altered the landscape. Critical Rev Plant Sci 29:148-161.

Augspurger C (1983) Recruitment around tropical trees: changes in cohort distance with time. Oikos 40:189-196.

Bacles CFE, Burczyk J, Lowe AJ, Ennos RA (2005) Historical and contemporary mating patterns in remnant populations of the forest tree Fraxinus excelsior L. Evolution 59:979990.

Bacles CFE, Lowe AJ, Ennos RA (2006) Effective seed dispersal across a fragmented landscape. Science 311:628.

Bacles CFE, Ennos RA (2008) Paternity analysis of pollen-mediated gene flow for Fraxinus excelsior L. in a chronically fragmented landscape. Heredity 101:368-380.

Brachet S, Jubier MF, Richard M, Jung-Muller B, Frascaria-Lacoste N (1999) Rapid identification of microsatellite loci using 5' anchored PCR in common ash Fraxinus excelsior. Mol Ecol Notes 8:160-163.

Connell JH (1971) On the role of natural enemies in preventing competitive exclusion in some marine animals and forest trees. In den Boer PJ, Gradwell GR (eds) Dynamics of Populations. Centre for Agricultural Publishing and Documentation. Wageningen, The Netherlands pp. 298-312.

Corander J, Waldmann P, Sillanpää MJ (2003) Bayesian analysis of genetic differentiation between populations. Genetics 163:367-374.

DeSalle R. Amato G (2004) The expansion of conservation genetics. Nature Rev Genet $5: 702-712$ 
Doyle JJ, Doyle JL (1987) A rapid DNA isolation procedure for small quantities of fresh leaf tissue. Phytochem Bull 19: 1-15.

Ebert D, Peakall R (2009a) Chloroplast simple sequence repeats (cpSSRs): technical resources and recommendations for expanding cpSSR discovery and applications to a wide array of plant species. Mol Ecol Resources 9:673-690.

Ebert D, Peakall R (2009b) A new set of universal de novo sequencing primers for extensive coverage of noncoding chloroplast DNA: new opportunities for phylogenetic studies and cpSSR discovery. Mol Ecol Resources 9:777-783.

Excoffier L, Smouse PE, Quattro JM (1992) Analysis of molecular variance inferred from metric distances among DNA haplotypes - application to human mitochondrial DNA restriction data. Genetics 131:479-491.

Excoffier L, Lischer HEL (2010) Arlequin suite ver 3.5: a new series of programs to perform population genetics analyses under Linux and Windows. Molecular Ecol Resources 10:564-567.

Ferrazzini D, Monteleoni I, Belletti P (2007) Genetic variability and divergence among Italian populations of common ash (Fraxinus excelsior L.). Annals Forest Sci 64:159-168.

Forget PM, Wenny D (2005) How to elucidate seed fate? A review of methods used to study seed removal and secondary seed dispersal. In: Forget PM et al. (eds) Seed Fate: Seed Predation, Seed Dispersal and Seedling Establishment. CABI Publishing, Wallingford, UK pp. 379-393.

FRAXIGEN (2005) Ash species in Europe: Biological Characteristics and Practical Guidelines for Sustainable Use. Oxford Forestry Institute, Oxford, UK.

Garcia C, Jordano P, Godoy JA (2007) Contemporary pollen and seed dispersal in a Prunus mahaleb population: patterns in distance and direction. Mol Ecol 16:1947-1955. 
552 Godoy JA, Jordano P (2001) Seed dispersal by animals: exact identification of source trees 553 with endocarp DNA microsatellites. Mol Ecol 10:2275-2283.

554 Gérard PR, Temunovic M, Sannier J, Bertolino P, Dufour J, Frascaria-Lacoste N, Fernández555 Manjarrés JF (2013) Chilled but not frosty: understanding the role of climate in the 556 hybridization between the Mediterranean Fraxinus angustifolia Vahl and the temperate 557 Fraxinus excelsior L. (Oleaceae) ash trees. J Biogeogr 40:835-846.

558 Godefroid S, Piazza C, Rossi G. et al. (2011) How successful are plant species reintroductions? Biol Conserv 144:672-682.

Goudet J (2001) FSTAT, version 2.9.3, A program to estimate and test gene diversities and fixation indices. http://www2.unil.ch/popgen/softwares/fstat.htm.

Grivet D, Robledo-Arnuncio JJ, Smouse PE, Sork VL (2009) Relative contribution of contemporary pollen and seed dispersal to the neighbourhood size of a seedling population

Hardy OJ, Vekemans X (2002) SPAGeDi: a versatile computer program to analyse spatial genetic structure at the individual or population levels. Mol Ecol Notes 2:618-620.

Hardy OJ, Maggia L, Bandou E, Breyne P, Caron J, Chevallier MH, Doligez A, Dutech C, Kremer A, Latouche-Hallé C, Troispoux V, Veron V, Degen B (2006) Fine-scale genetic structure and gene dispersal inferences in 10 neotropical tree species. Mol Ecol 15:559571.

Hebel I, Haas R, Dounavi A (2006) Genetic variation of common ash (Fraxinus excelsior L.) populations from provenance regions in southern Germany by using nuclear and chloroplast microsatellites. Silvae Genetica 55:38-44.

Page | 29 
577 Hedrick PW (2005) A standardized genetic differentiation measure. Evolution 59:1633$578 \quad 1638$.

579 Herbert R, Samuel S, Pattison G (1999) Using Local Stock for Planting Native Trees and 580 Shrubs. Forestry Commission Practice Note 8. Forestry Commission, Edinburgh, UK. 581 Heuertz M, Hausman J-F, Tsvetkov I, Frascaria-Lacoste N, Vekemans X (2001) Assessment of genetic structure within and among Bulgarian populations of common as (Fraxinus excelsior L.). Mol Ecol 10:1615-1623.

Heuertz M, Vekemans X, Hausman J-F, Palada M, Hardy OJ (2003) Estimating seed vs. Pollen dispersal from spatial genetic structure in the common ash. Mol Ecol 12:24832495.

Heuertz M, Fineschi S, Anzidei M et al. (2004a) Chloroplast DNA variation and postglacial recolonization of common ash (Fraxinus excelsior L.) in Europe. Mol Ecol 13:3437-3452.

Heuertz M, Hausman J-F, Hardy OJ, Vendramin GG, Frascaria-Lacoste N, Vekemans X (2004b) Nuclear microsatellites reveal contrasting patterns of genetic structure between western and southeastern European populations of the common ash (Fraxinus excelsior_. Evolution 58:976-988.

Howe HF, Smallwood J (1982) Ecology of seed dispersal. Annu Rev Ecol Syst 13:201-228.

Jones N, Burley J (1973) Seed certification, provenance nomenclature and genetic history in forestry. Silvae Genetica 23:53-58.

Kalinowski ST, Taper ML, Marshall TC (2007) Revising how the computer program CERVUS accommodates genotyping error increases success in paternity assignment. Mol Ecol 16:1099-1106. 
601 Kowalski T (2006) Chalara fraxinea sp nov associated with dieback of ash (Fraxinus 602 excelsior) in Poland. Forest Pathol 36:264-270.

603

Lefort F, Brachet S, Frascaria-Lacoste N, Edwards KJ, Douglas GC (1999) Identification and 604 characterization of microsatellite loci in ash (Fraxinus excelsior L.) and their conservation 605 in the olive family. Mol Ecol Notes 8:1088-1090.

606

Levine JM, Murrell DJ (200) The community-level consequences of seed dispersal patterns.

607 Annu Rev Ecol Evol Syst 34:549-574.

608

Loiselle BA, Sork VL, Nason J, Graham C (1995) Spatial genetic structure of a tropical understorey shrub, Psychotria officinalis (Rubiaceae). Am J Bot 82:1420-1425.

Marigo G, Peltier J-P, Girel J, Pautou G (2001) Success in the demographic expansion of Fraxinus excelsior L. Trees 15:1-13.

Morand ME, Brachet S, Rossignol P, Dufour J, Frascaria-Lacoste N (2002) A generalised heterozygote deficiency assessed with microsatellites in French common ash populations. Mol Ecol 11:377-385.

Nathan R, Muller-Landau HC (2000) Spatial patterns of seed dispersal, their determinants and consequences for recruitment. Trends Ecol Evol 15:278-285.

Pautasso M, Aas G, Queloz V, Holdenreider O (2013) European as (Fraxinus excelsior) dieback - a conservation biology challenge. Biol Conserv 158:37-49.

Powell W, Machray GC, Provan J (1996) Polymorphism revealed by simple sequence repeats. Trends Plant Sci 1:215-222.

Provan J, Powell W, Hollingsworth PM (2001) Chloroplast microsatellites: new tools for studies in plant ecology and systematic. Trends Ecol Evol 16:142-147.

623

Queloz V, Grüning CR, Berndt R, Kowalski T, Sieber TN, Holdenreider O (2011) Cryptic speciation in Hymenoscyphus albidus. Forest Pathol 41:133-142. 
Raymond M, Rousset F (1995) GENEPOP (version 1.2): population genetic software for exact tests and ecumenicism. J Hered 86:248-249.

Rousset F (1997) Genetic differentiation and estimation of gene flow from $F$-statistics under isolation by distance. Genetics 145:1219-1228.

Smouse PE, Sork VL, Scofield DG, Grivet D (2012) Using seedling and pericarp tissues to determine maternal parentage of dispersed valley oak recruits. J Hered 103:250-259.

Sork VL Smouse PE (2006) Genetic analysis of landscape connectivity in tree populations. Landscape Ecol 21:821-836.

Steinitz O, Troupin D, Vendramin GG, Nathan R (2011) Genetic evidence for a JanzenConnell recruitment pattern in reproductive offspring of Pin us halepensis trees. Mol Ecol $20: 4152-4164$

Sutherland BG, Belaj A, Nier S, Cottrell JE, Vaughan SP, Hubert J, Russell K (2010) Molecular biodiversity and population structure in common ash (Fraxinus excelsior L.) in Britain: implications for conservation. Mol Ecol 19:2196-2211.

Thomasset M, Fernández-Manjarrés JF, Douglas GC, Bertolino P, Frascaria-Lacoste N, Hodkinson TR (2013) Assignment testing reveals multiple introduced source populations including potential ash hybrids (Fraxinus excelsior $\times$ F. angustifolia) in Ireland. Eur J Forest Res 132:195-209.

Thomasset M, Hodkinson TR, Restoux G, Frascaria-Lacoste N, Douglas GC, FernándezManjarrés JF (2014) Thank you for not flowering: conservation genetics and gene flow analysis of native and non-native populations of Fraxinus (Oleaceae) in Ireland. Heredity 112:596-606.

Vekemans X, Hardy OJ (2004) New insights from fine-scale spatial genetic structure analysis in plant populations. Mol Ecol 13:921-935.

Wang BC, Smith TB (2002) Closing the seed dispersal loop. Trends Ecol Evol 17:379-385. Page | 32 
650 Wardle P. 1961. Biological flora of the British Isles: Fraxinus excelsior L. J Ecol 49:739$651 \quad 751$.

652 Webber J (1981) A natural biological control of Dutch elm disease. Nature 292:449-451.

653 Weir BS, Cockerham CC (1984) Estimating F-statistics for the analysis of population 654 structure. Evolution 38:1358-1370.

655 Wolfe KH, Li W-H, Sharp PM (1987) Rates of nucleotide substitution vary greatly among 656 plant mitochondrial, chloroplast and nuclear DNAs. Proceedings Natl Acad Sci USA $657 \quad 84: 9054-9058$.

658 Ziegenhagen B, Liepelt S, Kuhlenkamp V, Fladung M (2003) Molecular identification of 659 individual oak and fir trees from maternal tissues of their fruits or seeds. Trees 17:345660 350. 
Table 1 Details of populations studied. $N$ - number of individuals analysed; $A_{\mathrm{R}}$ - allelic richness; $P$ - number of private alleles; $H_{\mathrm{O}}-$ observed heterozygosity; $H_{\mathrm{E}}$ - expected heterozygosity; $F_{\mathrm{IS}}$ - inbreeding coefficient; H1-H8 - frequency of chloroplast haplotypes; $H$ - gene diversity.

\begin{tabular}{|c|c|c|c|c|c|c|c|c|c|c|c|c|c|c|c|c|c|c|c|c|}
\hline \multirow[t]{2}{*}{ No } & \multirow[t]{2}{*}{ Name } & \multirow{2}{*}{$\begin{array}{l}\text { Lat } \\
(\mathrm{N})\end{array}$} & \multirow{2}{*}{$\begin{array}{c}\text { Long } \\
\text { (W) }\end{array}$} & \multicolumn{7}{|c|}{ Nuclear } & \multicolumn{10}{|c|}{ Chloroplast } \\
\hline & & & & $N$ & $\overline{A_{R}}$ & $P$ & $H_{O}$ & $H_{E}$ & $F_{I S}$ & $S p^{a}$ & $N$ & $\mathrm{H} 1$ & $\mathrm{H} 2$ & H3 & $\mathrm{H} 4$ & $\mathrm{H} 5$ & H6 & $\mathrm{H} 7$ & $\mathrm{H} 8$ & $H$ \\
\hline 1 & Portaferry & 54.391 & 5.565 & 30 & 9.80 & - & 0.673 & 0.750 & $0.104^{* * *}$ & 0.000 & 30 & 28 & 2 & - & - & - & - & - & - & 0.129 \\
\hline 2 & Downpatrick & 54.352 & 5.700 & 30 & 10.16 & - & 0.647 & 0.734 & $0.121^{* * *}$ & 0.003 & 30 & 30 & - & - & - & - & - & - & - & 0.000 \\
\hline 3 & Helen's Bay & 54.672 & 5.731 & 30 & 10.17 & 2 & 0.656 & 0.730 & $0.103^{* * *}$ & 0.005 & 29 & 26 & 3 & - & - & - & - & - & - & 0.192 \\
\hline 4 & Magheramourne & 54.810 & 5.781 & 30 & 10.24 & - & 0.782 & 0.784 & $0.003^{\mathrm{NS}}$ & 0.001 & 30 & 30 & - & - & - & - & - & - & - & 0.000 \\
\hline 5 & Glenarm Forest & 54.962 & 5.958 & 30 & 9.52 & 2 & 0.823 & 0.770 & $-0.070^{\mathrm{NS}}$ & 0.008 & 30 & 29 & - & 1 & - & - & - & - & - & 0.067 \\
\hline 6 & Barnett Demesne & 54.552 & 5.960 & 29 & 10.11 & - & 0.733 & 0.759 & $0.034^{\mathrm{NS}}$ & 0.001 & 30 & 12 & 16 & - & - & 1 & 1 & - & - & 0.572 \\
\hline 7 & Trassey Road & 54.219 & 5.984 & 29 & 10.14 & - & 0.662 & 0.712 & $0.072^{* *}$ & 0.010 & 26 & 26 & - & - & - & - & - & - & - & 0.000 \\
\hline 8 & Dromara & 54.330 & 5.996 & 29 & 11.42 & 1 & 0.723 & 0.782 & $0.078^{* *}$ & 0.011 & 29 & 29 & - & - & - & - & - & - & - & 0.000 \\
\hline 9 & Hillsborough & 54.459 & 6.083 & 30 & 10.80 & - & 0.680 & 0.780 & $0.130^{* * *}$ & 0.007 & 28 & 19 & 9 & - & - & - & - & - & - & 0.452 \\
\hline 10 & Glenariff Forest & 55.016 & 6.100 & 30 & 10.85 & - & 0.727 & 0.775 & $0.063^{*}$ & 0.010 & 29 & 28 & - & - & - & - & - & 1 & - & 0.069 \\
\hline 11 & Rostrevor & 54.095 & 6.191 & 30 & 10.54 & 1 & 0.731 & 0.809 & $0.016^{\mathrm{NS}}$ & 0.013 & 26 & 26 & - & - & - & - & - & - & - & 0.000 \\
\hline 12 & Ballycastle Forest & 55.174 & 6.226 & 30 & 9.82 & 1 & 0.755 & 0.757 & $0.003^{\mathrm{NS}}$ & 0.016 & 28 & 28 & - & - & - & - & - & - & - & 0.000 \\
\hline 13 & Randalstown & 54.733 & 6.320 & 30 & 11.39 & 2 & 0.731 & 0.809 & $0.097^{* * *}$ & 0.015 & 28 & 28 & - & - & - & - & - & - & - & 0.000 \\
\hline 14 & Portglenone & 54.863 & 6.472 & 30 & 10.41 & 3 & 0.739 & 0.802 & $0.080^{* *}$ & 0.000 & 30 & 28 & 1 & - & - & - & - & - & 1 & 0.131 \\
\hline 15 & Gosford Park & 54.303 & 6.522 & 30 & 11.07 & 2 & 0.738 & 0.771 & $0.044^{\mathrm{NS}}$ & 0.007 & 30 & 29 & 1 & - & - & - & - & - & - & 0.067 \\
\hline 16 & Ballymoney & 55.062 & 6.560 & 30 & 9.90 & 1 & 0.697 & 0.771 & $0.098^{* * *}$ & 0.000 & 28 & 28 & - & - & - & - & - & - & - & 0.000 \\
\hline 17 & Peatlands Park & 54.486 & 6.616 & 29 & 10.42 & 3 & 0.667 & 0.730 & $0.086^{* *}$ & 0.012 & 29 & 26 & - & - & 3 & - & - & - & - & 0.192 \\
\hline 18 & Carndaisy Woods & 54.749 & 6.725 & 30 & 10.31 & 1 & 0.690 & 0.774 & $0.110^{* * *}$ & 0.000 & 30 & 30 & - & - & - & - & - & - & - & 0.000 \\
\hline 19 & Downhill & 55.160 & 6.807 & 29 & 10.33 & 1 & 0.656 & 0.765 & $0.145^{* * *}$ & 0.007 & 27 & 27 & - & - & - & - & - & - & - & 0.000 \\
\hline 20 & Drum Manor & 54.639 & 6.815 & 30 & 11.34 & 3 & 0.727 & 0.779 & $0.068^{* *}$ & 0.003 & 30 & 29 & 1 & - & - & - & - & - & - & 0.067 \\
\hline
\end{tabular}

Page | 34 
Table 1 (Continued)

\begin{tabular}{|c|c|c|c|c|c|c|c|c|c|c|c|c|c|c|c|c|c|c|c|c|}
\hline \multirow[t]{2}{*}{ No } & \multirow[t]{2}{*}{ Name } & \multirow{2}{*}{$\begin{array}{l}\text { Lat } \\
(\mathrm{N})\end{array}$} & \multirow{2}{*}{$\begin{array}{c}\text { Long } \\
\text { (W) }\end{array}$} & \multicolumn{7}{|c|}{ Nuclear } & \multicolumn{10}{|c|}{ Chloroplast } \\
\hline & & & & $N$ & $A_{\mathrm{R}}$ & $P$ & $H_{\mathrm{O}}$ & $H_{\mathrm{E}}$ & $F_{\text {IS }}$ & $S p^{a}$ & $N$ & H1 & $\mathrm{H} 2$ & $\mathrm{H} 3$ & $\mathrm{H} 4$ & H5 & H6 & $\mathrm{H} 7$ & H8 & $H$ \\
\hline 21 & Lemnagore Wood & 54.331 & 6.841 & 29 & 10.18 & - & 0.714 & 0.720 & $0.008^{\mathrm{NS}}$ & 0.012 & 30 & 30 & - & - & - & - & - & - & - & 0.000 \\
\hline 22 & Roe Valley & 55.025 & 6.938 & 30 & 9.93 & - & 0.669 & 0.777 & $0.141^{* * *}$ & 0.015 & 30 & 29 & - & 1 & - & - & - & - & - & 0.067 \\
\hline 23 & Knockmany Forest & 54.436 & 7.170 & 30 & 10.72 & 1 & 0.800 & 0.782 & $-0.023^{\mathrm{NS}}$ & 0.003 & 30 & 30 & - & - & - & - & - & - & - & 0.000 \\
\hline 24 & Slieve Beagh & 54.380 & 7.203 & 28 & 10.92 & - & 0.670 & 0.733 & $0.088^{* *}$ & 0.006 & 30 & 28 & - & 2 & - & - & - & - & - & 0.129 \\
\hline 25 & Stranbane Glen & 54.836 & 7.443 & 30 & 10.99 & 4 & 0.708 & 0.773 & $0.084^{* * *}$ & 0.002 & 30 & 30 & - & - & - & - & - & - & - & 0.000 \\
\hline 26 & Crom & 54.170 & 7.451 & 30 & 10.32 & 1 & 0.669 & 0.755 & $0.115^{* * *}$ & 0.009 & 30 & 30 & - & - & - & - & - & - & - & 0.000 \\
\hline 27 & Knockninny Hill & 54.231 & 7.573 & 28 & 11.15 & 3 & 0.691 & 0.770 & $0.103^{* * *}$ & 0.020 & 30 & 30 & - & - & - & - & - & - & - & 0.000 \\
\hline 28 & Sloughan Glen & 54.615 & 7.574 & 29 & 9.82 & - & 0.697 & 0.745 & $0.065^{*}$ & 0.004 & 30 & 30 & - & - & - & - & - & - & - & 0.000 \\
\hline 29 & Castle Hill & 54.484 & 7.722 & 30 & 11.14 & 1 & 0.637 & 0.757 & $0.161^{* * *}$ & 0.000 & 30 & 30 & - & - & - & - & - & - & - & 0.000 \\
\hline 30 & Ely Lodge & 54.412 & 7.725 & 30 & 11.39 & 3 & 0.728 & 0.776 & $0.062^{* *}$ & 0.011 & 30 & 30 & - & - & - & - & - & - & - & 0.000 \\
\hline 31 & Killeter Forest & 54.687 & 7.744 & 30 & 11.52 & 1 & 0.738 & 0.779 & $0.053^{*}$ & 0.001 & 30 & 30 & - & - & - & - & - & - & - & 0.000 \\
\hline 32 & Marble Arch & 54.267 & 7.810 & 28 & 10.24 & 1 & 0.710 & 0.763 & $0.071^{* *}$ & 0.008 & 30 & 30 & - & - & - & - & - & - & - & 0.000 \\
\hline 33 & Castle Caldwell & 54.493 & 7.965 & 30 & 11.21 & 2 & 0.687 & 0.742 & $0.075^{* *}$ & 0.000 & 30 & 30 & - & - & - & - & - & - & - & 0.000 \\
\hline 34 & Glenasmole Valley & 53.251 & 6.371 & 28 & 11.00 & 1 & 0.762 & 0.776 & $0.018^{\mathrm{NS}}$ & 0.007 & 30 & 19 & 11 & - & - & - & - & - & - & 0.481 \\
\hline 35 & Knocknamallavoge & 51.853 & 8.527 & 29 & 9.63 & - & 0.746 & 0.802 & $0.071^{*}$ & 0.000 & 29 & 29 & - & - & - & - & - & - & - & 0.000 \\
\hline 36 & Letterfrack & 53.553 & 9.948 & 26 & 10.02 & - & 0.644 & 0.771 & $0.168^{* * *}$ & 0.005 & 26 & 24 & 2 & - & - & - & - & - & - & 0.148 \\
\hline
\end{tabular}

${ }^{a} S p$ is a measure of spatial genetic structure proposed by Vekemans and Hardy (2004). See Materials and Methods for details. 
Table 2 Nuclear microsatellite loci analyzed in this study. $N$ - number of alleles; $H_{\mathrm{O}}$ - observed heterozygosity; $H_{\mathrm{E}}-$ expected heterozygosity; $F_{\text {IS }}$ - inbreeding coefficient; Null - null allele frequency; LAD - large allele dropout.

\begin{tabular}{|c|c|c|c|c|c|c|c|c|}
\hline Locus & Primers ${ }^{*}$ & $N$ & Range (bp) & $H_{\mathrm{O}}$ & $\overline{H_{\mathrm{E}}}$ & $F_{\text {IS }}$ & Null & $\% \mathrm{LAD}$ \\
\hline \multirow[t]{2}{*}{ FR639485 } & TGACAAACCCCAGCCTAACTCT & 21 & $310-348$ & 0.613 & 0.629 & 0.024 & 0.019 & - \\
\hline & GCCTGAGCAAGTAAAGACGCTA & & & & & & & \\
\hline \multirow[t]{2}{*}{ FR646655 } & TGGAGCAGTTGAAGCACTGAAA & 9 & $200-230$ & 0.442 & 0.477 & 0.075 & 0.040 & - \\
\hline & TCTTCATCTTCCCAACAGCAGC & & & & & & & \\
\hline \multirow[t]{2}{*}{ Femsatl-4 } & TTCATGCTTCTCCGTGTCTCAG & 48 & $134-220$ & 0.851 & 0.877 & 0.030 & 0.017 & 2.98 \\
\hline & GGGTGAAGAGGCTTTGTGTCAT & & & & & & & \\
\hline \multirow[t]{2}{*}{ Femsatl-8 } & TTGCCTTTGTAGCTCAGG & 32 & $165-229$ & 0.695 & 0.910 & 0.236 & 0.142 & 3.38 \\
\hline & GCGTTGTCCTTAACTTTTCA & & & & & & & \\
\hline \multirow[t]{2}{*}{ Femsatl-11 } & TGAACACAGCTCTTGACTCTGA & 38 & $188-264$ & 0.858 & 0.884 & 0.029 & 0.019 & 6.95 \\
\hline & GTTCTACTACTTCAAGAACAGGGGG & & & & & & & \\
\hline \multirow[t]{2}{*}{ Femsatl-16 } & TGATCTCGTCCGAATTCACTGC & 13 & $193-225$ & 0.500 & 0.499 & -0.004 & N/A & - \\
\hline & ATGATGGCGACTTTTGGTGTGA & & & & & & & \\
\hline \multirow[t]{2}{*}{ Femsatl-19 $9^{\dagger}$} & TCAAATTCCTGATTTCAGGGGGA & 49 & $137-217$ & 0.801 & 0.905 & 0.116 & 0.068 & - \\
\hline & CGCGTATGATGGTCTTTATCTCTGT & & & & & & & \\
\hline \multirow[t]{2}{*}{ M230 } & ACGCGCACGTTCTTTCTATTTG & 51 & $214-328$ & 0.909 & 0.937 & 0.030 & 0.019 & 11.59 \\
\hline & GCTTTCTTGACCGGCTGACTAT & & & & & & & \\
\hline
\end{tabular}

* Forward tailed with CACGACGTTGTAAAACGAC; Reverse tailed with GTGTCTT

${ }^{\dagger}$ Not used in fine-scale study 
Table 3 Analysis of molecular variance (AMOVA).

\begin{tabular}{llccc}
\hline Markers & Source of variation & Sum of squares & Variance & \% variation \\
\hline Nuclear & Among populations & 183.471 & 0.03917 & 1.31 \\
& Within populations & 6114.600 & 2.93971 & 98.69 \\
& & & & \\
Chloroplast & Among populations & 15.373 & 0.01370 & 26.29 \\
& Within populations & 39.066 & 0.03841 & 73.71 \\
\hline
\end{tabular}


Table 4 Pollination distances and realized pollen dispersal distances i.e. from father to sapling for the 13 saplings where the maternal parent was identified in the parent-pair.

\begin{tabular}{ccccc}
\hline Sapling & Father & Mother & \multicolumn{2}{c}{ Distance $(\mathrm{m})$} \\
\cline { 4 - 5 } & & & Pollination & Realized \\
\hline BS-03 & BA-006 & BA-056 & 83 & 67 \\
BS-08 & BA-001 & BA-009 & 2 & 8 \\
BS-10 & BA-005 & BA-015 & 22 & 9 \\
BS-18 & BA-083 & BA-054 & 158 & 149 \\
BS-34 & BA-105 & BA-026 & 190 & 168 \\
BS-50 & BA-033 & BA-017 & 12 & 7 \\
BS-52 & BA-032 & BA-081 & 167 & 23 \\
BS-55 & BA-076 & BA-025 & 68 & 100 \\
BS-62 & BA-135 & BA-068 & 108 & 135 \\
BS-65 & BA-037 & BA-006 & 22 & 41 \\
BS-70 & BA-076 & BA-092 & 266 & 47 \\
BS-72 & BA-109 & BA-116 & 2 & 75 \\
BS-83 & BA-135 & BA-074 & 112 & 13 \\
\hline
\end{tabular}


Table S1 Coordinates for samples analysed in the present study

\begin{tabular}{|c|c|c|c|}
\hline Location & Sample & Lat & Long \\
\hline Barnett Demesne & BA-001 & 54.55184233 & -5.961468454 \\
\hline \multirow[t]{48}{*}{ (Adults) } & BA-002 & 54.55175997 & -5.961379820 \\
\hline & BA-003 & 54.55189750 & -5.961542988 \\
\hline & BA-004 & 54.55175360 & -5.961534711 \\
\hline & BA-005 & 54.55183309 & -5.961453458 \\
\hline & BA-006 & 54.55174566 & -5.961596936 \\
\hline & BA-007 & 54.55175151 & -5.961411156 \\
\hline & BA-008 & 54.55181722 & -5.961577908 \\
\hline & BA-009 & 54.55183309 & -5.961453458 \\
\hline & BA-010 & 54.55162413 & -5.960783766 \\
\hline & BA-011 & 54.55179692 & -5.961439805 \\
\hline & BA-012 & 54.55170506 & -5.961320730 \\
\hline & BA-013 & 54.55171378 & -5.961304838 \\
\hline & BA-014 & 54.55163402 & -5.961370647 \\
\hline & BA-015 & 54.55165146 & -5.961338862 \\
\hline & BA-016 & 54.55167813 & -5.961322074 \\
\hline & BA-018 & 54.55176764 & -5.961302150 \\
\hline & BA-019 & 54.55178326 & -5.961162256 \\
\hline & BA-020 & 54.55186562 & -5.961250890 \\
\hline & BA-021 & 54.55166655 & -5.961168080 \\
\hline & BA-022 & 54.55192624 & -5.960583199 \\
\hline & BA-023 & 54.55163064 & -5.961169871 \\
\hline & BA-024 & 54.55162088 & -5.961123987 \\
\hline & BA-025 & 54.55163220 & -5.961262537 \\
\hline & BA-026 & 54.55156988 & -5.961296561 \\
\hline & BA-027 & 54.55164222 & -5.961323866 \\
\hline & BA-028 & 54.55161399 & -5.961247989 \\
\hline & BA-029 & 54.55161477 & -5.961294321 \\
\hline & BA-030 & 54.55156936 & -5.961265673 \\
\hline & BA-031 & 54.55157066 & -5.961342894 \\
\hline & BA-032 & 54.55164300 & -5.961370199 \\
\hline & BA-033 & 54.55164326 & -5.961385643 \\
\hline & BA-034 & 54.55161581 & -5.961356098 \\
\hline & BA-035 & 54.55158094 & -5.961419667 \\
\hline & BA-036 & 54.55178091 & -5.961023257 \\
\hline & BA-037 & 54.55189658 & -5.960955656 \\
\hline & BA-038 & 54.55170206 & -5.960609846 \\
\hline & BA-039 & 54.55179743 & -5.960404141 \\
\hline & BA-040 & 54.55149572 & -5.961161147 \\
\hline & BA-041 & 54.55205048 & -5.959958702 \\
\hline & BA-042 & 54.55192233 & -5.960351534 \\
\hline & BA-043 & 54.55188486 & -5.960260661 \\
\hline & BA-044 & 54.55184921 & -5.960277898 \\
\hline & BA-045 & 54.55195537 & -5.960179854 \\
\hline & BA-046 & 54.55185923 & -5.960339227 \\
\hline & BA-047 & 54.55188642 & -5.960353327 \\
\hline & BA-048 & 54.55178935 & -5.959925369 \\
\hline & BA-049 & 54.55206348 & -5.959664362 \\
\hline & BA-050 & 54.55209380 & -5.959863795 \\
\hline
\end{tabular}


Table S1 (continued)

\begin{tabular}{|c|c|c|c|}
\hline Location & Sample & Lat & Long \\
\hline Barnett Demesne & BA-051 & 54.551708 & -5.961574 \\
\hline \multirow[t]{49}{*}{ (Adults) } & BA-052 & 54.55170531 & -5.960269625 \\
\hline & BA-053 & 54.55199792 & -5.960038614 \\
\hline & BA-054 & 54.55188642 & -5.960353327 \\
\hline & BA-055 & 54.55194405 & -5.960041303 \\
\hline & BA-056 & 54.55192233 & -5.960351534 \\
\hline & BA-057 & 54.55197840 & -5.959946844 \\
\hline & BA-058 & 54.55188642 & -5.960353327 \\
\hline & BA-059 & 54.55189436 & -5.960291101 \\
\hline & BA-060 & 54.55186820 & -5.960338779 \\
\hline & BA-061 & 54.55170479 & -5.960238736 \\
\hline & BA-062 & 54.55194535 & -5.960118525 \\
\hline & BA-063 & 54.55178037 & -5.959925817 \\
\hline & BA-064 & 54.55197203 & -5.960101736 \\
\hline & BA-065 & 54.55165 & -5.960217 \\
\hline & BA-066 & 54.550867 & -5.960833 \\
\hline & BA-067 & 54.55165 & -5.960233 \\
\hline & BA-068 & 54.5515 & -5.960617 \\
\hline & BA-069 & 54.5516 & -5.96065 \\
\hline & BA-070 & 54.551883 & -5.961233 \\
\hline & BA-071 & 54.550917 & -5.960883 \\
\hline & BA-072 & 54.551 & -5.96145 \\
\hline & BA-073 & 54.551217 & -5.96175 \\
\hline & BA-074 & 54.550633 & -5.9616 \\
\hline & BA-075 & 54.5516 & -5.9608 \\
\hline & BA-076 & 54.551033 & -5.9615 \\
\hline & BA-077 & 54.5519 & -5.96125 \\
\hline & BA-078 & 54.551783 & -5.95995 \\
\hline & BA-079 & 54.5518 & -5.959883 \\
\hline & BA-080 & 54.551983 & -5.958883 \\
\hline & BA-081 & 54.55205 & -5.958883 \\
\hline & BA-082 & 54.55425 & -5.960983 \\
\hline & BA-083 & 54.5531 & -5.96165 \\
\hline & BA-084 & 54.55268 & -5.9602 \\
\hline & BA-085 & 54.55295 & -5.961483 \\
\hline & BA-086 & 54.5541 & -5.961 \\
\hline & BA-087 & 54.55417 & -5.9612 \\
\hline & BA-088 & 54.554 & -5.961867 \\
\hline & BA-089 & 54.55312 & -5.9617 \\
\hline & BA-090 & 54.55293 & -5.9613 \\
\hline & BA-091 & 54.55465 & -5.957533 \\
\hline & BA-092 & 54.55212 & -5.957833 \\
\hline & BA-093 & 54.55328 & -5.957567 \\
\hline & BA-094 & 54.55662 & -5.956933 \\
\hline & BA-095 & 54.55615 & -5.95775 \\
\hline & BA-096 & 54.55648 & -5.95715 \\
\hline & BA-097 & 54.55482 & -5.959767 \\
\hline & BA-098 & 54.5531 & -5.961717 \\
\hline & BA-099 & 54.55355 & -5.962033 \\
\hline & BA-100 & 54.55255 & -5.958633 \\
\hline
\end{tabular}

Page | 40 
Table S1 (continued)

\begin{tabular}{|c|c|c|c|}
\hline Location & Sample & Lat & Long \\
\hline $\begin{array}{l}\text { Barnett Demesne } \\
\text { (Adults) }\end{array}$ & $\begin{array}{l}\text { BA-101 } \\
\text { BA-102 } \\
\text { BA-103 } \\
\text { BA-104 } \\
\text { BA-105 } \\
\text { BA-106 } \\
\text { BA-107 } \\
\text { BA-108 } \\
\text { BA-109 } \\
\text { BA-110 } \\
\text { BA-111 } \\
\text { BA-112 } \\
\text { BA-113 } \\
\text { BA-116 } \\
\text { BA-117 } \\
\text { BA-118 } \\
\text { BA-120 } \\
\text { BA-121 } \\
\text { BA-122 } \\
\text { BA-124 } \\
\text { BA-125 } \\
\text { BA-126 } \\
\text { BA-128 } \\
\text { BA-129 } \\
\text { BA-130 } \\
\text { BA-131 } \\
\text { BA-132 } \\
\text { BA-133 } \\
\text { BA-134 } \\
\text { BA-135 } \\
\text { BA-136 } \\
\text { BA-137 } \\
\text { BA-139 } \\
\text { BA-140 }\end{array}$ & $\begin{array}{c}54.55208 \\
54.5532 \\
54.5525 \\
54.55667 \\
54.55325 \\
54.55333 \\
54.55247 \\
54.55075 \\
54.55063 \\
54.55063 \\
54.55133 \\
54.55077 \\
54.55067 \\
54.55063 \\
54.55068 \\
54.55068 \\
54.55063 \\
54.5507 \\
54.55055 \\
54.55068 \\
54.55063 \\
54.55055 \\
54.55062 \\
54.55057 \\
54.55057 \\
54.55055 \\
54.55055 \\
54.55068 \\
54.55065 \\
54.55063 \\
54.5508 \\
54.55085 \\
54.55075 \\
54.55125\end{array}$ & $\begin{array}{c}-5.9579 \\
-5.961767 \\
-5.957933 \\
-5.956883 \\
-5.96185 \\
-5.961967 \\
-5.959067 \\
-5.9604 \\
-5.960217 \\
-5.960367 \\
-5.961183 \\
-5.960083 \\
-5.960067 \\
-5.960183 \\
-5.959883 \\
-5.960067 \\
-5.959883 \\
-5.959917 \\
-5.959883 \\
-5.959633 \\
-5.959567 \\
-5.959483 \\
-5.959567 \\
-5.959483 \\
-5.959417 \\
-5.959467 \\
-5.959433 \\
-5.959733 \\
-5.960217 \\
-5.959867 \\
-5.960317 \\
-5.961217 \\
-5.96015 \\
-5.961083\end{array}$ \\
\hline $\begin{array}{l}\text { Barnett Demesne } \\
\text { (Saplings) }\end{array}$ & $\begin{array}{l}\text { BS-01 } \\
\text { BS-02 } \\
\text { BS-03 } \\
\text { BS-04 } \\
\text { BS-05 } \\
\text { BS-06 } \\
\text { BS-07 } \\
\text { BS-08 } \\
\text { BS-09 } \\
\text { BS-10 } \\
\text { BS-11 } \\
\text { BS-12 }\end{array}$ & $\begin{array}{c}54.551876 \\
54.551827 \\
54.551872 \\
54.551873 \\
54.551788 \\
54.551726 \\
54.55178 \\
54.55178 \\
54.551844 \\
54.551772 \\
54.551663 \\
54.551849\end{array}$ & $\begin{array}{l}-5.960802 \\
-5.960557 \\
-5.960586 \\
-5.960601 \\
-5.960915 \\
-5.961405 \\
-5.961518 \\
-5.961518 \\
-5.961592 \\
-5.961549 \\
-5.961477 \\
-5.960773\end{array}$ \\
\hline
\end{tabular}


Table S1 (continued)

\begin{tabular}{|c|c|c|c|}
\hline Location & Sample & Lat & Long \\
\hline Barnett Demesne & BS-13 & 54.551914 & -5.960383 \\
\hline \multirow[t]{47}{*}{ (Saplings) } & BS-14 & 54.551716 & -5.961428 \\
\hline & BS-15 & 54.551929 & -5.960212 \\
\hline & BS-16 & 54.552011 & -5.95912 \\
\hline & BS-18 & 54.55185 & -5.960881 \\
\hline & BS-19 & 54.55194 & -5.960335 \\
\hline & BS-20 & 54.551817 & -5.961037 \\
\hline & BS-21 & 54.551844 & -5.961051 \\
\hline & BS-22 & 54.551922 & -5.960877 \\
\hline & BS-23 & 54.55194 & -5.960892 \\
\hline & BS-24 & 54.551922 & -5.960893 \\
\hline & BS-26 & 54.551835 & -5.961021 \\
\hline & BS-27 & 54.551862 & -5.961035 \\
\hline & BS-28 & 54.551879 & -5.961003 \\
\hline & BS-29 & 54.551869 & -5.960926 \\
\hline & BS-30 & 54.55177 & -5.960916 \\
\hline & BS-31 & 54.551781 & -5.961054 \\
\hline & BS-32 & 54.551798 & -5.960961 \\
\hline & BS-33 & 54.551836 & -5.961082 \\
\hline & BS-34 & 54.551817 & -5.961037 \\
\hline & BS-35 & 54.551781 & -5.961023 \\
\hline & BS-36 & 54.551772 & -5.961039 \\
\hline & BS-37 & 54.55179 & -5.961579 \\
\hline & BS-38 & 54.55177 & -5.9609 \\
\hline & BS-39 & 54.551615 & -5.96131 \\
\hline & BS-40 & 54.551642 & -5.961308 \\
\hline & BS-41 & 54.551641 & -5.961278 \\
\hline & BS-42 & 54.551794 & -5.960729 \\
\hline & BS-43 & 54.552073 & -5.95971 \\
\hline & BS-44 & 54.55181 & -5.96062 \\
\hline & BS-45 & 54.55181 & -5.960635 \\
\hline & BS-46 & 54.552033 & -5.95999 \\
\hline & BS-47 & 54.551836 & -5.960572 \\
\hline & BS-48 & 54.551897 & -5.96043 \\
\hline & BS-49 & 54.551913 & -5.960321 \\
\hline & BS-50 & 54.551698 & -5.961445 \\
\hline & BS-51 & 54.551921 & -5.960831 \\
\hline & BS-52 & 54.551839 & -5.961268 \\
\hline & BS-53 & 54.551799 & -5.961038 \\
\hline & BS-54 & 54.551817 & -5.961006 \\
\hline & BS-55 & 54.551842 & -5.960927 \\
\hline & BS-56 & 54.551771 & -5.960977 \\
\hline & BS-57 & 54.551725 & -5.960902 \\
\hline & BS-58 & 54.551779 & -5.9609 \\
\hline & BS-59 & 54.551598 & -5.961342 \\
\hline & BS-60 & 54.551852 & -5.960463 \\
\hline & BS-61 & 54.551892 & -5.960693 \\
\hline & BS-62 & 54.551672 & -5.960951 \\
\hline
\end{tabular}


Table S1 (continued)

\begin{tabular}{|c|c|c|c|}
\hline Location & Sample & Lat & Long \\
\hline $\begin{array}{l}\text { Barnett Demesne } \\
\text { (Saplings) }\end{array}$ & $\begin{array}{l}\text { BS-63 } \\
\text { BS-64 } \\
\text { BS-65 } \\
\text { BS-66 } \\
\text { BS-67 } \\
\text { BS-68 } \\
\text { BS-69 } \\
\text { BS-70 } \\
\text { BS-71 } \\
\text { BS-72 } \\
\text { BS-73 } \\
\text { BS-74 } \\
\text { BS-75 } \\
\text { BS-76 } \\
\text { BS-77 } \\
\text { BS-79 } \\
\text { BS-80 } \\
\text { BS-81 } \\
\text { BS-82 } \\
\text { BS-83 } \\
\text { BS-84 } \\
\text { BS-85 } \\
\text { BS-86 } \\
\text { BS-87 } \\
\text { BS-88 } \\
\text { BS-89 } \\
\text { BS-90 } \\
\text { BS-91 } \\
\text { BS-92 } \\
\text { BS-93 } \\
\text { BS-94 } \\
\text { BS-95 } \\
\text { BS-96 }\end{array}$ & $\begin{array}{c}54.551852 \\
54.551617 \\
54.55165 \\
54.55193 \\
54.551781 \\
54.551167 \\
54.55095 \\
54.5511 \\
54.551167 \\
54.551167 \\
54.551167 \\
54.551067 \\
54.551117 \\
54.550733 \\
54.55065 \\
54.550733 \\
54.5509 \\
54.550717 \\
54.550667 \\
54.55065 \\
54.5506 \\
54.550567 \\
54.550783 \\
54.550883 \\
54.551317 \\
54.55135 \\
54.551217 \\
54.551333 \\
54.551067 \\
54.550967 \\
54.550917 \\
54.551117 \\
54.550883\end{array}$ & $\begin{array}{l}-5.960417 \\
-5.96145 \\
-5.961417 \\
-5.960815 \\
-5.961054 \\
-5.96095 \\
-5.9606 \\
-5.960783 \\
-5.960933 \\
-5.9609 \\
-5.960883 \\
-5.960933 \\
-5.960967 \\
-5.9596 \\
-5.9595 \\
-5.959633 \\
-5.960667 \\
-5.959633 \\
-5.959633 \\
-5.959667 \\
-5.959483 \\
-5.95955 \\
-5.960283 \\
-5.960683 \\
-5.961117 \\
-5.961167 \\
-5.961017 \\
-5.9611 \\
-5.960783 \\
-5.960717 \\
-5.960667 \\
-5.960967 \\
-5.960683\end{array}$ \\
\hline $\begin{array}{l}\text { Cregagh Glen } \\
\text { (Adults) }\end{array}$ & $\begin{array}{l}\text { CA-01 } \\
\text { CA-02 } \\
\text { CA-03 } \\
\text { CA-04 } \\
\text { CA-05 } \\
\text { CA-06 } \\
\text { CA-07 } \\
\text { CA-08 } \\
\text { CA-09 } \\
\text { CA-10 } \\
\text { CA-11 } \\
\text { CA-12 } \\
\text { CA-13 } \\
\text { CA-14 }\end{array}$ & $\begin{array}{c}54.56205 \\
54.56205 \\
54.56435 \\
54.564267 \\
54.563717 \\
54.56515 \\
54.563533 \\
54.5632833 \\
54.563033 \\
54.562333 \\
54.564633 \\
54.564167 \\
54.565033 \\
54.5620833\end{array}$ & $\begin{array}{c}-5.88915 \\
-5.88905 \\
-5.88995 \\
-5.88978 \\
-5.8897 \\
-5.889833 \\
-5.889533 \\
-5.88945 \\
-5.88941667 \\
-5.88933 \\
-5.8897167 \\
-5.8899667 \\
-5.8899167 \\
-5.88905\end{array}$ \\
\hline
\end{tabular}


Table S1 (continued)

\begin{tabular}{|c|c|c|c|}
\hline Location & Sample & Lat & Long \\
\hline $\begin{array}{l}\text { Cregagh Glen } \\
\text { (Adults) }\end{array}$ & $\begin{array}{l}\text { CA-15 } \\
\text { CA-16 } \\
\text { CA-17 } \\
\text { CA-18 } \\
\text { CA-19 } \\
\text { CA-20 } \\
\text { CA-21 } \\
\text { CA-22 } \\
\text { CA-23 } \\
\text { CA-24 } \\
\text { CA-25 } \\
\text { CA-26 } \\
\text { CA-27 } \\
\text { CA-28 } \\
\text { CA-29 } \\
\text { CA-30 } \\
\text { CA-31 } \\
\text { CA-32 } \\
\text { CA-33 } \\
\text { CA-34 } \\
\text { CA-35 } \\
\text { CA-36 } \\
\text { CA-37 } \\
\text { CA-38 } \\
\text { CA-39 } \\
\text { CA-40 } \\
\text { CA-41 } \\
\text { CA-42 } \\
\text { CA-43 } \\
\text { CA-44 }\end{array}$ & $\begin{array}{c}54.5637 \\
54.5644833 \\
54.5621667 \\
54.5632167 \\
54.5644167 \\
54.563733 \\
54.5640833 \\
54.5637667 \\
54.564133 \\
54.5678 \\
54.5666 \\
54.5616 \\
54.5665833 \\
54.5665833 \\
54.566633 \\
54.565933 \\
54.5655833 \\
54.567233 \\
54.5668667 \\
54.562068 \\
54.560998 \\
54.5617167 \\
54.56395 \\
54.5638 \\
54.5649197 \\
54.5641167 \\
54.5663167 \\
54.565033 \\
54.565136 \\
54.565233\end{array}$ & $\begin{array}{c}-5.8896 \\
-5.8897 \\
-5888733 \\
-5.889433 \\
-5.8897167 \\
-5.8898 \\
-5.8898 \\
-5.8895667 \\
-5.8894667 \\
-5.8914167 \\
-5.8909 \\
-5.8887333 \\
-5.8910333 \\
-5.89115 \\
-5.89115 \\
-5.8905833 \\
-5.890416 \\
-5.89115 \\
-5.8910167 \\
-5.888221 \\
-5.88841 \\
-5.8885 \\
-5.8894167 \\
-5.88955 \\
-5.88985 \\
-5.889333 \\
-5.890783 \\
-5.889797 \\
-5.889807 \\
-5.889806\end{array}$ \\
\hline $\begin{array}{l}\text { Cregagh Glen } \\
\text { (Saplings) }\end{array}$ & $\begin{array}{l}\text { CS-01 } \\
\text { CS-02 } \\
\text { CS-03 } \\
\text { CS-04 } \\
\text { CS-05 } \\
\text { CS-06 } \\
\text { CS-07 } \\
\text { CS-08 } \\
\text { CS-10 } \\
\text { CS-11 } \\
\text { CS-12 } \\
\text { CS-13 } \\
\text { CS-14 } \\
\text { CS-15 } \\
\text { CS-16 } \\
\text { CS-17 } \\
\text { CS- }-18\end{array}$ & $\begin{array}{c}54.565041 \\
54.565037 \\
54.565042 \\
54.565037 \\
54.565044 \\
54.565044 \\
54.565031 \\
54.565033 \\
54.565033 \\
54.5643 \\
54.565046 \\
54.56429 \\
54.565036 \\
54.56429 \\
54.564968 \\
54.565041 \\
54.565043\end{array}$ & $\begin{array}{c}-5.889909 \\
-5.889909 \\
-5.889898 \\
-5.889885 \\
-5.889906 \\
-5.889908 \\
-5.889896 \\
-5.889889 \\
-5.889883 \\
-5.8898 \\
-5.889922 \\
-5.889808 \\
-5.889877 \\
-5.88979 \\
-5.890064 \\
-5.889916 \\
-5.889904 \\
\end{array}$ \\
\hline
\end{tabular}


Table S1 (continued)

\begin{tabular}{lccc}
\hline Location & Sample & Lat & Long \\
\hline Cregagh Glen & CS-19 & 54.565045 & -5.889924 \\
(Saplings) & CS-20 & 54.565024 & -5.889896 \\
& CS-21 & 54.56502 & -5.88989 \\
CS-22 & 54.565033 & -5.8899 \\
CS-23 & 54.565033 & -5.889867 \\
CS-24 & 54.565033 & -5.889933 \\
CS-25 & 54.564 & -5.88955 \\
CS-26 & 54.565 & -5.8899167 \\
CS-27 & 54.5642 & -5.88985 \\
CS-28 & 54.564 & -5.88955 \\
CS-29 & 54.564 & -5.889533 \\
CS-30 & 54.564 & -5.8895667 \\
CS-31 & 54.564 & -5.88955 \\
CS-32 & 54.56503 & -5.8899 \\
CS-33 & 54.564 & -5.88955 \\
CS-34 & 54.564 & -5.889533 \\
CS-35 & 54.5636 & -5.889533 \\
CS-36 & 54.565067 & -5.8899 \\
CS-37 & 54.565033 & -5.8899 \\
CS-38 & 54.564217 & -5.88975 \\
CS-39 & 54.564 & -5.88955 \\
CS-40 & 54.5637167 & -5.8897 \\
\hline
\end{tabular}


Table S2 Chloroplast microsatellite loci analyzed in this study.

\begin{tabular}{|c|c|c|c|}
\hline Multiplex & Locus & Primers* & Alleles (bp) \\
\hline \multirow[t]{6}{*}{1} & AF528042.1 & ACGAGCCAAAGTTCTAGCACAA & 181 \\
\hline & & GCCGGTTCGGGCTGATTTAT & \\
\hline & AM933080.1 & ACATTCCTCCGCTTTCATTCCT & $125,127,128,129$ \\
\hline & & TCTTCCTGCCACCTTTCCCA & \\
\hline & AF225238 & GGGGGTAAAGACCACTCAATAAATGAA & 265 \\
\hline & & TCCTCGTACGGCTCGAGAAA & \\
\hline \multirow[t]{6}{*}{2} & AF528042.2 & ATGGATGGGGTGGGGTATTAGT & 224 \\
\hline & & CTCAAATCATATCAGAGGGGTTTGC & \\
\hline & JN590973 & AGATAAAGGAAGGGGTCGAACG & 131,132 \\
\hline & & CAGGCCAGGCCATCAGAATAA & \\
\hline & AY911655 & ACAGGAATCTTTCACAAACTTCCCA & 270,271 \\
\hline & & CGAATTCCGCATATTTTCACATCTAGG & \\
\hline \multirow[t]{4}{*}{3} & AF528042.3 & GCTGGTTGCTTTTTCTTTCCCA & 184 \\
\hline & & CGTCTCAACGGAGAGTTCTGAGTC & \\
\hline & HM222783 & CTTAGGGAAATCTCTTTCTACCG & 121 \\
\hline & & GTCAAGTCGATTCAGATTATTCCAACG & \\
\hline \multirow[t]{4}{*}{4} & AM933080.2 & GGATCAAGTACGGGTTTCCGAT & $122,123,124$ \\
\hline & & ACTGGAACCCTTGAATTCATTAGATACT & \\
\hline & FR639483 & TGACAAACCCCAGCCTAACTCT & $172,173,174$ \\
\hline & & GCCTGAGCAAGTAAAGACGCTA & \\
\hline
\end{tabular}

* Forward tailed with CACGACGTTGTAAAACGAC; Reverse tailed with GTGTCTT 
Table S3 Diversity statistics for each locus by population

\begin{tabular}{|c|c|c|c|c|c|c|c|c|}
\hline \multirow{2}{*}{ Population } & \multicolumn{8}{|c|}{ Locus } \\
\hline & FR639485 & FR646655 & Femsatl-4 & Femsatl-8 & Femsatl-11 & Femsatl-16 & Femsatl-19 & M230 \\
\hline Portaferry & $\begin{array}{c}H_{O}=0.552 \\
H_{E}=0.645 \\
F_{I S}=0.147^{\mathrm{NS}}\end{array}$ & $\begin{array}{c}H_{O}=0.367 \\
H_{E}=0.461 \\
F_{I S}=0.207^{\mathrm{NS}}\end{array}$ & $\begin{array}{c}H_{O}=0.900 \\
H_{E}=0.880 \\
F_{I S}=-0.024^{\mathrm{NS}}\end{array}$ & $\begin{array}{c}H_{O}=0.600 \\
H_{E}=0.836 \\
F_{I S}=0.286^{* * *}\end{array}$ & $\begin{array}{c}H_{O}=0.759 \\
H_{E}=0.893 \\
F_{I S}=0.153 *\end{array}$ & $\begin{array}{c}H_{O}=0.448 \\
H_{E}=0.448 \\
F_{I S}=0.000^{\mathrm{NS}}\end{array}$ & $\begin{array}{c}H_{O}=0.897 \\
H_{E}=0.908 \\
F_{I S}=0.013^{\mathrm{NS}}\end{array}$ & $\begin{array}{c}H_{O}=0.862 \\
H_{E}=0.926 \\
F_{I S}=0.070^{\mathrm{NS}}\end{array}$ \\
\hline Downpatrick & $\begin{array}{c}H_{O}=0.428 \\
H_{E}=0.442 \\
F_{I S}=0.031^{\mathrm{NS}}\end{array}$ & $\begin{array}{c}H_{O}=0.345 \\
H_{E}=0.448 \\
F_{I S}=0.234^{\mathrm{NS}}\end{array}$ & $\begin{array}{c}H_{O}=0.759 \\
H_{E}=0.737 \\
F_{I S}=-0.028^{\mathrm{NS}}\end{array}$ & $\begin{array}{c}H_{O}=0.483 \\
H_{E}=0.912 \\
F_{I S}=0.475^{* * *}\end{array}$ & $\begin{array}{c}H_{O}=0.897 \\
H_{E}=0.897 \\
F_{I S}=0.000^{\mathrm{NS}}\end{array}$ & $\begin{array}{c}H_{O}=0.500 \\
H_{E}=0.590 \\
F_{I S}=0.155^{\mathrm{NS}}\end{array}$ & $\begin{array}{c}H_{O}=0.862 \\
H_{E}=0.890 \\
F_{I S}=0.032^{\mathrm{NS}}\end{array}$ & $\begin{array}{c}H_{O}=0.900 \\
H_{E}=0.958 \\
F_{I S}=0.062^{\mathrm{NS}}\end{array}$ \\
\hline Helen's Bay & $\begin{array}{c}H_{O}=0.536 \\
H_{E}=0.544 \\
F_{I S}=0.016^{\mathrm{NS}}\end{array}$ & $\begin{array}{c}H_{O}=0.379 \\
H_{E}=0.468 \\
F_{I S}=0.192^{\mathrm{NS}}\end{array}$ & $\begin{array}{c}H_{O}=0.700 \\
H_{E}=0.843 \\
F_{I S}=0.172 *\end{array}$ & $\begin{array}{c}H_{O}=0.593 \\
H_{E}=0.872 \\
F_{I S}=0.325 * * *\end{array}$ & $\begin{array}{c}H_{O}=0.931 \\
H_{E}=0.859 \\
F_{I S}=-0.085^{\mathrm{NS}}\end{array}$ & $\begin{array}{c}H_{O}=0.433 \\
H_{E}=0.433 \\
F_{I S}=0.000^{\mathrm{NS}}\end{array}$ & $\begin{array}{c}H_{O}=0.793 \\
H_{E}=0.930 \\
F_{I S}=0.150^{* *}\end{array}$ & $\begin{array}{c}H_{O}=0.884 \\
H_{E}=0.890 \\
F_{I S}=0.006^{\mathrm{NS}}\end{array}$ \\
\hline Magheramourne & $\begin{array}{c}H_{O}=0.621 \\
H_{E}=0.623 \\
F_{I S}=0.003^{\mathrm{NS}}\end{array}$ & $\begin{array}{c}H_{O}=0.500 \\
H_{E}=0.497 \\
F_{I S}=-0.007^{\mathrm{NS}}\end{array}$ & $\begin{array}{c}H_{O}=0.933 \\
H_{E}=0.870 \\
F_{I S}=-0.074^{\mathrm{NS}}\end{array}$ & $\begin{array}{c}H_{O}=0.767 \\
H_{E}=0.904 \\
F_{I S}=0.152 *\end{array}$ & $\begin{array}{c}H_{O}=0.900 \\
H_{E}=0.896 \\
F_{I S}=-0.004^{\mathrm{NS}}\end{array}$ & $\begin{array}{c}H_{O}=0.633 \\
H_{E}=0.627 \\
F_{I S}=-0.010^{\mathrm{NS}}\end{array}$ & $\begin{array}{c}H_{O}=0.900 \\
H_{E}=0.905 \\
F_{I S}=0.006^{\mathrm{NS}}\end{array}$ & $\begin{array}{c}H_{O}=1.000 \\
H_{E}=0.949 \\
F_{I S}=-0.055^{\mathrm{NS}}\end{array}$ \\
\hline Glenarm Forest & $\begin{array}{c}H_{O}=0.759 \\
H_{E}=0.734 \\
F_{I S}=-0.034^{\mathrm{NS}}\end{array}$ & $\begin{array}{c}H_{O}=0.467 \\
H_{E}=0.494 \\
F_{I S}=0.057^{\mathrm{NS}}\end{array}$ & $\begin{array}{c}H_{O}=1.000 \\
H_{E}=0.828 \\
F_{I S}=-0.213^{\mathrm{NS}}\end{array}$ & $\begin{array}{c}H_{O}=0.897 \\
H_{E}=0.881 \\
F_{I S}=-0.018^{\mathrm{NS}}\end{array}$ & $\begin{array}{c}H_{O}=0.867 \\
H_{E}=0.830 \\
F_{I S}=-0.045^{\mathrm{NS}}\end{array}$ & $\begin{array}{c}H_{O}=0.733 \\
H_{E}=0.596 \\
F_{I S}=-0.235^{\mathrm{NS}}\end{array}$ & $\begin{array}{c}H_{O}=0.862 \\
H_{E}=0.899 \\
F_{I S}=0.042^{\mathrm{NS}}\end{array}$ & $\begin{array}{c}H_{O}=1.000 \\
H_{E}=0.901 \\
F_{I S}=-0.112^{\mathrm{NS}}\end{array}$ \\
\hline Barnett Demesne & $\begin{array}{c}H_{O}=0.679 \\
H_{E}=0.521 \\
F_{I S}=-0.310^{\mathrm{NS}}\end{array}$ & $\begin{array}{c}H_{O}=0.536 \\
H_{E}=0.529 \\
F_{I S}=-0.013^{\mathrm{NS}}\end{array}$ & $\begin{array}{c}H_{O}=0.929 \\
H_{E}=0.889 \\
F_{I S}=-0.045^{\mathrm{NS}}\end{array}$ & $\begin{array}{c}H_{O}=0.759 \\
H_{E}=0.919 \\
F_{I S}=0.177 *\end{array}$ & $\begin{array}{c}H_{O}=0.793 \\
H_{E}=0.885 \\
F_{I S}=0.106^{\mathrm{NS}}\end{array}$ & $\begin{array}{c}H_{O}=0.418 \\
H_{E}=0.497 \\
F_{I S}=0.169^{\mathrm{NS}}\end{array}$ & $\begin{array}{c}H_{O}=0.793 \\
H_{E}=0.913 \\
F_{I S}=0.133 *\end{array}$ & $\begin{array}{c}H_{O}=0.966 \\
H_{E}=0.917 \\
F_{I S}=-0.054^{\mathrm{NS}}\end{array}$ \\
\hline Trassey Road & $\begin{array}{c}H_{O}=0.418 \\
H_{E}=0.492 \\
F_{I S}=0.162^{\mathrm{NS}}\end{array}$ & $\begin{array}{c}H_{O}=0.345 \\
H_{E}=0.328 \\
F_{I S}=-0.051^{\mathrm{NS}}\end{array}$ & $\begin{array}{c}H_{O}=0.897 \\
H_{E}=0.898 \\
F_{I S}=0.001^{\mathrm{NS}}\end{array}$ & $\begin{array}{c}H_{O}=0.750 \\
H_{E}=0.879 \\
F_{I S}=0.149 *\end{array}$ & $\begin{array}{c}H_{O}=0.893 \\
H_{E}=0.917 \\
F_{I S}=0.027^{\mathrm{NS}}\end{array}$ & $\begin{array}{c}H_{O}=0.310 \\
H_{E}=0.337 \\
F_{I S}=0.080^{\mathrm{NS}}\end{array}$ & $\begin{array}{c}H_{O}=0.759 \\
H_{E}=0.901 \\
F_{I S}=0.160 *\end{array}$ & $\begin{array}{c}H_{O}=0.931 \\
H_{E}=0.949 \\
F_{I S}=0.019^{\mathrm{NS}}\end{array}$ \\
\hline
\end{tabular}

Page | 47 
Table S3 (cont.)

\begin{tabular}{|c|c|c|c|c|c|c|c|c|}
\hline \multirow{2}{*}{ Population } & \multicolumn{8}{|c|}{ Locus } \\
\hline & FR639485 & FR646655 & Femsatl-4 & Femsatl-8 & Femsatl-11 & Femsatl-16 & Femsatl-19 & M230 \\
\hline Dromara & $\begin{array}{c}H_{O}=0.607 \\
H_{E}=0.609 \\
F_{I S}=0.003^{\mathrm{NS}}\end{array}$ & $\begin{array}{c}H_{O}=0.429 \\
H_{E}=0.577 \\
F_{I S}=0.260 *\end{array}$ & $\begin{array}{c}H_{O}=0.862 \\
H_{E}=0.873 \\
F_{I S}=0.013^{\mathrm{NS}}\end{array}$ & $\begin{array}{c}H_{O}=0.793 \\
H_{E}=0.938 \\
F_{I S}=0.157 * *\end{array}$ & $\begin{array}{c}H_{O}=0.824 \\
H_{E}=0.897 \\
F_{I S}=0.084^{\mathrm{NS}}\end{array}$ & $\begin{array}{c}H_{O}=0.536 \\
H_{E}=0.494 \\
F_{I S}=-0.087^{\mathrm{NS}}\end{array}$ & $\begin{array}{c}H_{O}=0.828 \\
H_{E}=0.913 \\
F_{I S}=0.096^{\mathrm{NS}}\end{array}$ & $\begin{array}{c}H_{O}=0.897 \\
H_{E}=0.954 \\
F_{I S}=0.061^{\mathrm{NS}}\end{array}$ \\
\hline Hillsborough & $\begin{array}{c}H_{O}=0.433 \\
H_{E}=0.586 \\
F_{I S}=0.264^{\mathrm{NS}}\end{array}$ & $\begin{array}{c}H_{O}=0.700 \\
H_{E}=0.677 \\
F_{I S}=-0.034^{\mathrm{NS}}\end{array}$ & $\begin{array}{c}H_{O}=0.679 \\
H_{E}=0.877 \\
F_{I S}=0.229 * *\end{array}$ & $\begin{array}{c}H_{O}=0.600 \\
H_{E}=0.929 \\
F_{I S}=0.358^{* * *}\end{array}$ & $\begin{array}{c}H_{O}=0.900 \\
H_{E}=0.849 \\
F_{I S}=-0.06^{\mathrm{NS}}\end{array}$ & $\begin{array}{c}H_{O}=0.400 \\
H_{E}=0.458 \\
F_{I S}=0.128^{\mathrm{NS}}\end{array}$ & $\begin{array}{c}H_{O}=0.769 \\
H_{E}=0.911 \\
F_{I S}=0.170^{* *}\end{array}$ & $\begin{array}{c}H_{O}=0.967 \\
H_{E}=0.949 \\
F_{I S}=-0.019^{\mathrm{NS}}\end{array}$ \\
\hline Glenariff Forest & $\begin{array}{c}H_{O}=0.655 \\
H_{E}=0.620 \\
F_{I S}=-0.058^{\mathrm{NS}}\end{array}$ & $\begin{array}{c}H_{O}=0.400 \\
H_{E}=0.513 \\
F_{I S}=0.223^{*}\end{array}$ & $\begin{array}{c}H_{O}=0.893 \\
H_{E}=0.925 \\
F_{I S}=0.035^{\mathrm{NS}}\end{array}$ & $\begin{array}{c}H_{O}=0.759 \\
H_{E}=0.895 \\
F_{I S}=0.155^{*}\end{array}$ & $\begin{array}{c}H_{O}=0.900 \\
H_{E}=0.889 \\
F_{I S}=-0.012^{\mathrm{NS}}\end{array}$ & $\begin{array}{c}H_{O}=0.517 \\
H_{E}=0.514 \\
F_{I S}=-0.006^{\mathrm{NS}}\end{array}$ & $\begin{array}{c}H_{O}=0.759 \\
H_{E}=0.887 \\
F_{I S}=0.147^{*}\end{array}$ & $\begin{array}{c}H_{O}=0.933 \\
H_{E}=0.954 \\
F_{I S}=0.022^{\mathrm{NS}}\end{array}$ \\
\hline Rostrevor & $\begin{array}{c}H_{O}=0.571 \\
H_{E}=0.692 \\
F_{I S}=0.176^{\mathrm{NS}}\end{array}$ & $\begin{array}{c}H_{O}=0.464 \\
H_{E}=0.384 \\
F_{I S}=-0.215^{\mathrm{NS}}\end{array}$ & $\begin{array}{c}H_{O}=0.893 \\
H_{E}=0.863 \\
F_{I S}=-0.035^{\mathrm{NS}}\end{array}$ & $\begin{array}{c}H_{O}=0.750 \\
H_{E}=0.865 \\
F_{I S}=0.135^{\mathrm{NS}}\end{array}$ & $\begin{array}{c}H_{O}=0.964 \\
H_{E}=0.918 \\
F_{I S}=-0.052^{\mathrm{NS}}\end{array}$ & $\begin{array}{c}H_{O}=0.500 \\
H_{E}=0.444 \\
F_{I S}=-0.130^{\mathrm{NS}}\end{array}$ & $\begin{array}{c}H_{O}=0.786 \\
H_{E}=0.873 \\
F_{I S}=0.102^{\mathrm{NS}}\end{array}$ & $\begin{array}{c}H_{O}=0.964 \\
H_{E}=0.952 \\
F_{I S}=-0.013^{\mathrm{NS}}\end{array}$ \\
\hline Ballycastle Forest & $\begin{array}{c}H_{O}=0.533 \\
H_{E}=0.576 \\
F_{I S}=0.076^{\mathrm{NS}}\end{array}$ & $\begin{array}{c}H_{O}=0.567 \\
H_{E}=0.485 \\
F_{I S}=-0.171^{\mathrm{NS}}\end{array}$ & $\begin{array}{c}H_{O}=0.933 \\
H_{E}=0.920 \\
F_{I S}=-0.014^{\mathrm{NS}}\end{array}$ & $\begin{array}{c}H_{O}=0.759 \\
H_{E}=0.874 \\
F_{I S}=0.134^{*}\end{array}$ & $\begin{array}{c}H_{O}=0.963 \\
H_{E}=0.893 \\
F_{I S}=-0.080^{\mathrm{NS}}\end{array}$ & $\begin{array}{c}H_{O}=0.660 \\
H_{E}=0.544 \\
F_{I S}=-0.105^{\mathrm{NS}}\end{array}$ & $\begin{array}{c}H_{O}=0.900 \\
H_{E}=0.876 \\
F_{I S}=-0.028^{\mathrm{NS}}\end{array}$ & $\begin{array}{c}H_{O}=0.786 \\
H_{E}=0.892 \\
F_{I S}=0.121^{\mathrm{NS}}\end{array}$ \\
\hline Randalstown & $\begin{array}{c}H_{O}=0.733 \\
H_{E}=0.669 \\
F_{I S}=-0.097^{\mathrm{NS}}\end{array}$ & $\begin{array}{c}H_{O}=0.552 \\
H_{E}=0.590 \\
F_{I S}=0.067^{\mathrm{NS}}\end{array}$ & $\begin{array}{c}H_{O}=0.900 \\
H_{E}=0.912 \\
F_{I S}=0.014^{\mathrm{NS}}\end{array}$ & $\begin{array}{c}H_{O}=0.733 \\
H_{E}=0.928 \\
F_{I S}=0.212 * * *\end{array}$ & $\begin{array}{c}H_{O}=0.833 \\
H_{E}=0.911 \\
F_{I S}=0.086^{\mathrm{NS}}\end{array}$ & $\begin{array}{c}H_{O}=0.500 \\
H_{E}=0.611 \\
F_{I S}=0.185^{\mathrm{NS}}\end{array}$ & $\begin{array}{c}H_{O}=0.633 \\
H_{E}=0.898 \\
F_{I S}=0.299 * * *\end{array}$ & $\begin{array}{c}H_{O}=0.967 \\
H_{E}=0.948 \\
F_{I S}=-0.020^{\mathrm{NS}}\end{array}$ \\
\hline Portglenone & $\begin{array}{c}H_{O}=0.833 \\
H_{E}=0.758 \\
F_{I S}=-0.101^{\mathrm{NS}}\end{array}$ & $\begin{array}{c}H_{O}=0.500 \\
H_{E}=0.544 \\
F_{I S}=0.081^{\mathrm{NS}}\end{array}$ & $\begin{array}{c}H_{O}=0.862 \\
H_{E}=0.858 \\
F_{I S}=-0.004^{\mathrm{NS}}\end{array}$ & $\begin{array}{c}H_{O}=0.633 \\
H_{E}=0.918 \\
F_{I S}=0.313^{* * *}\end{array}$ & $\begin{array}{c}H_{O}=0.867 \\
H_{E}=0.891 \\
F_{I S}=0.028^{\mathrm{NS}}\end{array}$ & $\begin{array}{c}H_{O}=0.586 \\
H_{E}=0.620 \\
F_{I S}=0.056^{\mathrm{NS}}\end{array}$ & $\begin{array}{c}H_{O}=0.800 \\
H_{E}=0.914 \\
F_{I S}=0.127 *\end{array}$ & $\begin{array}{c}H_{O}=0.828 \\
H_{E}=0.910 \\
F_{I S}=0.093^{\mathrm{NS}}\end{array}$ \\
\hline
\end{tabular}

Page | 48 
Table S3 (cont.)

\begin{tabular}{|c|c|c|c|c|c|c|c|c|}
\hline \multirow{2}{*}{ Population } & \multicolumn{8}{|c|}{ Locus } \\
\hline & FR639485 & FR646655 & Femsatl-4 & Femsatl-8 & Femsatl-11 & Femsatl-16 & Femsatl-19 & M230 \\
\hline Gosford Park & $\begin{array}{c}H_{O}=0.552 \\
H_{E}=0.606 \\
F_{I S}=0.090^{\mathrm{NS}}\end{array}$ & $\begin{array}{c}H_{O}=0.517 \\
H_{E}=0.506 \\
F_{I S}=-0.022^{\mathrm{NS}}\end{array}$ & $\begin{array}{c}H_{O}=0.867 \\
H_{E}=0.912 \\
F_{I S}=0.051^{\mathrm{NS}}\end{array}$ & $\begin{array}{c}H_{O}=0.633 \\
H_{E}=0.895 \\
F_{I S}=0.296^{* * *}\end{array}$ & $\begin{array}{c}H_{O}=1.000 \\
H_{E}=0.913 \\
F_{I S}=-0.097^{\mathrm{NS}}\end{array}$ & $\begin{array}{c}H_{O}=0.567 \\
H_{E}=0.489 \\
F_{I S}=-0.163^{\mathrm{NS}}\end{array}$ & $\begin{array}{c}H_{O}=0.800 \\
H_{E}=0.894 \\
F_{I S}=0.107^{\mathrm{NS}}\end{array}$ & $\begin{array}{c}H_{O}=0.967 \\
H_{E}=0.951 \\
F_{I S}=-0.016^{\mathrm{NS}}\end{array}$ \\
\hline Ballymoney & $\begin{array}{c}H_{O}=0.655 \\
H_{E}=0.630 \\
F_{I S}=-0.040^{\mathrm{NS}}\end{array}$ & $\begin{array}{c}H_{O}=0.367 \\
H_{E}=0.472 \\
F_{I S}=0.226^{*}\end{array}$ & $\begin{array}{c}H_{O}=0.750 \\
H_{E}=0.886 \\
F_{I S}=0.156^{*}\end{array}$ & $\begin{array}{c}H_{O}=0.690 \\
H_{E}=0.913 \\
F_{I S}=0.248^{* * *}\end{array}$ & $\begin{array}{c}H_{O}=0.815 \\
H_{E}=0.853 \\
F_{I S}=0.045^{\mathrm{NS}}\end{array}$ & $\begin{array}{c}H_{O}=0.633 \\
H_{E}=0.616 \\
F_{I S}=-0.028^{\mathrm{NS}}\end{array}$ & $\begin{array}{c}H_{O}=0.733 \\
H_{E}=0.873 \\
F_{I S}=0.163 *\end{array}$ & $\begin{array}{c}H_{O}=0.933 \\
H_{E}=0.926 \\
F_{I S}=-0.008^{\mathrm{NS}}\end{array}$ \\
\hline Peatlands Park & $\begin{array}{c}H_{O}=0.690 \\
H_{E}=0.626 \\
F_{I S}=-0.105^{\mathrm{NS}}\end{array}$ & $\begin{array}{c}H_{O}=0.345 \\
H_{E}=0.388 \\
F_{I S}=0.113^{\mathrm{NS}}\end{array}$ & $\begin{array}{c}H_{O}=0.655 \\
H_{E}=0.814 \\
F_{I S}=0.198^{*}\end{array}$ & $\begin{array}{c}H_{O}=0.536 \\
H_{E}=0.886 \\
F_{I S}=0.400 * * *\end{array}$ & $\begin{array}{c}H_{O}=0.828 \\
H_{E}=0.840 \\
F_{I S}=0.015^{\mathrm{NS}}\end{array}$ & $\begin{array}{c}H_{O}=0.464 \\
H_{E}=0.430 \\
F_{I S}=-0.082^{\mathrm{NS}}\end{array}$ & $\begin{array}{c}H_{O}=0.862 \\
H_{E}=0.909 \\
F_{I S}=0.052^{\mathrm{NS}}\end{array}$ & $\begin{array}{c}H_{O}=0.964 \\
H_{E}=0.946 \\
F_{I S}=-0.020^{\mathrm{NS}}\end{array}$ \\
\hline Carndaisy Woods & $\begin{array}{c}H_{O}=0.552 \\
H_{E}=0.657 \\
F_{I S}=0.163^{\mathrm{NS}}\end{array}$ & $\begin{array}{c}H_{O}=0.367 \\
H_{E}=0.457 \\
F_{I S}=0.199^{\mathrm{NS}}\end{array}$ & $\begin{array}{c}H_{O}=0.800 \\
H_{E}=0.891 \\
F_{I S}=0.104^{\mathrm{NS}}\end{array}$ & $\begin{array}{c}H_{O}=0.767 \\
H_{E}=0.920 \\
F_{I S}=0.169^{* *}\end{array}$ & $\begin{array}{c}H_{O}=0.767 \\
H_{E}=0.864 \\
F_{I S}=0.115^{\mathrm{NS}}\end{array}$ & $\begin{array}{c}H_{O}=0.667 \\
H_{E}=0.550 \\
F_{I S}=-0.216^{\mathrm{NS}}\end{array}$ & $\begin{array}{c}H_{O}=0.800 \\
H_{E}=0.924 \\
F_{I S}=0.136^{*}\end{array}$ & $\begin{array}{c}H_{O}=0.800 \\
H_{E}=0.925 \\
F_{I S}=0.137^{*}\end{array}$ \\
\hline Downhill & $\begin{array}{c}H_{O}=0.621 \\
H_{E}=0.719 \\
F_{I S}=0.139^{\mathrm{NS}}\end{array}$ & $\begin{array}{c}H_{O}=0.414 \\
H_{E}=0.402 \\
F_{I S}=-0.029^{\mathrm{NS}}\end{array}$ & $\begin{array}{c}H_{O}=0.655 \\
H_{E}=0.910 \\
F_{I S}=0.284 * * *\end{array}$ & $\begin{array}{c}H_{O}=0.556 \\
H_{E}=0.929 \\
F_{I S}=0.406^{* * *}\end{array}$ & $\begin{array}{c}H_{O}=0.897 \\
H_{E}=0.905 \\
F_{I S}=0.010^{\mathrm{NS}}\end{array}$ & $\begin{array}{c}H_{O}=0.517 \\
H_{E}=0.431 \\
F_{I S}=-0.203^{\mathrm{NS}}\end{array}$ & $\begin{array}{c}H_{O}=0.621 \\
H_{E}=0.873 \\
F_{I S}=0.293 * * *\end{array}$ & $\begin{array}{c}H_{O}=0.966 \\
H_{E}=0.951 \\
F_{I S}=-0.016^{\mathrm{NS}}\end{array}$ \\
\hline Drum Manor & $\begin{array}{c}H_{O}=0.536 \\
H_{E}=0.622 \\
F_{I S}=0.141^{\mathrm{NS}}\end{array}$ & $\begin{array}{c}H_{O}=0.467 \\
H_{E}=0.502 \\
F_{I S}=0.071^{\mathrm{NS}}\end{array}$ & $\begin{array}{c}H_{O}=0.964 \\
H_{E}=0.913 \\
F_{I S}=-0.057^{\mathrm{NS}}\end{array}$ & $\begin{array}{c}H_{O}=0.867 \\
H_{E}=0.906 \\
F_{I S}=0.044^{\mathrm{NS}}\end{array}$ & $\begin{array}{c}H_{O}=0.833 \\
H_{E}=0.851 \\
F_{I S}=0.021^{\mathrm{NS}}\end{array}$ & $\begin{array}{c}H_{O}=0.586 \\
H_{E}=0.547 \\
F_{I S}=-0.072^{\mathrm{NS}}\end{array}$ & $\begin{array}{c}H_{O}=0.633 \\
H_{E}=0.933 \\
F_{I S}=0.325^{* * *}\end{array}$ & $\begin{array}{c}H_{O}=0.929 \\
H_{E}=0.956 \\
F_{I S}=0.029^{\mathrm{NS}}\end{array}$ \\
\hline Lemnagore Wood & $\begin{array}{c}H_{O}=0.586 \\
H_{E}=0.576 \\
F_{I S}=-0.018^{\mathrm{NS}}\end{array}$ & $\begin{array}{c}H_{O}=0.414 \\
H_{E}=0.413 \\
F_{I S}=-0.001^{\mathrm{NS}}\end{array}$ & $\begin{array}{c}H_{O}=0.964 \\
H_{E}=0.818 \\
F_{I S}=-0.183^{\mathrm{NS}}\end{array}$ & $\begin{array}{c}H_{O}=0.724 \\
H_{E}=0.906 \\
F_{I S}=0.204 * *\end{array}$ & $\begin{array}{c}H_{O}=0.929 \\
H_{E}=0.927 \\
F_{I S}=-0.002^{\mathrm{NS}}\end{array}$ & $\begin{array}{c}H_{O}=0.250 \\
H_{E}=0.265 \\
F_{I S}=0.057^{\mathrm{NS}}\end{array}$ & $\begin{array}{c}H_{O}=0.846 \\
H_{E}=0.916 \\
F_{I S}=0.077^{\mathrm{NS}}\end{array}$ & $\begin{array}{c}H_{O}=1.000 \\
H_{E}=0.939 \\
F_{I S}=-0.066^{\mathrm{NS}}\end{array}$ \\
\hline
\end{tabular}

Page | 49 
Table S3 (cont.)

\begin{tabular}{|c|c|c|c|c|c|c|c|c|}
\hline \multirow{2}{*}{ Population } & \multicolumn{8}{|c|}{ Locus } \\
\hline & FR639485 & FR646655 & Femsatl-4 & Femsatl-8 & Femsatl-11 & Femsatl-16 & Femsatl-19 & M230 \\
\hline Roe Valley & $\begin{array}{c}H_{O}=0.533 \\
H_{E}=0.642 \\
F_{I S}=0.172^{\mathrm{NS}}\end{array}$ & $\begin{array}{c}H_{O}=0.533 \\
H_{E}=0.596 \\
F_{I S}=0.107^{\mathrm{NS}}\end{array}$ & $\begin{array}{c}H_{O}=0.778 \\
H_{E}=0.882 \\
F_{I S}=0.120^{\mathrm{NS}}\end{array}$ & $\begin{array}{c}H_{O}=0.679 \\
H_{E}=0.918 \\
F_{I S}=0.265^{* * *}\end{array}$ & $\begin{array}{c}H_{O}=0.893 \\
H_{E}=0.907 \\
F_{I S}=0.016^{\mathrm{NS}}\end{array}$ & $\begin{array}{c}H_{O}=0.400 \\
H_{E}=0.451 \\
F_{I S}=0.116^{\mathrm{NS}}\end{array}$ & $\begin{array}{c}H_{O}=0.571 \\
H_{E}=0.873 \\
F_{I S}=0.350^{* * *}\end{array}$ & $\begin{array}{c}H_{O}=0.966 \\
H_{E}=0.949 \\
F_{I S}=-0.018^{\mathrm{NS}}\end{array}$ \\
\hline Knockmany Forest & $\begin{array}{c}H_{O}=0.833 \\
H_{E}=0.669 \\
F_{I S}=-0.250^{\mathrm{NS}}\end{array}$ & $\begin{array}{c}H_{O}=0.567 \\
H_{E}=0.455 \\
F_{I S}=-0.250^{\mathrm{NS}}\end{array}$ & $\begin{array}{c}H_{O}=0.933 \\
H_{E}=0.916 \\
F_{I S}=-0.019^{\mathrm{NS}}\end{array}$ & $\begin{array}{c}H_{O}=0.700 \\
H_{E}=0.918 \\
F_{I S}=0.240 * * *\end{array}$ & $\begin{array}{c}H_{O}=0.833 \\
H_{E}=0.911 \\
F_{I S}=0.087^{\mathrm{NS}}\end{array}$ & $\begin{array}{c}H_{O}=0.667 \\
H_{E}=0.564 \\
F_{I S}=-0.186^{\mathrm{NS}}\end{array}$ & $\begin{array}{c}H_{O}=0.900 \\
H_{E}=0.889 \\
F_{I S}=-0.013^{\mathrm{NS}}\end{array}$ & $\begin{array}{c}H_{O}=0.967 \\
H_{E}=0.933 \\
F_{I S}=-0.036^{\mathrm{NS}}\end{array}$ \\
\hline Slieve Beagh & $\begin{array}{c}H_{O}=0.643 \\
H_{E}=0.599 \\
F_{I S}=-0.075^{\mathrm{NS}}\end{array}$ & $\begin{array}{c}H_{O}=0.536 \\
H_{E}=0.497 \\
F_{I S}=-0.079^{\mathrm{NS}}\end{array}$ & $\begin{array}{c}H_{O}=0.786 \\
H_{E}=0.873 \\
F_{I S}=0.102^{\mathrm{NS}}\end{array}$ & $\begin{array}{c}H_{O}=0.750 \\
H_{E}=0.931 \\
F_{I S}=0.197 * *\end{array}$ & $\begin{array}{c}H_{O}=0.750 \\
H_{E}=0.818 \\
F_{I S}=0.085^{\mathrm{NS}}\end{array}$ & $\begin{array}{c}H_{O}=0.357 \\
H_{E}=0.317 \\
F_{I S}=-0.130^{\mathrm{NS}}\end{array}$ & $\begin{array}{c}H_{O}=0.679 \\
H_{E}=0.898 \\
F_{I S}=0.248^{* * *}\end{array}$ & $\begin{array}{c}H_{O}=0.857 \\
H_{E}=0.932 \\
F_{I S}=0.082^{\mathrm{NS}}\end{array}$ \\
\hline Stranbane Glen & $\begin{array}{c}H_{O}=0.483 \\
H_{E}=0.606 \\
F_{I S}=0.206^{\mathrm{NS}}\end{array}$ & $\begin{array}{c}H_{O}=0.433 \\
H_{E}=0.553 \\
F_{I S}=0.219^{\mathrm{NS}}\end{array}$ & $\begin{array}{c}H_{O}=0.900 \\
H_{E}=0.888 \\
F_{I S}=-0.014^{\mathrm{NS}}\end{array}$ & $\begin{array}{c}H_{O}=0.793 \\
H_{E}=0.922 \\
F_{I S}=0.142 *\end{array}$ & $\begin{array}{c}H_{O}=0.862 \\
H_{E}=0.909 \\
F_{I S}=0.053^{\mathrm{NS}}\end{array}$ & $\begin{array}{c}H_{O}=0.467 \\
H_{E}=0.448 \\
F_{I S}=-0.042^{\mathrm{NS}}\end{array}$ & $\begin{array}{c}H_{O}=0.833 \\
H_{E}=0.904 \\
F_{I S}=0.079^{\mathrm{NS}}\end{array}$ & $\begin{array}{c}H_{O}=0.897 \\
H_{E}=0.951 \\
F_{I S}=0.058^{\mathrm{NS}}\end{array}$ \\
\hline Crom & $\begin{array}{c}H_{O}=0.552 \\
H_{E}=0.621 \\
F_{I S}=0.113^{\mathrm{NS}}\end{array}$ & $\begin{array}{c}H_{O}=0.500 \\
H_{E}=0.460 \\
F_{I S}=-0.088^{\mathrm{NS}}\end{array}$ & $\begin{array}{c}H_{O}=0.833 \\
H_{E}=0.891 \\
F_{I S}=0.066^{\mathrm{NS}}\end{array}$ & $\begin{array}{c}H_{O}=0.679 \\
H_{E}=0.939 \\
F_{I S}=0.281 * * *\end{array}$ & $\begin{array}{c}H_{O}=0.724 \\
H_{E}=0.836 \\
F_{I S}=0.137^{\mathrm{NS}}\end{array}$ & $\begin{array}{c}H_{O}=0.400 \\
H_{E}=0.456 \\
F_{I S}=0.125^{\mathrm{NS}}\end{array}$ & $\begin{array}{c}H_{O}=0.867 \\
H_{E}=0.897 \\
F_{I S}=0.034^{\mathrm{NS}}\end{array}$ & $\begin{array}{c}H_{O}=0.800 \\
H_{E}=0.941 \\
F_{I S}=0.152 * *\end{array}$ \\
\hline Knockninny Hill & $\begin{array}{c}H_{O}=0.607 \\
H_{E}=0.642 \\
F_{I S}=0.055^{\mathrm{NS}}\end{array}$ & $\begin{array}{c}H_{O}=0.393 \\
H_{E}=0.384 \\
F_{I S}=-0.024^{\mathrm{NS}}\end{array}$ & $\begin{array}{c}H_{O}=1.000 \\
H_{E}=0.929 \\
F_{I S}=-0.078^{\mathrm{NS}}\end{array}$ & $\begin{array}{c}H_{O}=0.464 \\
H_{E}=0.919 \\
F_{I S}=0.500^{* * *}\end{array}$ & $\begin{array}{c}H_{O}=0.929 \\
H_{E}=0.893 \\
F_{I S}=-0.041^{\mathrm{NS}}\end{array}$ & $\begin{array}{c}H_{O}=0.429 \\
H_{E}=0.525 \\
F_{I S}=0.187^{\mathrm{NS}}\end{array}$ & $\begin{array}{c}H_{O}=0.821 \\
H_{E}=0.907 \\
F_{I S}=0.096^{\mathrm{NS}}\end{array}$ & $\begin{array}{c}H_{O}=0.889 \\
H_{E}=0.957 \\
F_{I S}=0.072^{\mathrm{NS}}\end{array}$ \\
\hline Sloughan Glen & $\begin{array}{c}H_{O}=0.690 \\
H_{E}=0.584 \\
F_{I S}=-0.184^{\mathrm{NS}}\end{array}$ & $\begin{array}{c}H_{O}=0.483 \\
H_{E}=0.451 \\
F_{I S}=-0.073^{\mathrm{NS}}\end{array}$ & $\begin{array}{c}H_{O}=0.897 \\
H_{E}=0.874 \\
F_{I S}=-0.027^{\mathrm{NS}}\end{array}$ & $\begin{array}{c}H_{O}=0.655 \\
H_{E}=0.909 \\
F_{I S}=0.283 * * *\end{array}$ & $\begin{array}{c}H_{O}=0.862 \\
H_{E}=0.855 \\
F_{I S}=-0.008^{\mathrm{NS}}\end{array}$ & $\begin{array}{c}H_{O}=0.414 \\
H_{E}=0.453 \\
F_{I S}=0.088^{\mathrm{NS}}\end{array}$ & $\begin{array}{c}H_{O}=0.714 \\
H_{E}=0.898 \\
F_{I S}=0.208 * *\end{array}$ & $\begin{array}{c}H_{O}=0.862 \\
H_{E}=0.935 \\
F_{I S}=0.080^{\mathrm{NS}}\end{array}$ \\
\hline
\end{tabular}

Page | 50 
Table S3 (cont.)

\begin{tabular}{|c|c|c|c|c|c|c|c|c|}
\hline \multirow{2}{*}{ Population } & \multicolumn{8}{|c|}{ Locus } \\
\hline & FR639485 & FR646655 & Femsatl-4 & Femsatl-8 & Femsatl-11 & Femsatl-16 & Femsatl-19 & M230 \\
\hline Castle Hill & $\begin{array}{c}H_{O}=0.467 \\
H_{E}=0.704 \\
F_{I S}=0.341^{* *}\end{array}$ & $\begin{array}{c}H_{O}=0.200 \\
H_{E}=0.367 \\
F_{I S}=0.461^{* *}\end{array}$ & $\begin{array}{c}H_{O}=0.800 \\
H_{E}=0.866 \\
F_{I S}=0.078^{\mathrm{NS}}\end{array}$ & $\begin{array}{c}H_{O}=0.633 \\
H_{E}=0.903 \\
F_{I S}=0.302 * * *\end{array}$ & $\begin{array}{c}H_{O}=0.833 \\
H_{E}=0.877 \\
F_{I S}=0.051^{\mathrm{NS}}\end{array}$ & $\begin{array}{c}H_{O}=0.467 \\
H_{E}=0.471 \\
F_{I S}=0.009^{\mathrm{NS}}\end{array}$ & $\begin{array}{c}H_{O}=0.867 \\
H_{E}=0.911 \\
F_{I S}=0.049^{\mathrm{NS}}\end{array}$ & $\begin{array}{c}H_{O}=0.828 \\
H_{E}=0.955 \\
F_{I S}=0.135^{* *}\end{array}$ \\
\hline Ely Lodge & $\begin{array}{c}H_{O}=0.621 \\
H_{E}=0.650 \\
F_{I S}=0.045^{\mathrm{NS}}\end{array}$ & $\begin{array}{c}H_{O}=0.483 \\
H_{E}=0.550 \\
F_{I S}=0.124^{\mathrm{NS}}\end{array}$ & $\begin{array}{c}H_{O}=0.900 \\
H_{E}=0.912 \\
F_{I S}=0.013^{\mathrm{NS}}\end{array}$ & $\begin{array}{c}H_{O}=0.724 \\
H_{E}=0.939 \\
F_{I S}=0.232 * * *\end{array}$ & $\begin{array}{c}H_{O}=0.800 \\
H_{E}=0.911 \\
F_{I S}=0.124^{\mathrm{NS}}\end{array}$ & $\begin{array}{c}H_{O}=0.433 \\
H_{E}=0.419 \\
F_{I S}=-0.036^{\mathrm{NS}}\end{array}$ & $\begin{array}{c}H_{O}=0.900 \\
H_{E}=0.904 \\
F_{I S}=0.004^{\mathrm{NS}}\end{array}$ & $\begin{array}{c}H_{O}=0.964 \\
H_{E}=0.920 \\
F_{I S}=-0.049^{\mathrm{NS}}\end{array}$ \\
\hline Killeter Forest & $\begin{array}{c}H_{O}=0.793 \\
H_{E}=0.663 \\
F_{I S}=-0.200^{\mathrm{NS}}\end{array}$ & $\begin{array}{c}H_{O}=0.467 \\
H_{E}=0.445 \\
F_{I S}=-0.050^{\mathrm{NS}}\end{array}$ & $\begin{array}{c}H_{O}=0.767 \\
H_{E}=0.849 \\
F_{I S}=0.098^{\mathrm{NS}}\end{array}$ & $\begin{array}{c}H_{O}=0.857 \\
H_{E}=0.924 \\
F_{I S}=0.074^{\mathrm{NS}}\end{array}$ & $\begin{array}{c}H_{O}=0.862 \\
H_{E}=0.903 \\
F_{I S}=0.046^{\mathrm{NS}}\end{array}$ & $\begin{array}{c}H_{O}=0.567 \\
H_{E}=0.547 \\
F_{I S}=-0.036^{\mathrm{NS}}\end{array}$ & $\begin{array}{c}H_{O}=0.724 \\
H_{E}=0.935 \\
F_{I S}=0.228 * * *\end{array}$ & $\begin{array}{c}H_{O}=0.867 \\
H_{E}=0.964 \\
F_{I S}=0.102 *\end{array}$ \\
\hline Marble Arch & $\begin{array}{c}H_{O}=0.522 \\
H_{E}=0.610 \\
F_{I S}=0.147^{\mathrm{NS}}\end{array}$ & $\begin{array}{c}H_{O}=0.259 \\
H_{E}=0.349 \\
F_{I S}=0.262^{\mathrm{NS}}\end{array}$ & $\begin{array}{c}H_{O}=0.893 \\
H_{E}=0.888 \\
F_{I S}=-0.005^{\mathrm{NS}}\end{array}$ & $\begin{array}{c}H_{O}=0.808 \\
H_{E}=0.937 \\
F_{I S}=0.140^{*}\end{array}$ & $\begin{array}{c}H_{O}=0.857 \\
H_{E}=0.866 \\
F_{I S}=0.010^{\mathrm{NS}}\end{array}$ & $\begin{array}{c}H_{O}=0.571 \\
H_{E}=0.598 \\
F_{I S}=0.045^{\mathrm{NS}}\end{array}$ & $\begin{array}{c}H_{O}=0.889 \\
H_{E}=0.918 \\
F_{I S}=0.032^{\mathrm{NS}}\end{array}$ & $\begin{array}{c}H_{O}=0.885 \\
H_{E}=0.941 \\
F_{I S}=0.061^{\mathrm{NS}}\end{array}$ \\
\hline Castle Caldwell & $\begin{array}{c}H_{O}=0.724 \\
H_{E}=0.665 \\
F_{I S}=-0.091^{\mathrm{NS}}\end{array}$ & $\begin{array}{c}H_{O}=0.172 \\
H_{E}=0.226 \\
F_{I S}=0.241^{\mathrm{NS}}\end{array}$ & $\begin{array}{c}H_{O}=0.897 \\
H_{E}=0.836 \\
F_{I S}=-0.074^{\mathrm{NS}}\end{array}$ & $\begin{array}{c}H_{O}=0.533 \\
H_{E}=0.936 \\
F_{I S}=0.434^{* * *}\end{array}$ & $\begin{array}{c}H_{O}=0.867 \\
H_{E}=0.895 \\
F_{I S}=0.033^{\mathrm{NS}}\end{array}$ & $\begin{array}{c}H_{O}=0.533 \\
H_{E}=0.517 \\
F_{I S}=-0.032^{\mathrm{NS}}\end{array}$ & $\begin{array}{c}H_{O}=0.900 \\
H_{E}=0.920 \\
F_{I S}=0.022^{\mathrm{NS}}\end{array}$ & $\begin{array}{c}H_{O}=0.867 \\
H_{E}=0.937 \\
F_{I S}=0.077^{\mathrm{NS}}\end{array}$ \\
\hline Glenasmole Valley & $\begin{array}{c}H_{O}=0.821 \\
H_{E}=0.738 \\
F_{I S}=-0.116^{\mathrm{NS}}\end{array}$ & $\begin{array}{c}H_{O}=0.500 \\
H_{E}=0.466 \\
F_{I S}=-0.075^{\mathrm{NS}}\end{array}$ & $\begin{array}{c}H_{O}=0.926 \\
H_{E}=0.897 \\
F_{I S}=-0.033^{\mathrm{NS}}\end{array}$ & $\begin{array}{c}H_{O}=0.750 \\
H_{E}=0.894 \\
F_{I S}=0.163 *\end{array}$ & $\begin{array}{c}H_{O}=0.821 \\
H_{E}=0.894 \\
F_{I S}=0.082^{\mathrm{NS}}\end{array}$ & $\begin{array}{c}H_{O}=0.500 \\
H_{E}=0.477 \\
F_{I S}=-0.050^{\mathrm{NS}}\end{array}$ & $\begin{array}{c}H_{O}=0.893 \\
H_{E}=0.898 \\
F_{I S}=0.006^{\mathrm{NS}}\end{array}$ & $\begin{array}{c}H_{O}=0.885 \\
H_{E}=0.945 \\
F_{I S}=0.065^{\mathrm{NS}}\end{array}$ \\
\hline Knocknamallavoge & $\begin{array}{c}H_{O}=0.828 \\
H_{E}=0.638 \\
F_{I S}=-0.304^{\mathrm{NS}}\end{array}$ & $\begin{array}{c}H_{O}=0.552 \\
H_{E}=0.757 \\
F_{I S}=0.274^{*}\end{array}$ & $\begin{array}{c}H_{O}=0.724 \\
H_{E}=0.822 \\
F_{I S}=0.121^{\mathrm{NS}}\end{array}$ & $\begin{array}{c}H_{O}=0.724 \\
H_{E}=0.910 \\
F_{I S}=0.208^{* *}\end{array}$ & $\begin{array}{c}H_{O}=0.759 \\
H_{E}=0.866 \\
F_{I S}=0.126^{\mathrm{NS}}\end{array}$ & $\begin{array}{c}H_{O}=0.621 \\
H_{E}=0.614 \\
F_{I S}=-0.011^{\mathrm{NS}}\end{array}$ & $\begin{array}{c}H_{O}=0.828 \\
H_{E}=0.918 \\
F_{I S}=0.100^{\mathrm{NS}}\end{array}$ & $\begin{array}{c}H_{O}=0.931 \\
H_{E}=0.891 \\
F_{I S}=-0.046^{\mathrm{NS}}\end{array}$ \\
\hline
\end{tabular}

Page | 51 
Table S3 (cont.)

\begin{tabular}{|c|c|c|c|c|c|c|c|c|}
\hline \multirow{2}{*}{ Population } & \multicolumn{8}{|c|}{ Locus } \\
\hline & FR639485 & FR646655 & Femsatl-4 & Femsatl-8 & Femsatl-11 & Femsatl-16 & Femsatl-19 & M230 \\
\hline Letterfrack & $\begin{array}{c}H_{O}=0.423 \\
H_{E}=0.659 \\
F_{I S}=0.363 * *\end{array}$ & $\begin{array}{c}H_{O}=0.385 \\
H_{E}=0.465 \\
F_{I S}=0.176^{\mathrm{NS}}\end{array}$ & $\begin{array}{c}H_{O}=0.800 \\
H_{E}=0.914 \\
F_{I S}=0.127^{*}\end{array}$ & $\begin{array}{c}H_{O}=0.640 \\
H_{E}=0.825 \\
F_{I S}=0.228^{* *}\end{array}$ & $\begin{array}{c}H_{O}=0.885 \\
H_{E}=0.902 \\
F_{I S}=0.020^{\mathrm{NS}}\end{array}$ & $\begin{array}{c}H_{O}=0.391 \\
H_{E}=0.580 \\
F_{I S}=0.330 *\end{array}$ & $\begin{array}{c}H_{O}=0.818 \\
H_{E}=0.909 \\
F_{I S}=0.102^{\mathrm{NS}}\end{array}$ & $\begin{array}{c}H_{O}=0.808 \\
H_{E}=0.911 \\
F_{I S}=0.115^{\mathrm{NS}}\end{array}$ \\
\hline
\end{tabular}




\section{Figure Legends}

Fig. 1 Locations of sites sampled in this study. Numbers correspond to those in Table 1.

Fig. 2. Two woodland sites sampled at (a) Belfast, Northern Ireland (insert) showing tree cover from orthophotographs of (b) Barnett Demesne and c) Cregagh Glen. Adult trees that were sampled are shown as red dots and saplings as blue dots; surrounding trees, hedgerows and woodlands are clearly visible. North is aligned with the top of the page. Image $\mathbb{C}$ 07/08/2006 DigitalGlobe, Google Earth.

Fig. 3. Mantel test for isolation-by-distance (IBD) between populations including (above) and excluding (below) the three Republic of Ireland populations.

Fig. 4. Summary of identified seed dispersal events in Barnett Demesne. (a) Histogram showing dispersal distances in $10 \mathrm{~m}$ classes. Black shading indicates assignment of a maternal plant from a parent-pair. Grey shading shows assignment of a maternal plant to a single identified parent. (b) Distance and direction of identified dispersal events. Broken arrows represent dispersal distances of greater than $50 \mathrm{~m}$ (values given in parentheses).

Fig. S1 Network showing relationships between the eight cpSSR haplotypes observed. Each mutation is shown by a dash, with the locus and allele size change indicated. An alternative homoplasious linkage between haplotypes $\mathrm{H} 2$ and $\mathrm{H} 7$ is indicated by the dashed line.

Fig. S2 Correlograms of autocorrelation coefficient $(\theta$; y-axis) plotted against distance (xaxis). $95 \%$ confidence intervals are indicated by dashed red lines. Note that in some Page | 53 
correlograms, the first two distance intervals $(0-50 \mathrm{~m}$ and $50-100 \mathrm{~m})$ may be at a different scale to subsequent intervals.

Fig. S3 Example of large allele dropout in consecutive individuals at locus M230. Note that in both cases, the large allele has not been called by the genotyping software. 


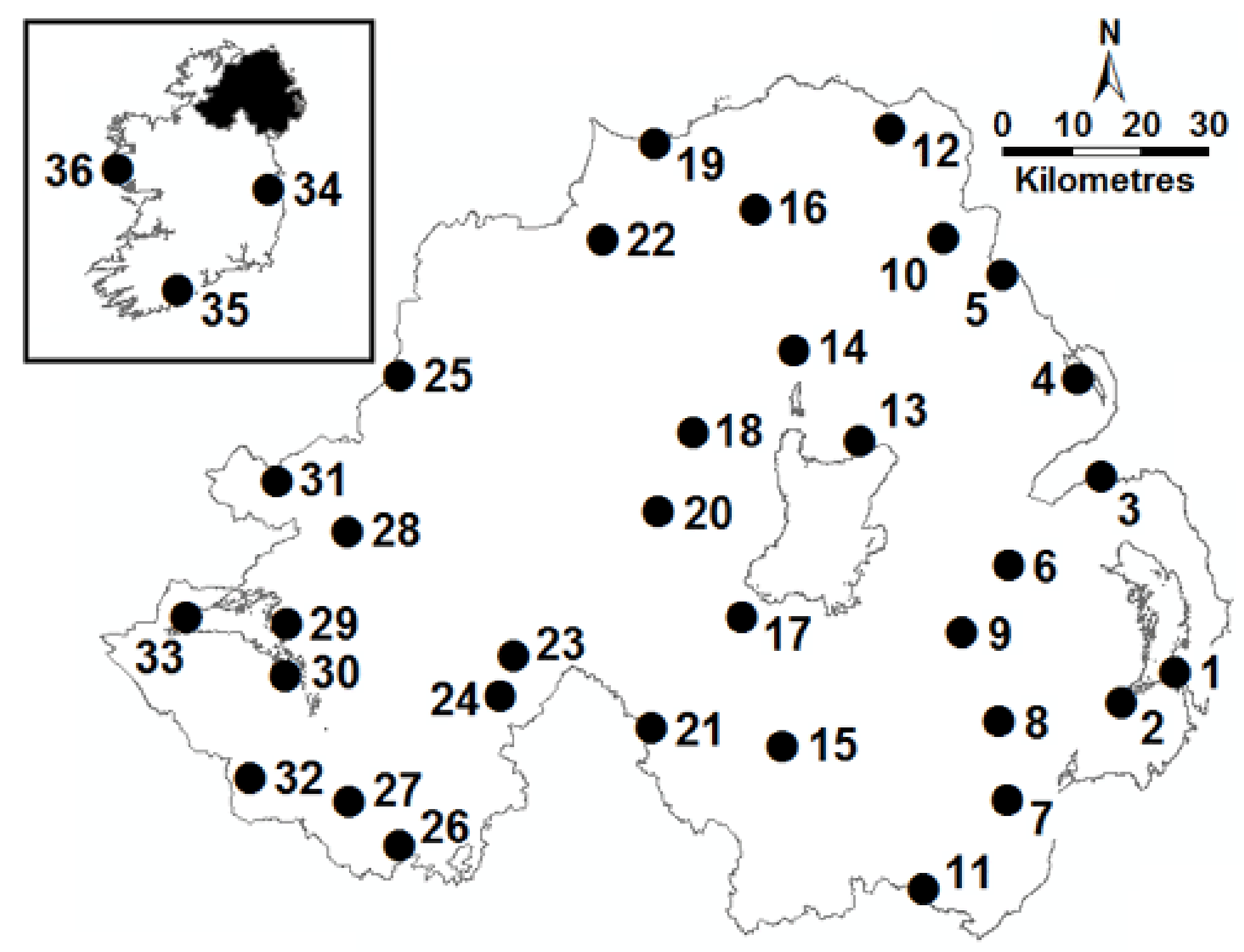



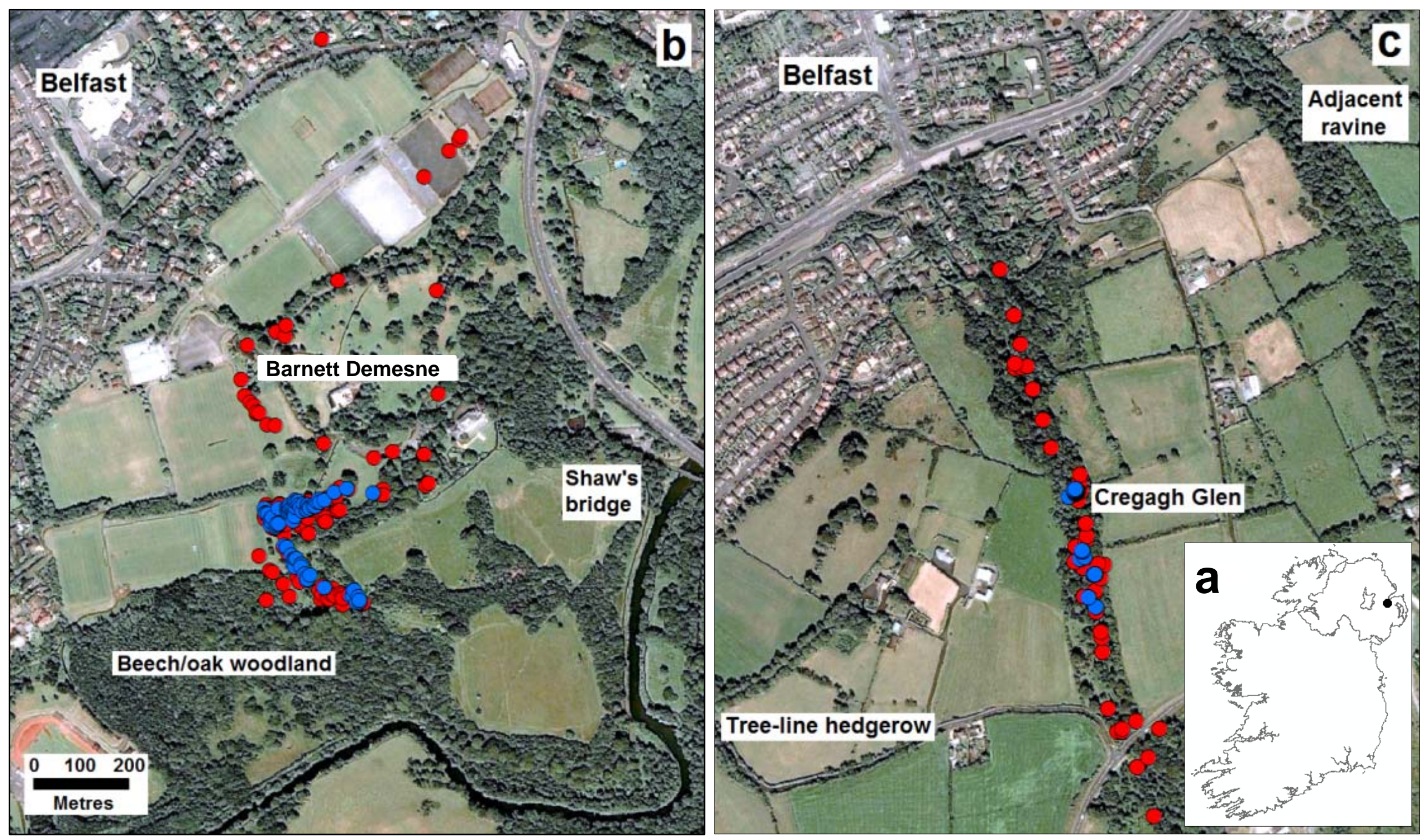

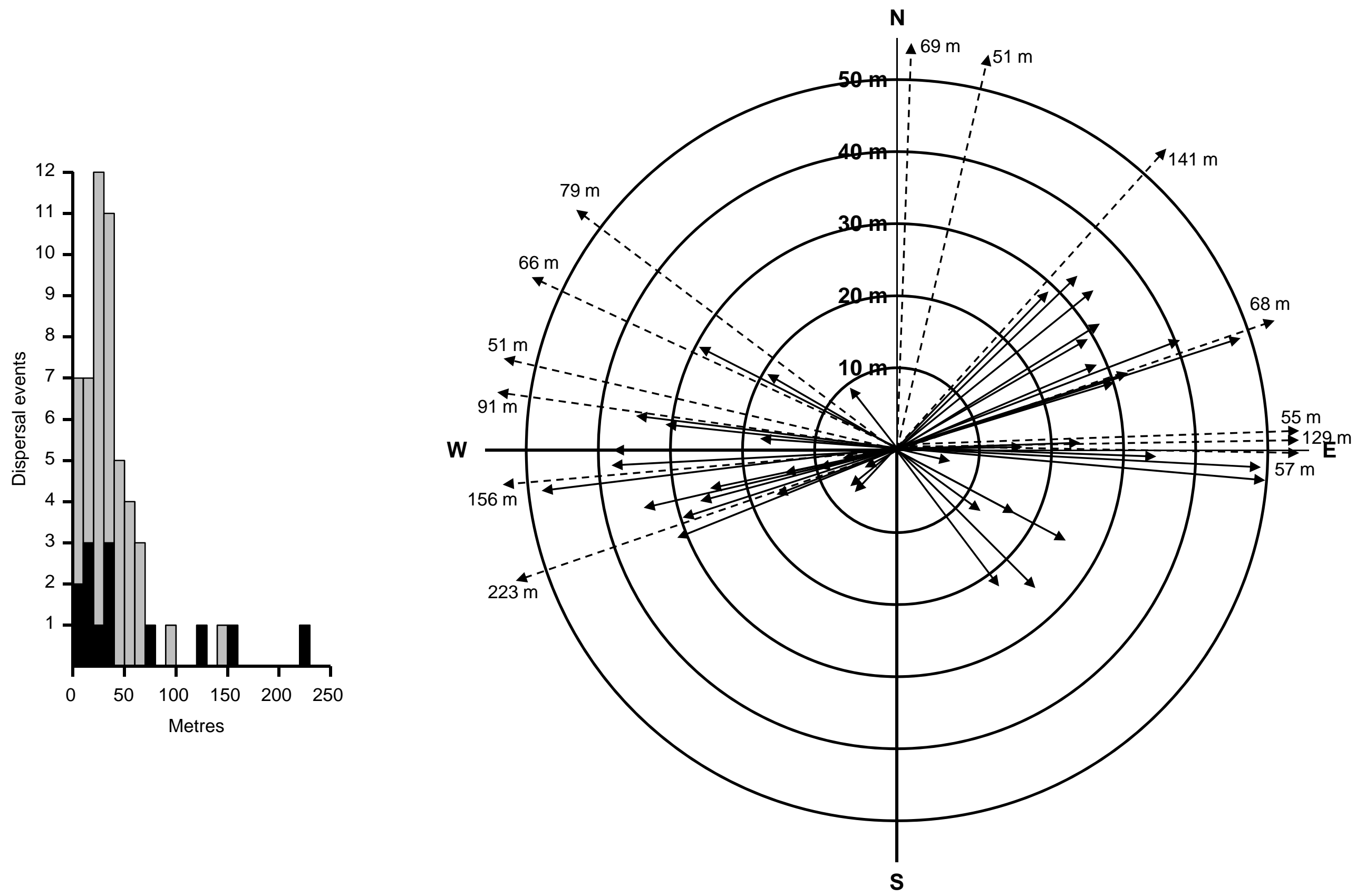


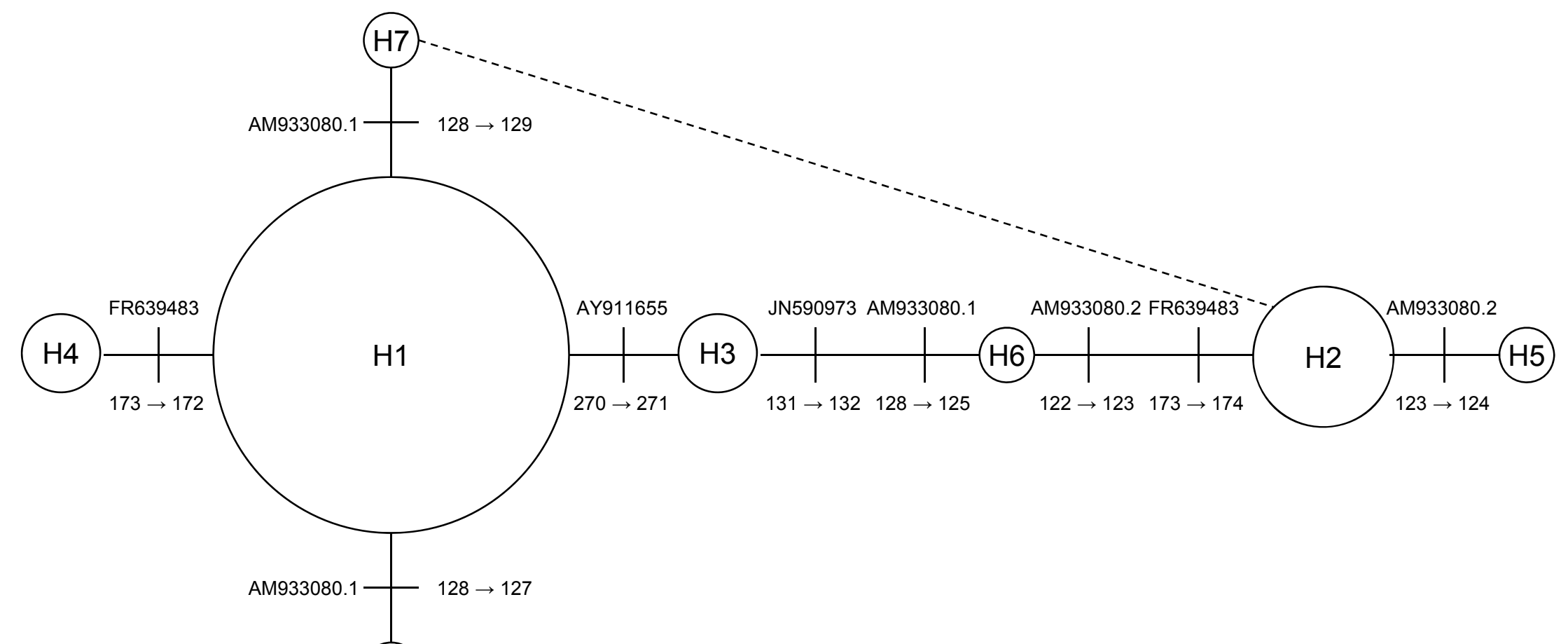

(H8) 


0.15
0.10
0.05
0.00
-0.05
-0.10

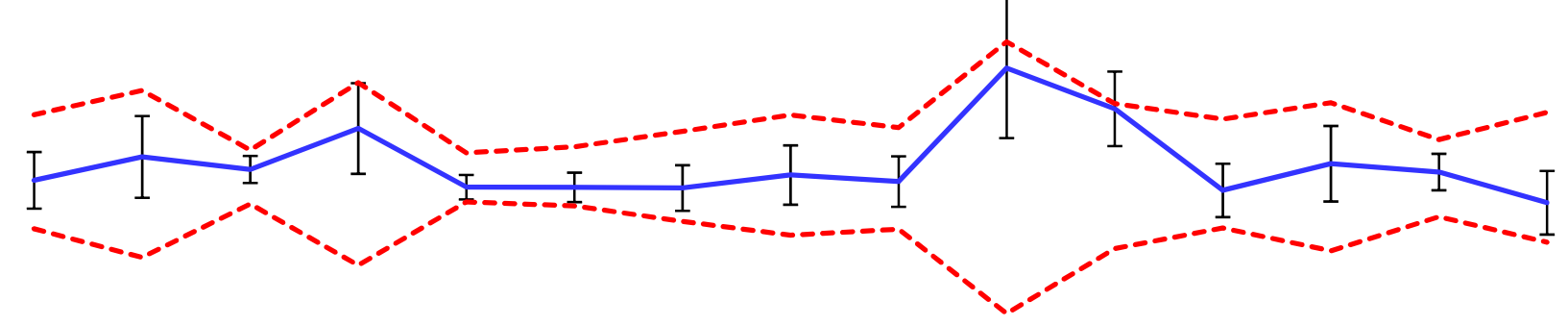

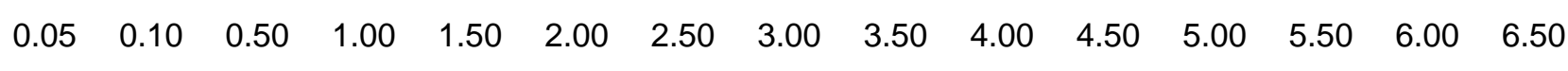

\section{Magheramourne}

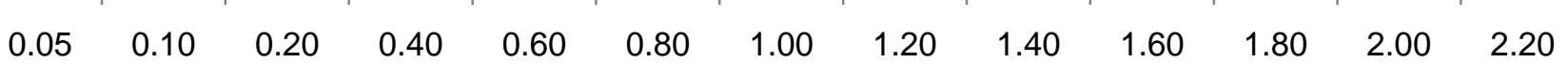

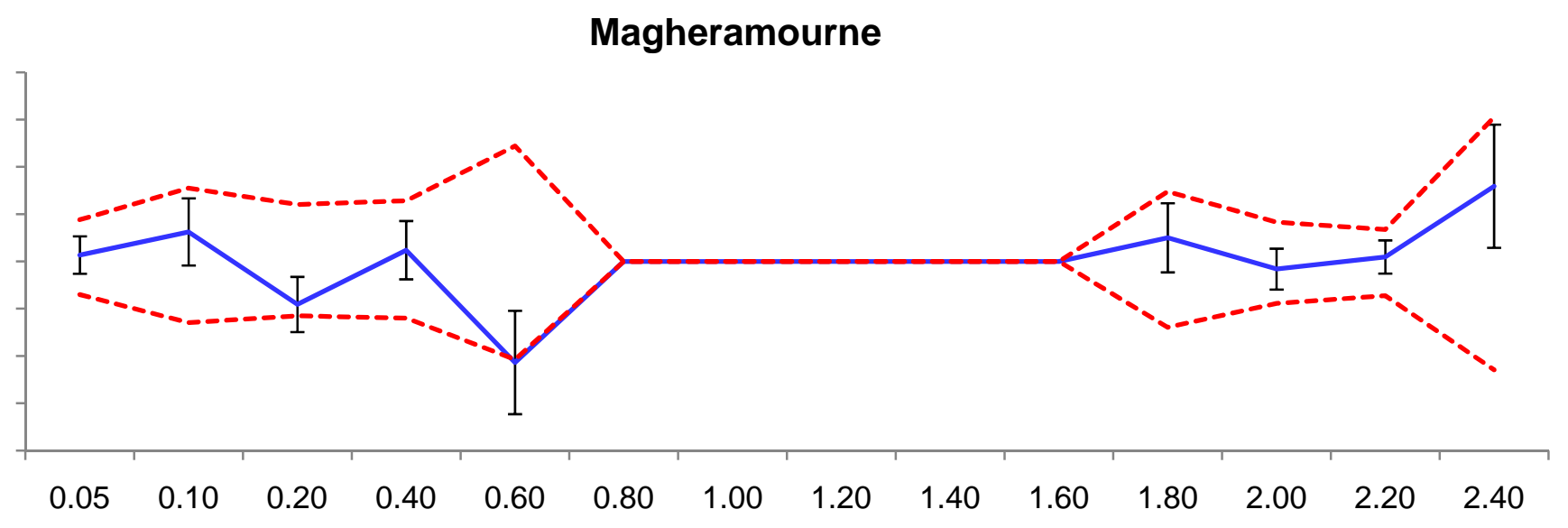




0.30
0.20
0.10
0.00
-0.10
-0.20
-0.30

\section{Glenarm Forest}

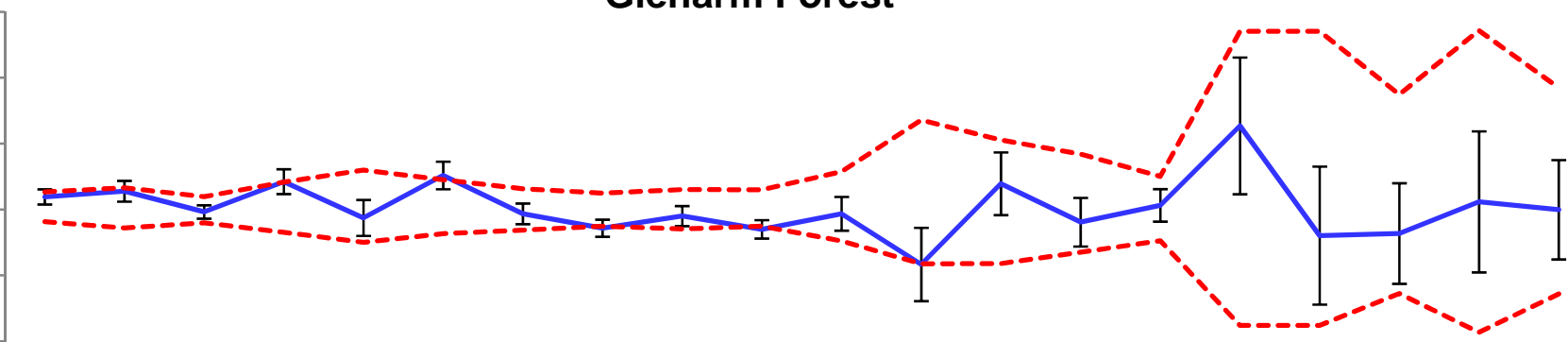

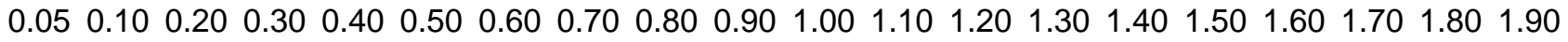

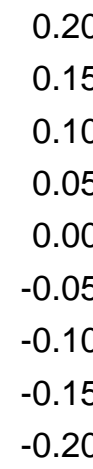

\section{Barnett Demesne}

0.15

0.10

0.05

0.00

$-0.05$

$-0.10$

$-0.15$

$-0.20$

$\begin{array}{llllllllllllllllll}0.05 & 0.10 & 0.20 & 0.30 & 0.40 & 0.50 & 0.60 & 0.70 & 0.80 & 0.90 & 1.00 & 1.10 & 1.20 & 1.30 & 1.40 & 1.50 & 1.60 & 1.70\end{array}$

\subsection{5 \\ 0.10 \\ 0.05 \\ 0.00 \\ $-0.15$}

$-0.05$

$-0.10$

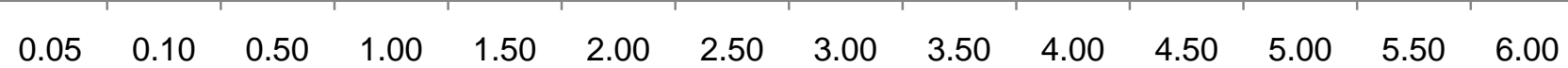

\section{Trassey Road}

0.15
0.10
0.05
0.00
-0.05
-0.10

\section{Dromara}

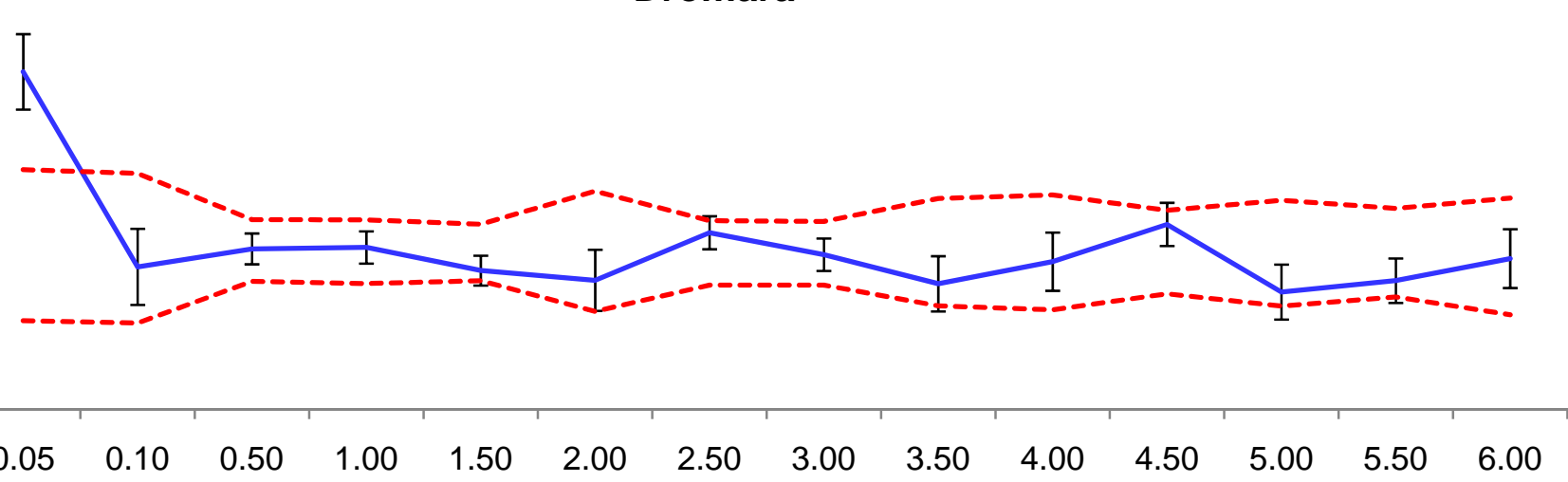




\section{Glenariff Forest}

0.20

0.15

0.10

0.05

0.00

$-0.10$

$-0.15$

$-0.20$

$-0.25$

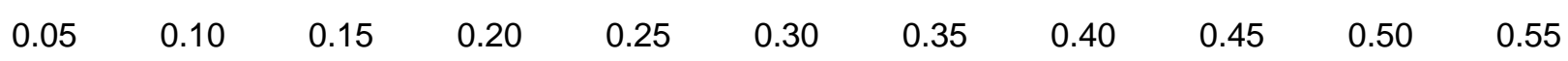

0.20
0.15
0.10
0.05
0.00
-0.05
-0.10

$\begin{array}{llllllllllllllllll}0.05 & 0.10 & 0.50 & 1.00 & 1.50 & 2.00 & 2.50 & 3.00 & 3.50 & 4.00 & 4.50 & 5.00 & 5.50 & 6.00 & 6.50 & 7.00 & 7.50 & 8.00\end{array}$

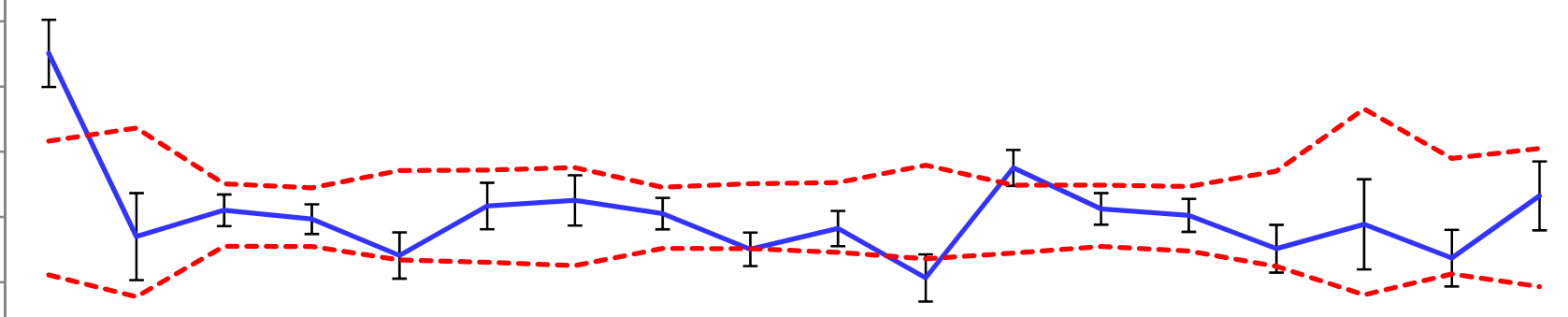

Rostrevor

\section{Ballycastle Forest}

0.25
0.20
0.15
0.10
0.05
0.00
-0.05
-0.10
-0.15
-0.20

$\begin{array}{llllllllllllllllll}0.05 & 0.10 & 0.20 & 0.30 & 0.40 & 0.50 & 0.60 & 0.70 & 0.80 & 0.90 & 1.00 & 1.10 & 1.20 & 1.30 & 1.40 & 1.50 & 1.60 & 1.70\end{array}$

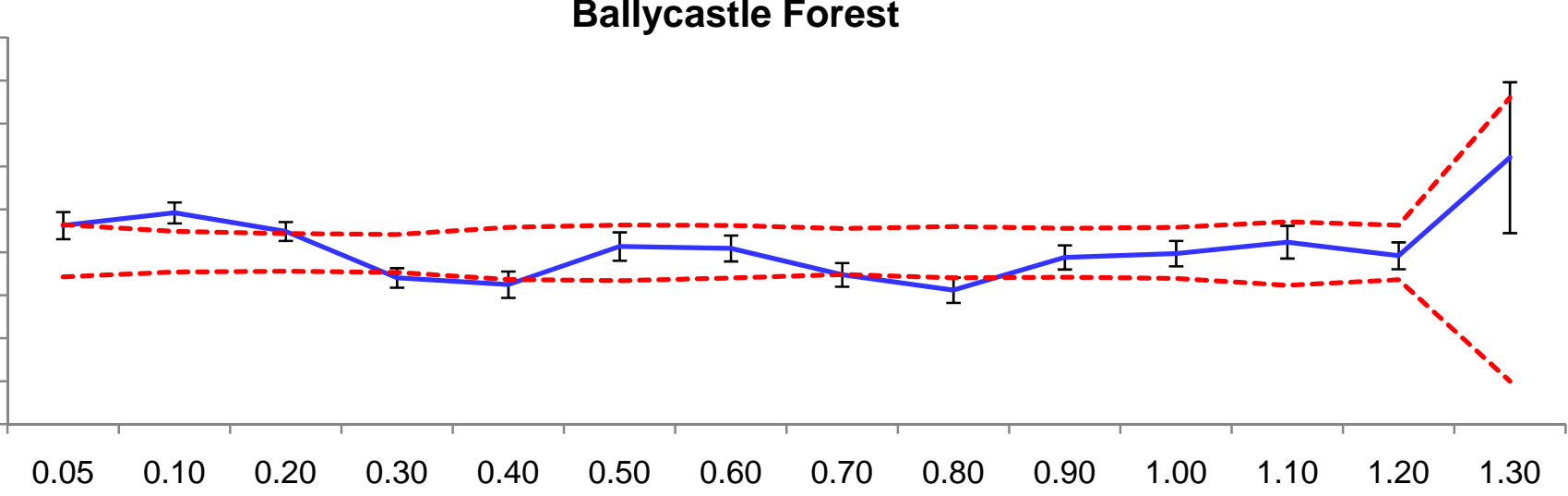


0.25

0.20

0.15

0.10

0.05

0.00

$-0.05$

$-0.10$

$-0.15$

$-0.20$

\section{Gosford Park}

0.20
0.15
0.10
0.05
0.00
-0.05
-0.10
-0.15

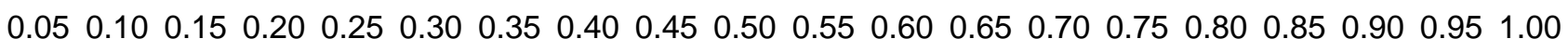

\section{Portglenone}

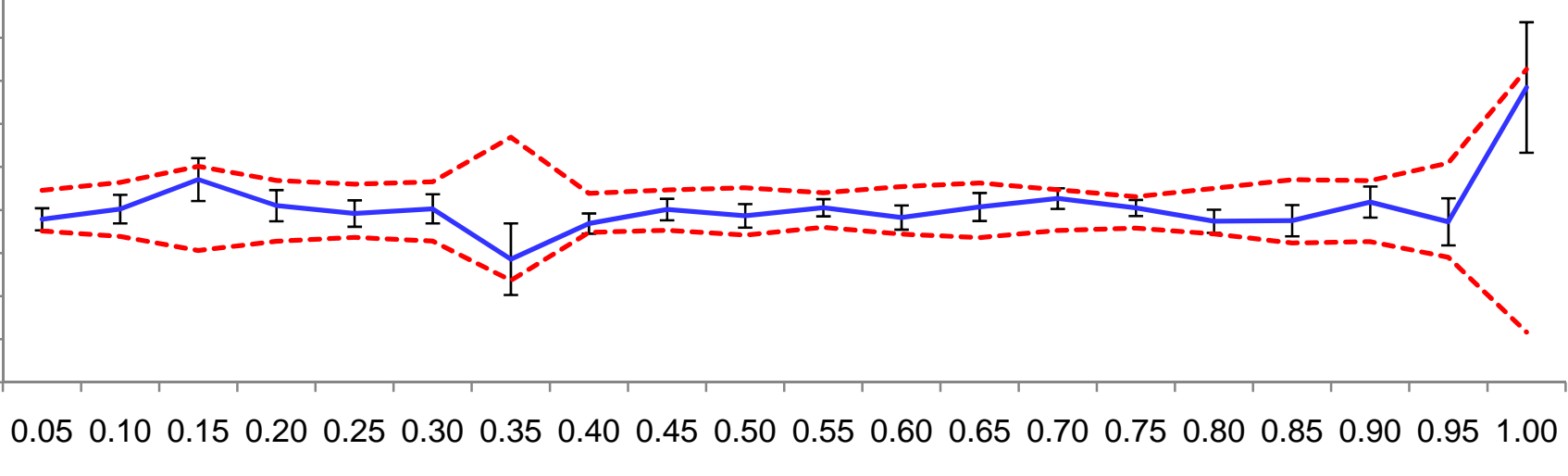

0.20
0.15
0.10
0.05
0.00
-0.05
-0.10
-0.15
-0.20

\section{Ballymoney}

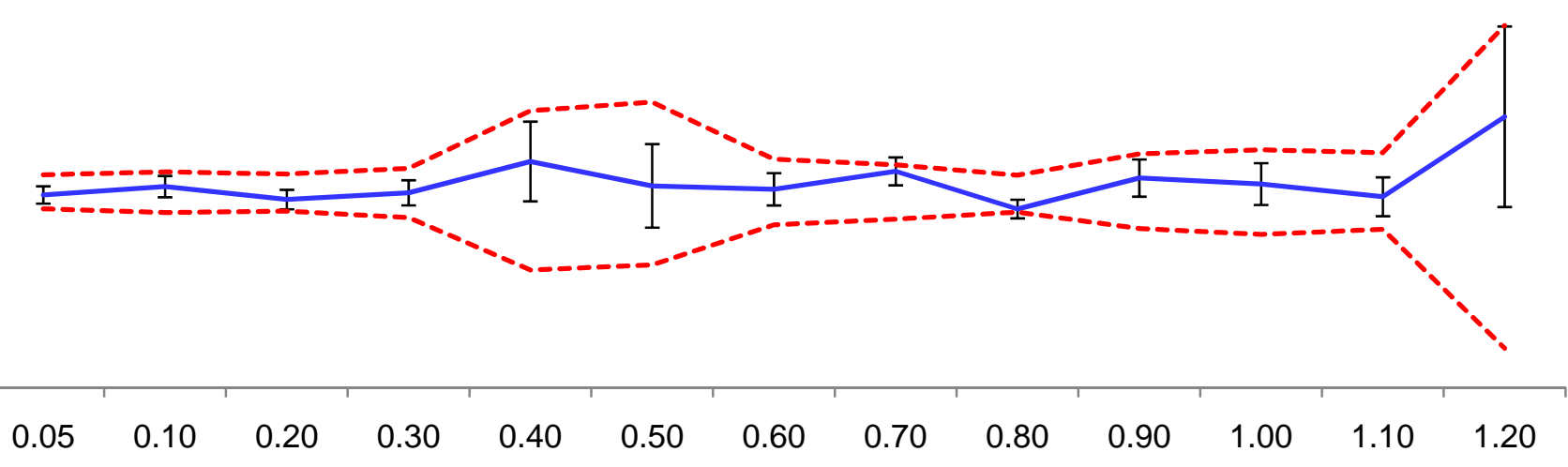


$\begin{array}{llllllllllllllllll}0.05 & 0.10 & 0.50 & 1.00 & 1.50 & 2.00 & 2.50 & 3.00 & 3.50 & 4.00 & 4.50 & 5.00 & 5.50 & 6.00 & 6.50 & 7.00 & 7.50 & 8.00\end{array}$

\section{Downhill}

0.20
0.15
0.10
0.05
0.00
-0.05
-0.10
-0.15

\section{Drum Manor}

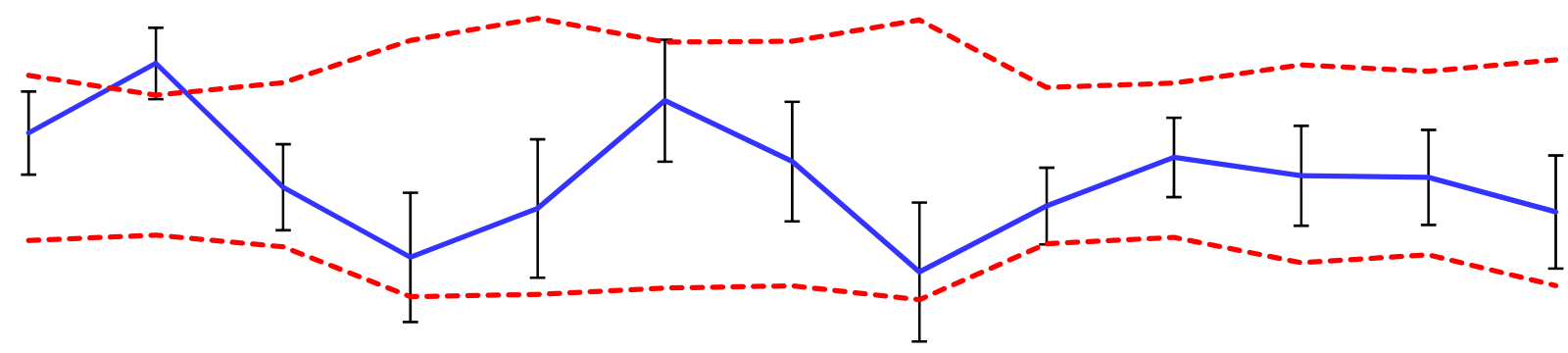

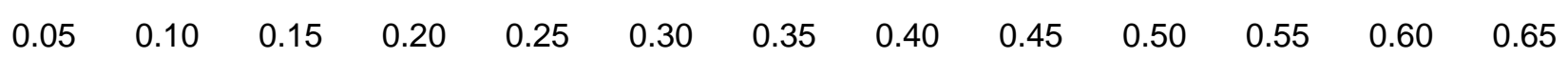

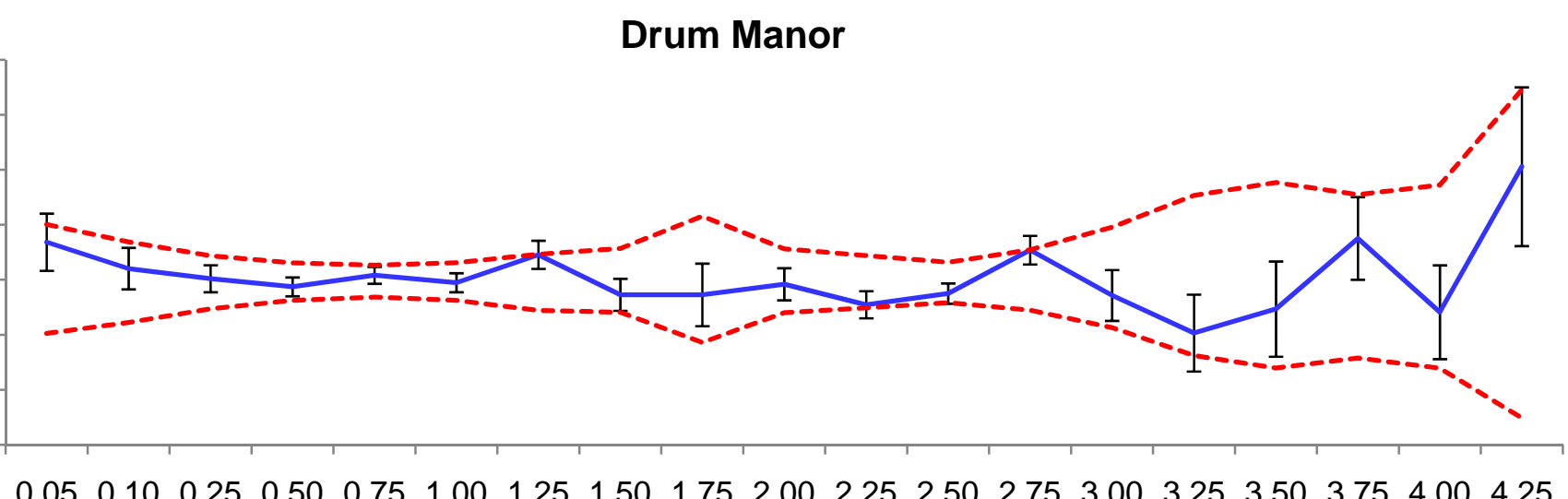




0.15
0.10
0.05
0.00
-0.05
-0.10
-0.15

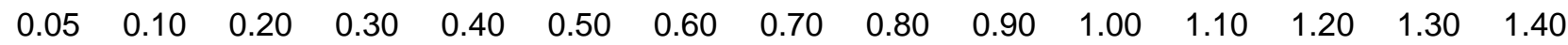
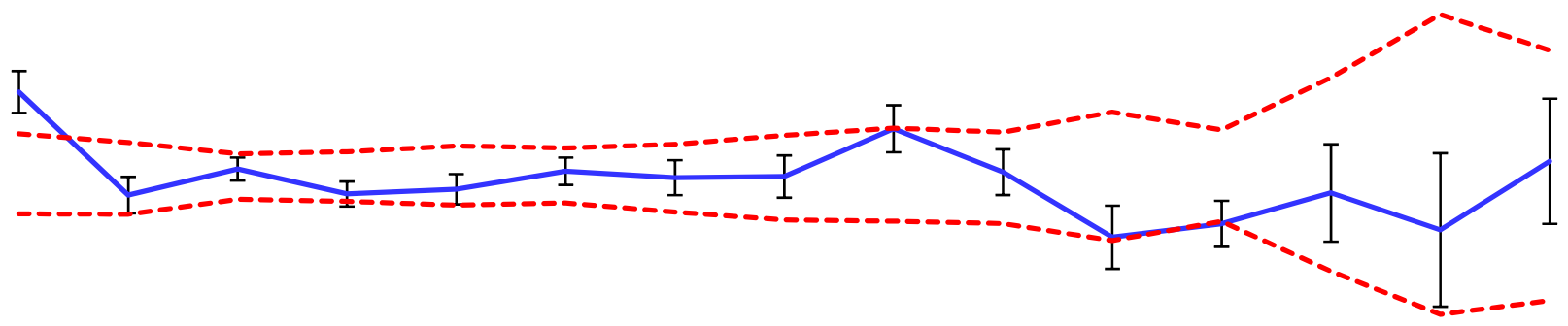

\subsection{0 \\ 0.20 \\ 0.10 \\ 0.00 \\ $-0.10$ \\ $-0.20$ \\ $-0.30$}

\section{Roe Valley}

\subsection{6 0.04} 0.02 0.00 $-0.02$ $-0.04$ $-0.06$ $-0.08$

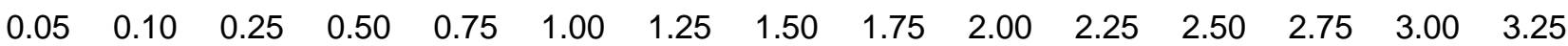

\section{Knockmaney Forest}

0.08
0.06
0.04
0.02
0.00
-0.02
-0.04
-0.06
-0.08

\section{Slieve Beagh}

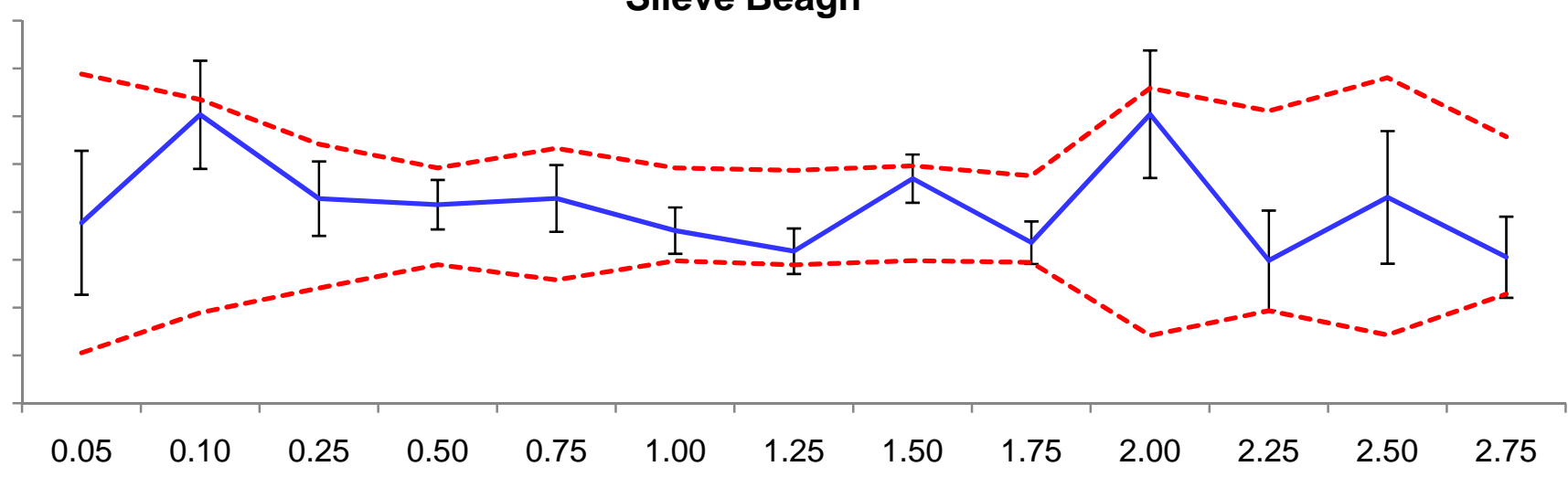



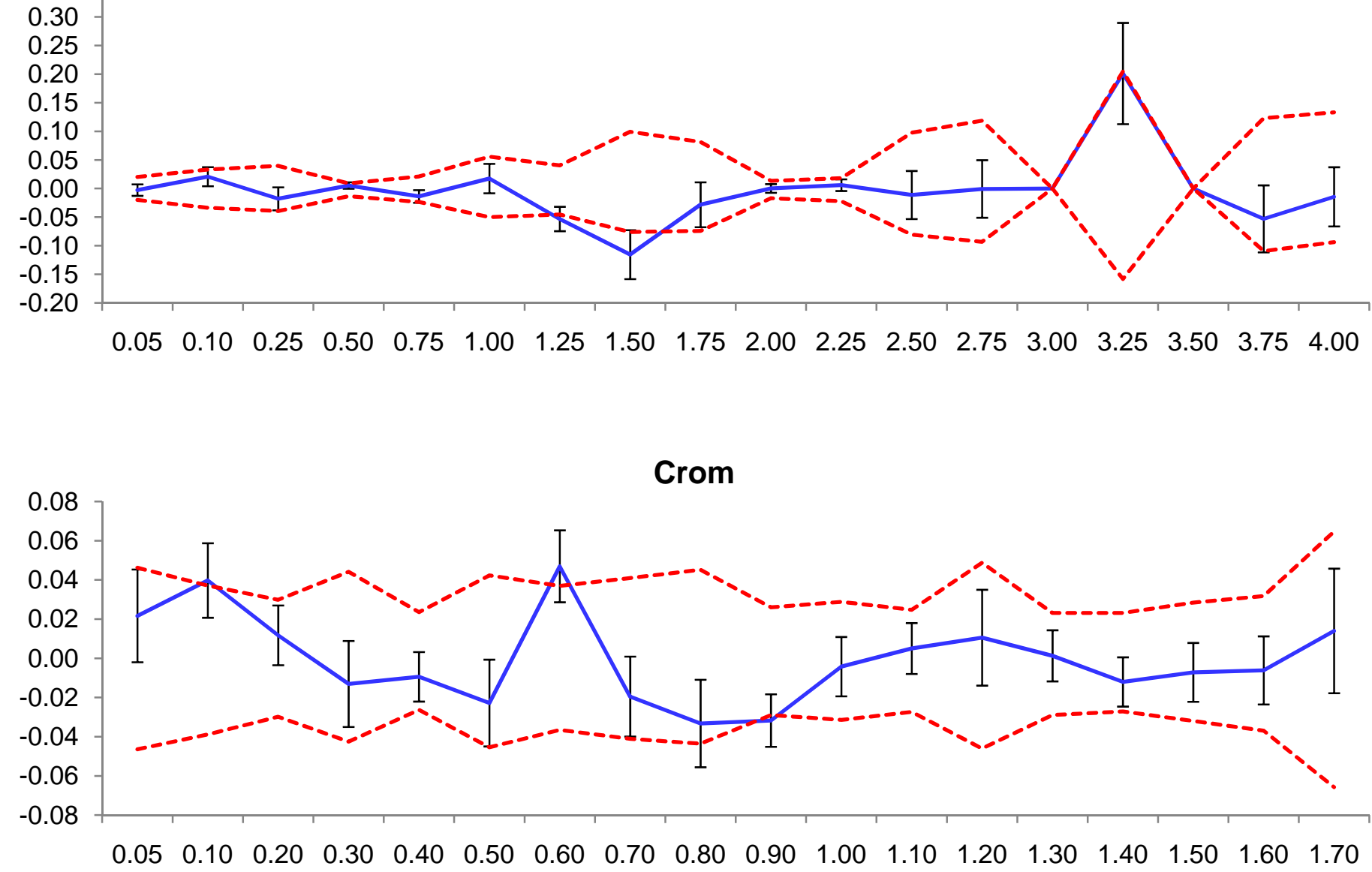

$\begin{array}{llllllllllllllllll}0.05 & 0.10 & 0.25 & 0.50 & 0.75 & 1.00 & 1.25 & 1.50 & 1.75 & 2.00 & 2.25 & 2.50 & 2.75 & 3.00 & 3.25 & 3.50 & 3.75 & 4.00\end{array}$

\section{Crom}

\section{Knockninney Hill}

0.15
0.10
0.05
0.00
-0.05
-0.10

\section{Sloughan Glen}

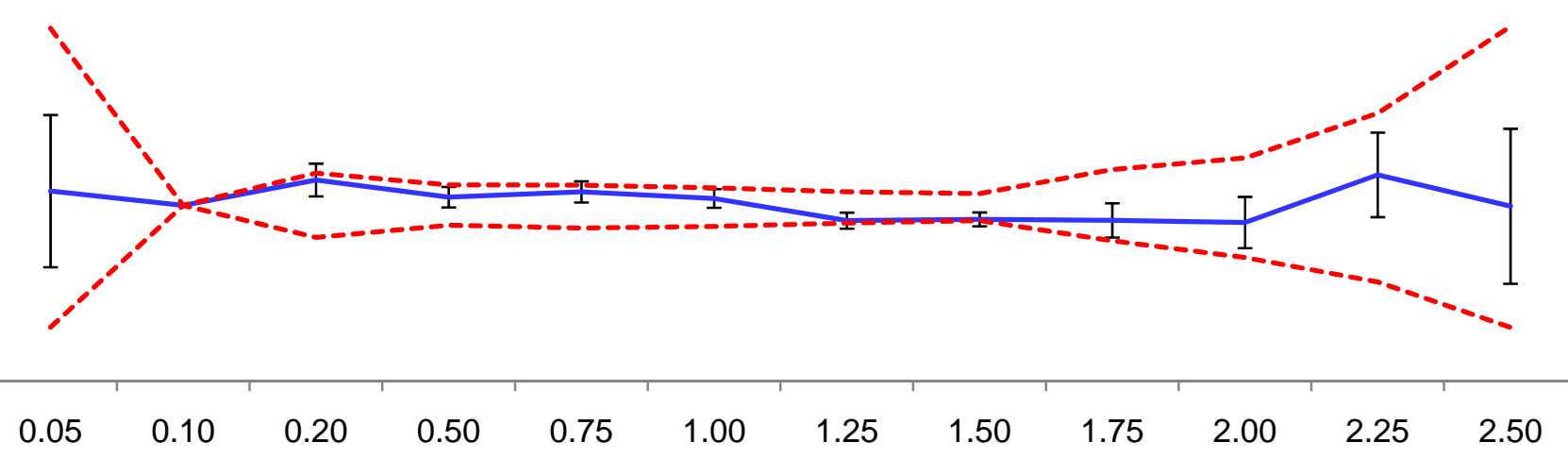




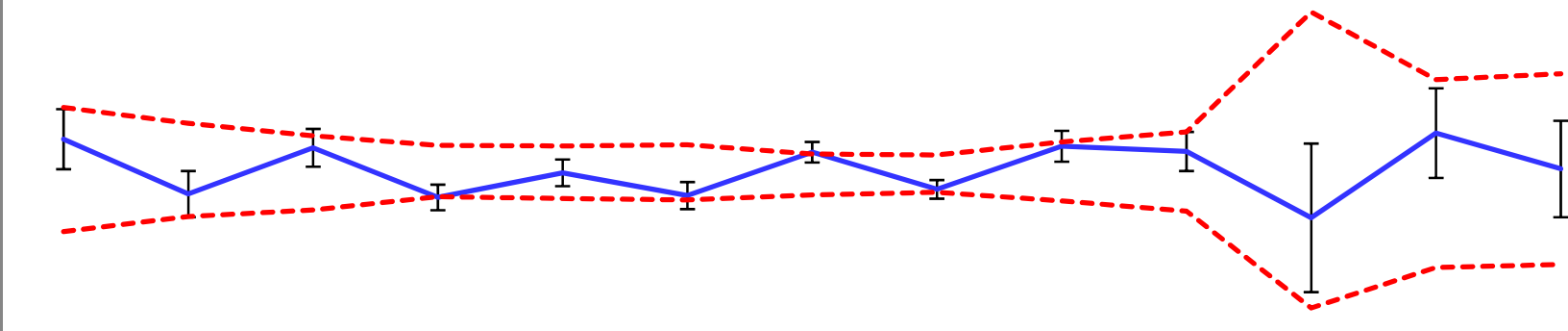

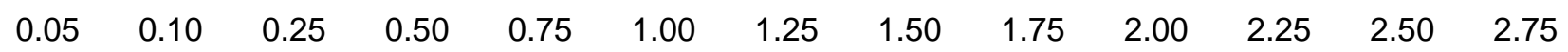

Ely Lodge
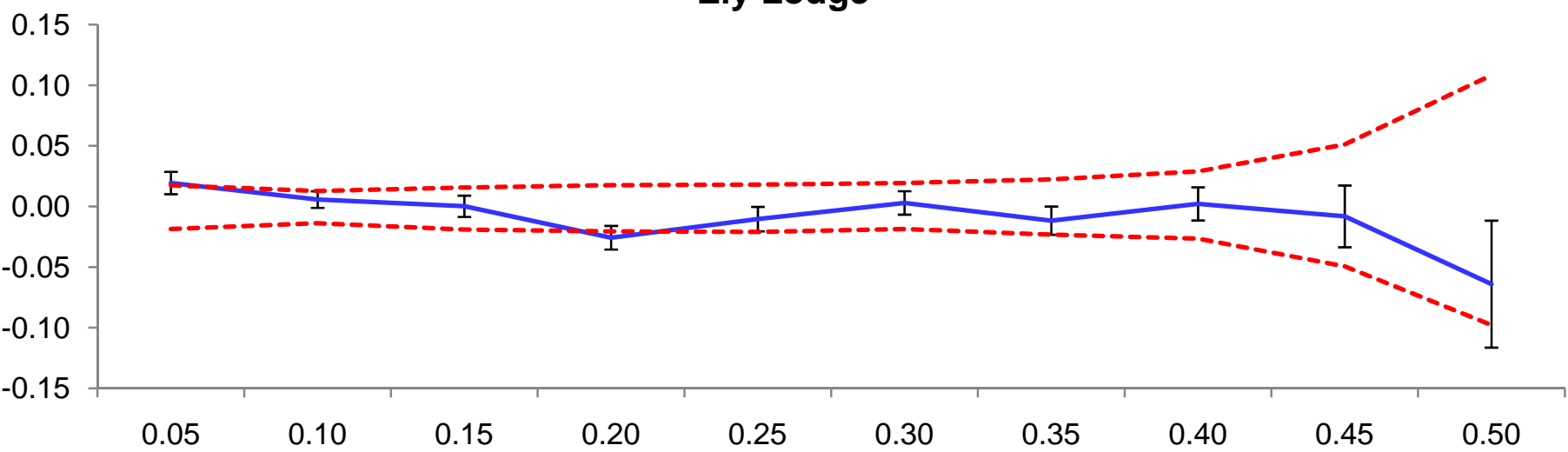

0.08
0.06
0.04
0.02
0.00
-0.02
-0.04
-0.06

Killeter Forest

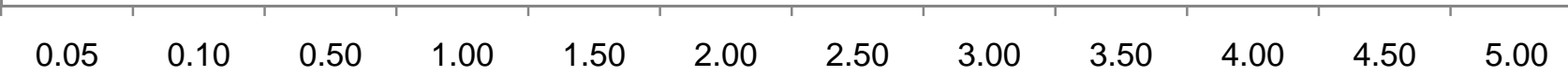

Marble Arch

0.20

0.15

0.10
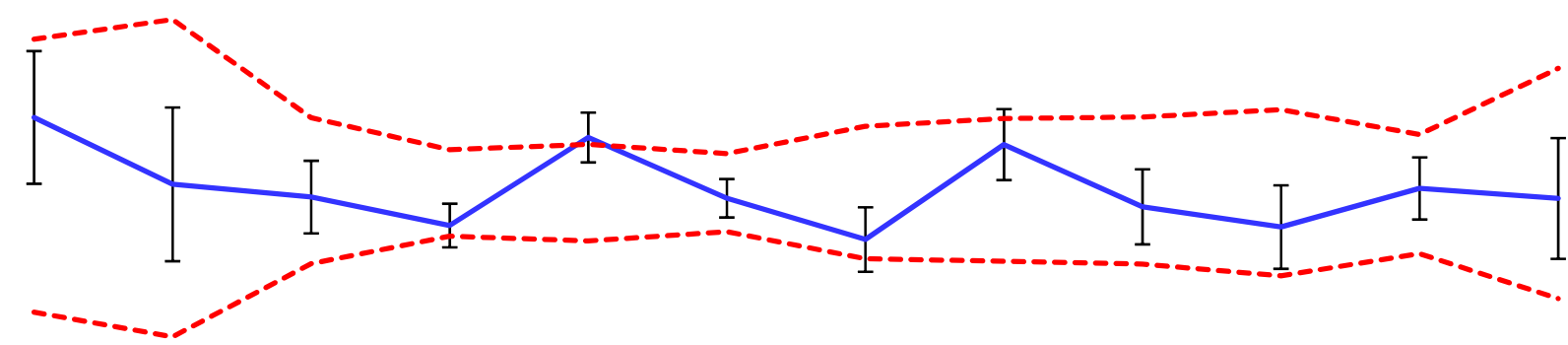

0.05

0.10

1.50

2.00 
0.15
0.10
0.05
0.00
-0.05
-0.10
-0.15

0.10 0.08 0.06 0.04 0.02 0.00 $-0.02$ $-0.04$ $-0.06$ $-0.08$ $-0.10$

0.25
0.20
0.15
0.10
0.05
0.00
-0.05
-0.10
-0.15
-0.20

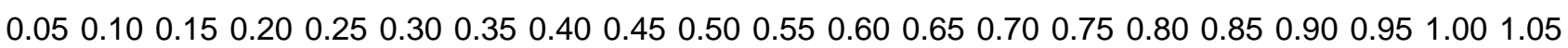

\section{Glenasmole Valley}

\section{Knocknamallavoge}

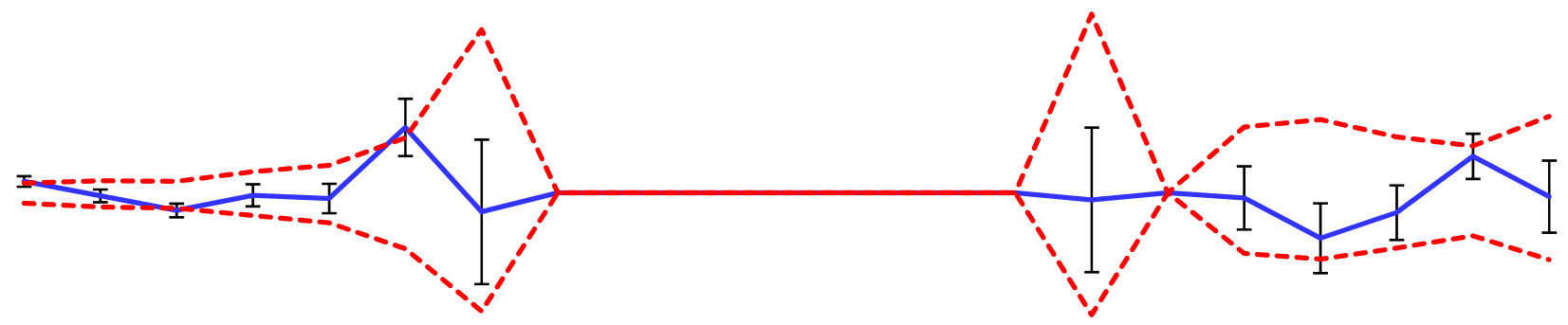

0.15

Letterfrack

0.10

0.05

0.00

$-0.05$

$-0.10$

$-0.15$

$\begin{array}{llllllllllllllll}0.05 & 0.10 & 0.15 & 0.20 & 0.25 & 0.30 & 0.35 & 0.40 & 0.45 & 0.50 & 0.55 & 0.60 & 0.65 & 0.70 & 0.75 & 0.80\end{array}$


\begin{tabular}{|l}
\hline Fin Genotypes Plot \\
\hline File Edit View Tools Alleles Help \\
\hline Plot Setting: Microsatellite Default \\
\hline
\end{tabular}

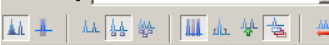

Sample File Sample Name Panel Marker OS SHP OBA SPA SP BIN PHR LPH SPU AN BD DP NB CC OOL GQ

A08_A08__lim_15 A08

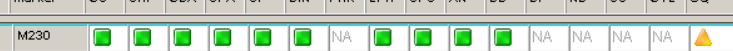
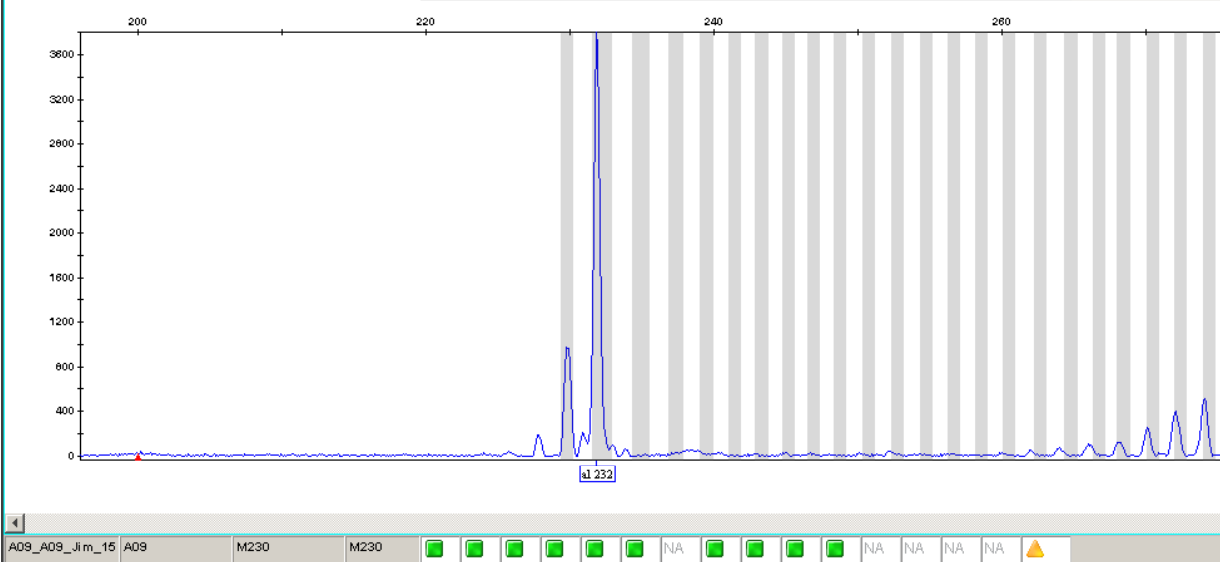

A09_-

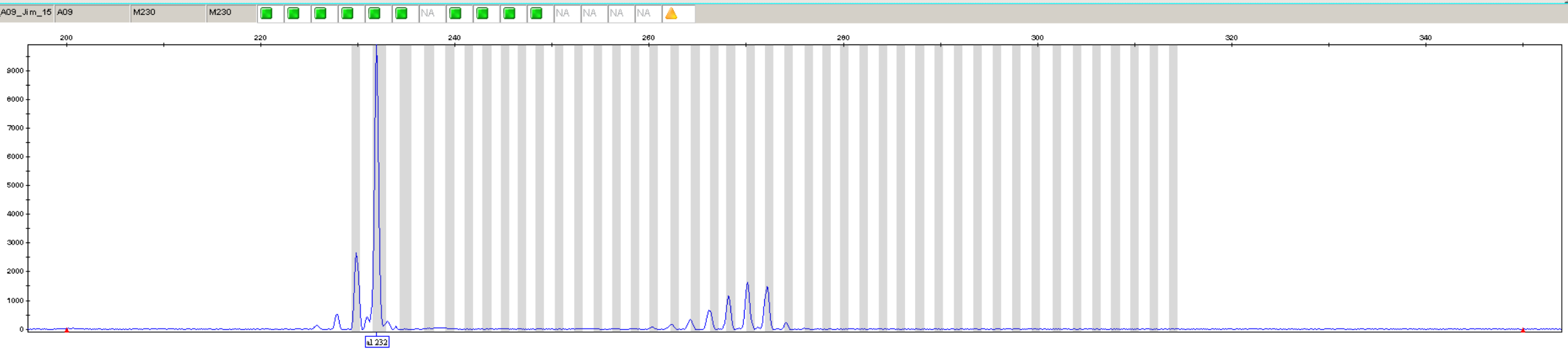

